\title{
Experimental Plasma Research Project Summaries
}

September 1980

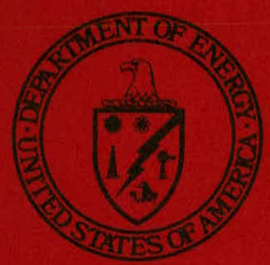

U.S. Department of Energy

Office of Fusion Energy

Division of Applied Plasma Physics

Washington, D.C. 20545 


\section{DISCLAIMER}

This report was prepared as an account of work sponsored by an agency of the United States Government. Neither the United States Government nor any agency Thereof, nor any of their employees, makes any warranty, express or implied, or assumes any legal liability or responsibility for the accuracy, completeness, or usefulness of any information, apparatus, product, or process disclosed, or represents that its use would not infringe privately owned rights. Reference herein to any specific commercial product, process, or service by trade name, trademark, manufacturer, or otherwise does not necessarily constitute or imply its endorsement, recommendation, or favoring by the United States Government or any agency thereof. The views and opinions of authors expressed herein do not necessarily state or reflect those of the United States Government or any agency thereof. 


\section{DISCLAIMER}

Portions of this document may be illegible in electronic image products. Images are produced from the best available original document. 
Printed in the United States of America

$$
\text { Available from }
$$

National Technical Information Service U.S. Department of Commerce

5285 Port Royal Road

Springficld, VA 22161

NTIS price codes

Printed Copy: $\quad \$ 7.25$

Microfiche Copy: $\$ 3.50$ 


\section{Experimental Plasma Research Project Summaries}

September 1980
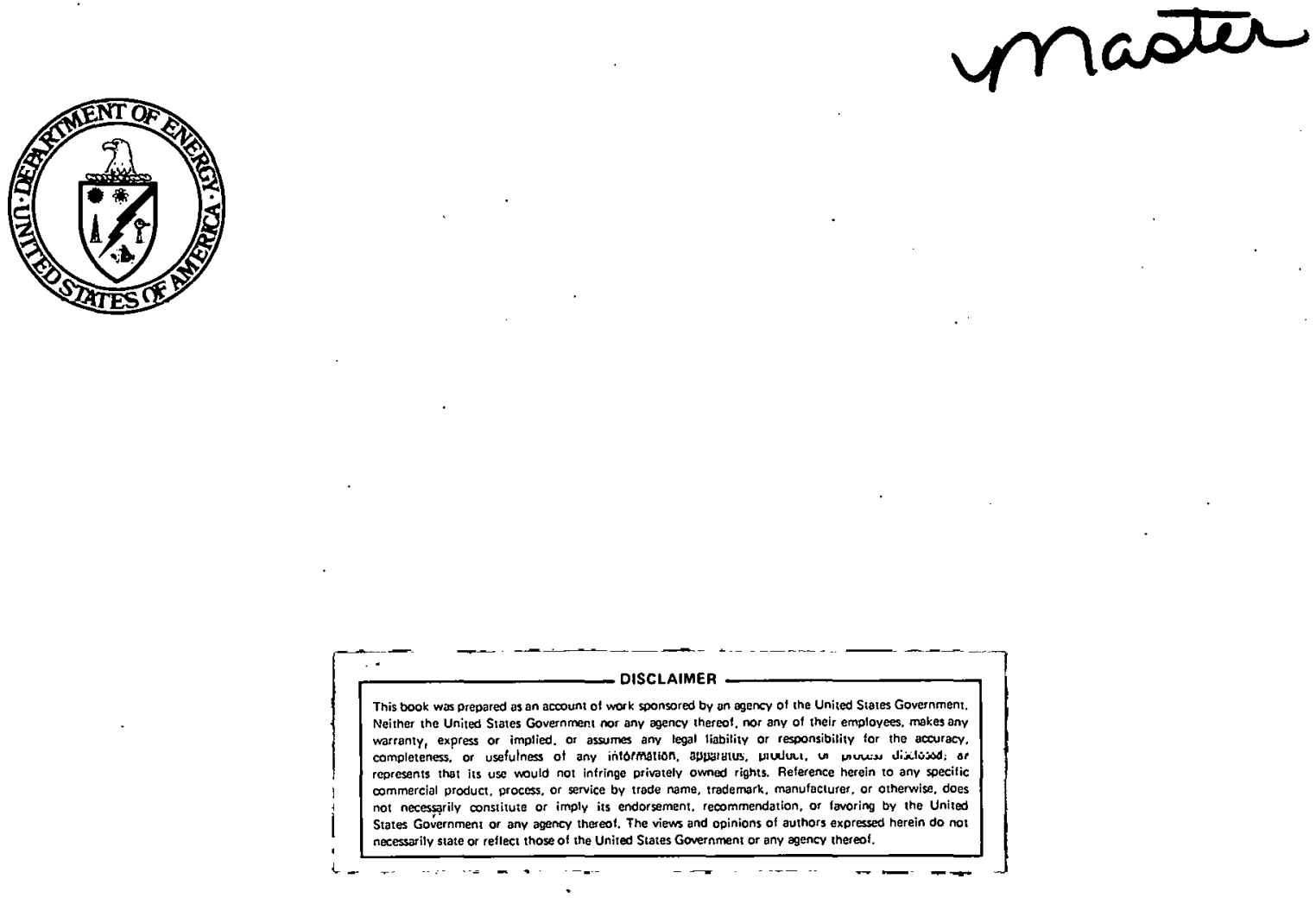

\section{U.S. Department of Energy}

Office of Fusion Energy

Division of Applied Plasma Physics 
THIS PAGE

\section{WAS INTENTIONALLY LEFT BLANK}




\section{TABLE OF CONTENTS}

Page

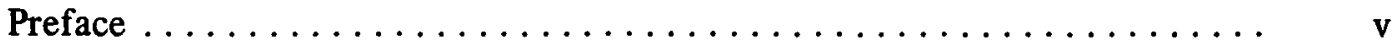

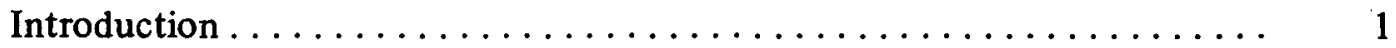

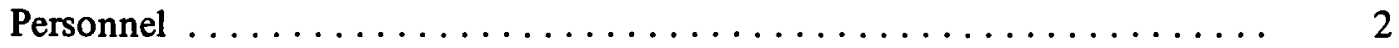

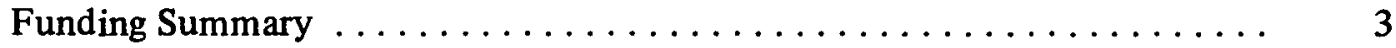

Plasma Properties (PP) Program $\ldots \ldots \ldots \ldots \ldots \ldots \ldots \ldots \ldots \ldots$

Princeton Plasma Physics Laboratory . . . . . . . . . . . . . . . . 7

University of California at Los Angeles $\ldots \ldots \ldots \ldots \ldots \ldots \ldots \ldots \ldots$

University of California at Los Angeles $\ldots \ldots \ldots \ldots \ldots \ldots \ldots \ldots \ldots \ldots$

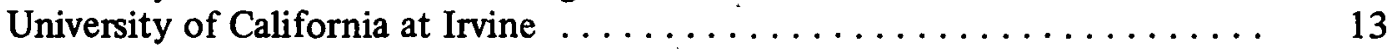

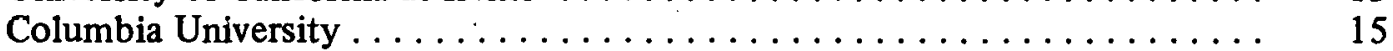

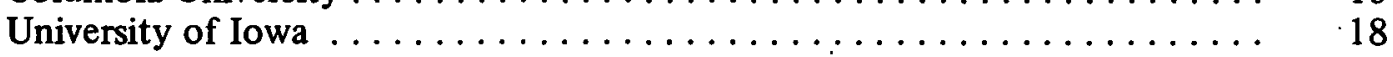

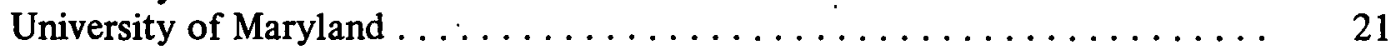

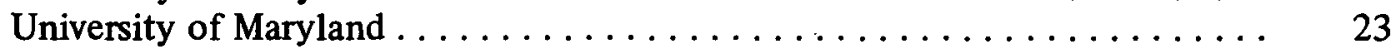

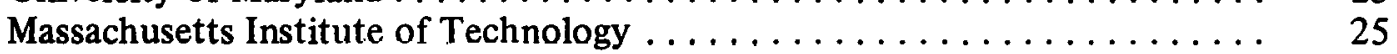

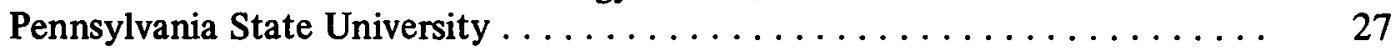

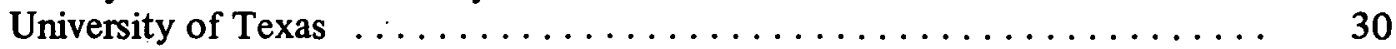

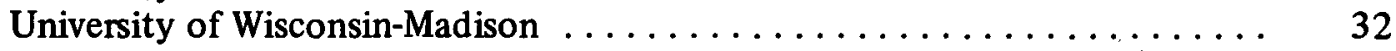

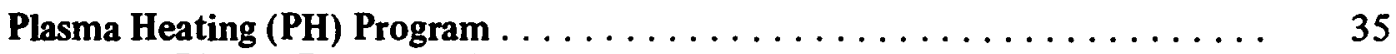

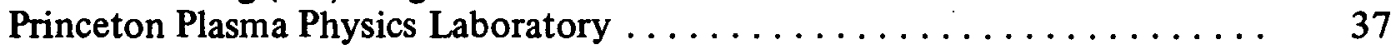

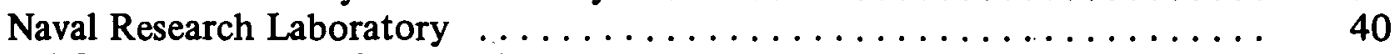

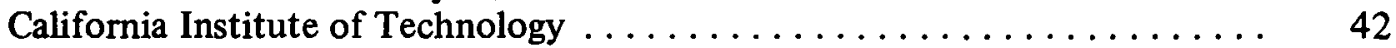

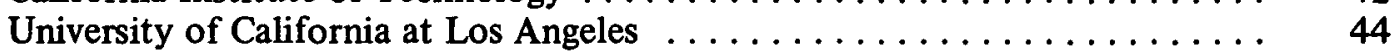

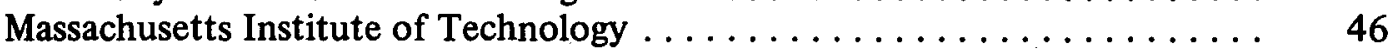

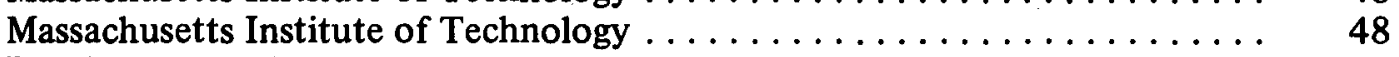

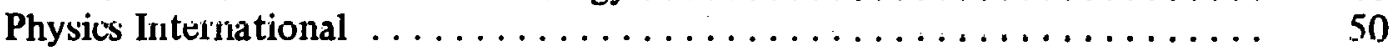

Plasma Diagnostics (PD) Program . . . . . . . . . . . . . . . . . 52

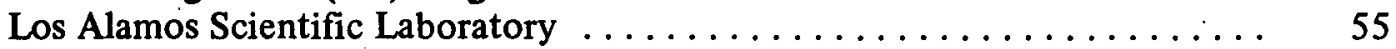

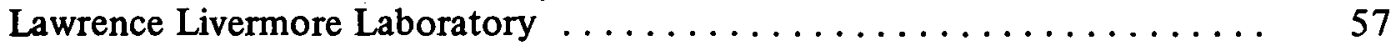

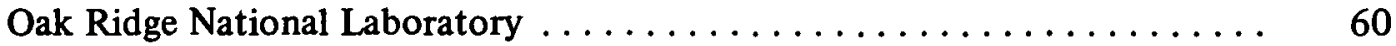

The Aerospace Corporation . . . . . . . . . . . . . . . . . . . 63

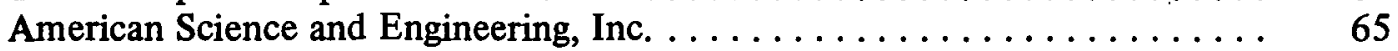

University of California at Los Angeles ................ 67

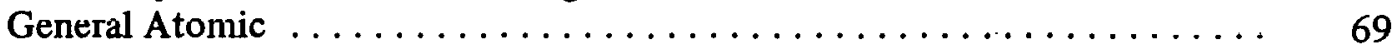

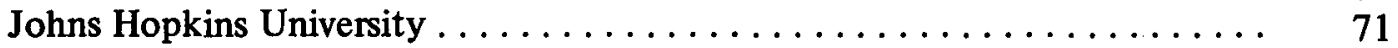

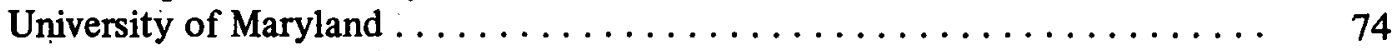

University of Maryland . . . . . . . . . . . .

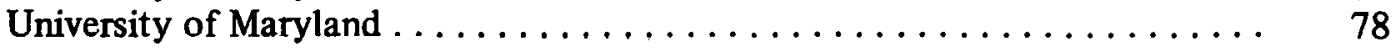

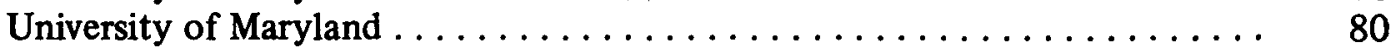

Massachusetts Institute of Technology $\ldots \ldots \ldots \ldots \ldots \ldots \ldots \ldots \ldots \ldots, \quad 82$

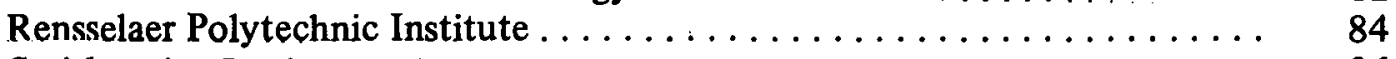

Smithsonian Institution Astrophysical Observatory $\ldots \ldots \ldots \ldots \ldots \ldots$ 
Page

Atomic, Molecular and Nuclear Physics (AM) Program $\ldots \ldots \ldots \ldots \ldots \ldots$

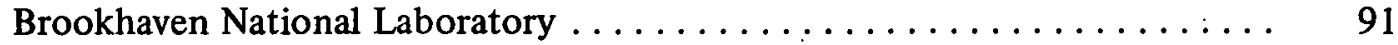

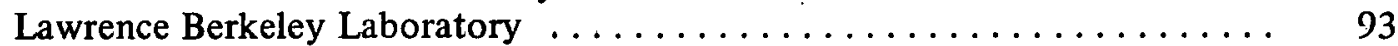

Lawrence Berkeley Laboratory $\ldots \ldots \ldots \ldots \ldots \ldots \ldots \ldots \ldots \ldots \ldots$

Oak Ridge National Laboratory $\ldots \ldots \ldots \ldots \ldots \ldots \ldots \ldots \ldots \ldots \ldots$

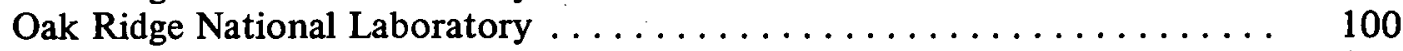

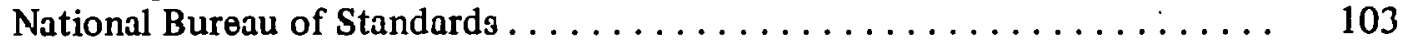

Naval Research Laboratory $\ldots \ldots \ldots \ldots \ldots \ldots \ldots \ldots \ldots \ldots \ldots \ldots$

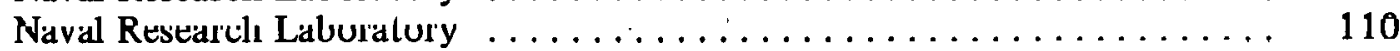

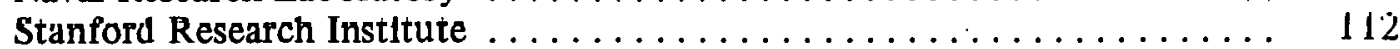

University of California at Los Angeles $\ldots \ldots \ldots \ldots \ldots \ldots \ldots \ldots \ldots \ldots \ldots$

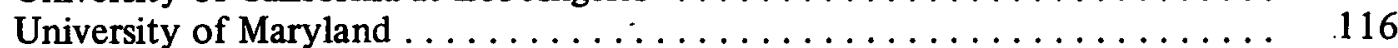

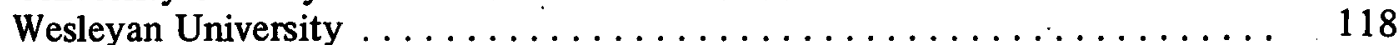

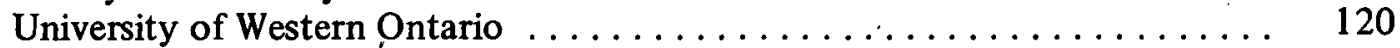

Fusion Plasma Research Facility (FPRF) Program . . . . . . . . . . . . . . 124

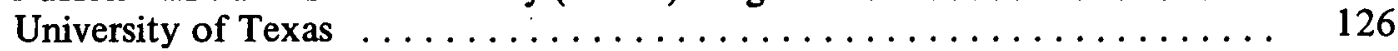

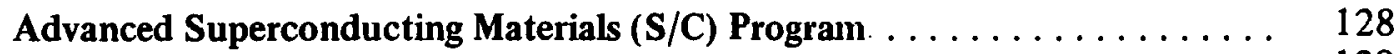

Massachusetts Institute of Technology . . . . . . . . . . . . . . . . . . . . 129 


\section{PREFACE}

This report contains descriptions of the activities supported by the Experimental Plasma Research Branch of APP. The individual project summaries were prepared by the principal investigators and include objectives and milestones for each project. The projects are arranged in six research categories: Plasma Properties; Plasma Heating; Plasma Diagnostics; Atomic, Molecular and Nuclear Physics; Advanced Superconducting Materials; and the Fusion Plasma Research Facility (FPRF). Each category is introduced with a statement of objectives and recent progress and followed by descriptions of individual projects. An overall budget summary is provided at the beginning of the report.

The report is distributed to various segments of the fusion community and serves several purposes. For scientists in the field, it is intended that the report will help provide the information about on-going programs needed to improve communications among scientists and with the Branch. For OFE staff, the primary purpose is to improve coordination between the Experimental Plasma Research Branch and other branches within the Office.

Philip M. Stone, Chief

Experimental Plasma Research Branch

Division of Applied Plasma Physics

Office of Fusion Energy 


\section{INTRODUCTION}

The Experimental Plasma Research Branch has responsibility for developing a broad range of experimental data and new experimental techniques that are required for operating and interpreting present large-scale confinement experiments, and for designing future deuterium-tritium burning facilities.

The Branch pursues these objectives by supporting research in DOE laboratories, other Federal laboratories, universities, and private industry. Initiation and renewal of research projects are primarily through submission of unsolicited proposals by these institutions to DOE.

The objectives, as stated above, result in support of a wide variety of plasma physics research, as well as some specific areas of atomic and nuclear physics and superconducting research that are important to ETM. The research has been divided into six categories for budgeting and planning purposes as follows: Plasma Properties (PP); Plasma Heating (PH); Plasma Diagnostics (PD); Atomic, Molecular and Nuclear Physics (AM); Advanced Superconducting Materials (S/C); and the Fusion Plasma Research Facility (FPRF). A breakdown of funding by category and by type of institution is provided, followed by the general objectives, recent progress, and project descriptions for each category.

The Fusion Plasma Research Facility is a medium-sized tokamak at the University of Texas at Austin. This project was initiated in FY 1977 and operation is scheduled for FY 1980. This device will be a national facility available to experimenters from throughout the nation. Research in all of the categories of the present experimental research program is appropriate for this facility as well as plasmasurface studies. This project is described in a separate section of this report.

The Branch has expanded and reorganized during the past year. Charles R. Finfgeld has joined the Branch from D\&T and Milton Johnson has left to work with the DOE area office at Princeton. Areas of responsibility for each staff member are shown in the following table. 


\section{Experimental Plasma Research Branch \\ Personnel}

\section{Staff Member}

Philip M. Stone

Donald H. Priestert

Charles R. Finfgeld
Area of Responsibility

Branch Chief

Atomic, Molecular and Nuclear Superconducting Materials

Plasina Diagnostics

FPRF Fabrication and Operation

Plasma Properties

Plasma Heating

FPRF Experimental Program 


\title{
FUNDING SUMMARY
}

\section{(In Thousands of Dollars)}

1979

1980 (Est.)

\section{OPERATING BUDGET}

\author{
Area \\ $\mathrm{PP}$ \\ $\mathrm{PH}$ \\ PD \\ AM \\ $\mathrm{S} / \mathrm{C}$ \\ FPRF \\ Total Operating \\ EQUIPMENT BUDGET \\ Area
FPRF
Other \\ Total Equipment \\ OPERATING BUDGET

\section{Institution} \\ DOE Lab \\ University \\ Industry \\ Federal Lab \\ Total Operating
}

3,000

3,055

1,576

2,304

1,900

330

3,200

1,545

3,155

1,905

360

2,480

12,310

12,500

1,400

800

815

1,075

2,215

1,875

2,742

8,050

470

1,048

2,205

8,364

920

1,011

12,310

12,500 


\section{PLASMA PROPERTIES (PP) PROGRAM}

The goal of the APP plasma properties program is to explore and understand the physics of plasma processes relevant to fusion and to test and guide theoretical models of fusion plasma behavior.

The plasma properties program consists of approximately 10 university-sized plasma experiments with a breadth and diversity from Q-machines to high-beta tokamaks to single-cell mirror machines. 


\section{PROGRESS - PLASMA PROPERTIES}

- Experiments on Macrotor have shown that impurities released from tokamak surfaces are caused primarily by ions bombarding the walls after acceleration through the plasma-wall sheath. These unique and important experiments have shown that the impurity influx can be significantly reduced when the sheath potential is reduced.

- Experiments on drift cyclotron loss cone (DCLC) stabilization by electron beam and ECRH injection have been completed at MIT. The hot-electron temperature and diamagnetism have been measured over a range of injected E-beam power, and the effect on DCLC amplitude has been plotted. MIT has determined the approximate lengths of the trapped plasma and of the beam-produced hot-electron component by diamagnetic measurements. The plasma is short, $\sim 20 \mathrm{~cm}$ and is trapped in a shallow $(\sim 1.2 / 1)$ mirror. The hot electron density distribution is about $50 \%$ longer than the plasma ion distribution, and thus are very different from Ioffe's presumed concentration very close to the mid-plane.

- The Columbia high-beta tokamak, Torus II, has achieved a volume averaged beta of $10 \%$, peak beta of $30 \%$ with a poloidal beta equal to 10 . The plasma is elongated (b/a $~ 3.5)$ and the safety factor at $\mathrm{q}(\mathrm{a})$ is 2.5 . The plasma is observed to be macroscopically stable and it appears to be in the second, high-beta stability regime.

- An improved discharge cleaning technique for tokamaks has been developed on Microtor and is being used on PLT and other large experimental devices. A low temperature AC discharge is used for cleaning, which forms $\mathrm{H}_{2} \mathrm{O}$ vapor that is pumped out in the normal manner. Oxygen on the inner surfaces of the vacuum vessel is reduced in this manner to about 1 percent of a monolayer and tokamak discharges with oxygen content as low as $10^{10}$ atoms $/ \mathrm{cm}^{3}$ can be produced. The concentrations of carbon impurities are also reduced.

- Preliminary tests of injection of plasma into the 2X-IIB mirror machine by the deflagration plasma gun at Santa Clara have been completed. The gun is one possible means of fueling large devices. It has also been tested on the Microtor tokamak.

- At Maryland, the first direct observation of tearing modes on neutral sheets was made. These magnetic field measurements demonstrate that reconnection of the inner and outer axial flux leads to the formation of closed magnetic surfaces which should result in greatly improved electron energy confinement over an open field system.

- Simple flutes have been generated and stabilized in a Q-machine at the University of California at Irvine. The stabilization was provided by a electron-rich conducting annular blanket which surrounded the unstable center column.

- The stability of dee, inverse-dee and square cross section plasmas to axisymmetric modes has been investigated experimentally in Tokapole II, a tokamak with a four-null poloidal divertor. This study represents the first time that (1) the axisymmetric instability of different shapes has been experimentally studied in such detail and (2) a stability code has been applied to and compared closely with experimental results of this mode. Poloidal flux plots are produced by magnetic probe measurements internal to the plasma. Experimental results are carefully comnared with predictions of two numerical stability codes - the PEST code (ideal 
MHD, linear stability) adapted to tokapole geometry and a code which follows the nonlinear evolution of shapes similar to tokapole equilibria. Experimentally, the square is vertically stable and both dee's unstable to a vertical nonrigid axisymmetric shift. The central magnetic axis displacement grows exponentially with a growth time $\sim 10^{3}$ poloidal Alfven times $\sim$ plasma L/R time. Proper initial positioning of the plasma on the midplane allows passive feedback to nonlinearly restore vertical motion to a small stable oscillation. The PEST code, ignoring passive feedback, predicts all equilibria to be vertically unstable with the square having the slowest growth and growth times $\simeq$ poloidal Alfven time. With passive feedback, all are stable. Thus, experiment and code agree that the square is the most stable shape, but experiment indicates that passive feedback is partially defeated by finite plasma resistivity which causes damping of the induced image currents. In both the code and the experiment, squarelike equilibria exhibit a relatively harmless horizontal instability. 


\section{Project}

Q-1, QED-1: Plasma Properties and Divertor Simulation

M. Yamada

FY $79 \quad \begin{array}{lll}\$ 199 \mathrm{~K} & \text { FY80 } & \$ 0 \mathrm{~K}\end{array}$

\section{Purpose}

To investigate particle and heat transport in a flowing plasma which simulates the divertor scrape-off region and to obtain fundamental physics data on particle gettering, plasma collection, boundary conditions, impurity backflow, and shock formation (QED-1).

To investigate waves, and collective phenomena in high (QED-1) and low (Q-1) $\beta$ plasmas, including physics simulation study of trapped-ion modes and waves driven by neutral-beam injection and $\alpha$ particle plasma-interaction.

\section{Approach}

QED-1 (Quiet, Energetic, Dense Plasma) utilizes a $75 \mathrm{~kW}$ arc to provide a finite- $\beta$ plasma column $128 \mathrm{~cm}$ in length $\left(\beta=10^{-4} \rightarrow 10^{-1}\right), 1.5 \mathrm{~cm}$ in diameter with $\mathrm{n}_{\mathrm{e}}=10^{15} \mathrm{~cm}^{-3}, \mathrm{~T}_{\mathrm{i}} \simeq \mathrm{T}_{\mathrm{e}} \lesssim 20 \mathrm{eV}$.

The present Q-1 machine provides an isothermal low $\beta$ plasma for the study of transport, waves (trapped ion modes, drift waves), instabilities and linear and nonlinear wave-particle interactions.

\section{Progress}

1. Sputtering yields of various wall/limiter materials of fusion devices have been extensively measured in the relevant plasma environment for low-energy light ions ( $E<300 \mathrm{eV})$. As a plasma source we have used an energetic arc device (QED-1 machine) generating hydrogen, deuterium, helium and argon plasma. Target materials used were $\mathrm{C}$ (graphite), Ti, Mo, Ta, W and $\mathrm{Fe}$ (stainless steel). The date obtained in the present experiment agree well with those previously obtained at the higher energies $(\mathrm{E} \gtrsim 200 \mathrm{eV})$ by other authors using different schemes; the present data also extended to substantially lower energies $(E \gtrsim 30 \mathrm{eV}$ ) than hitherto.

2. In the Q-1 device, an impurity driven drift wave has been observed and identified for the first time. 
3. In the divertor simulation chamber of the QED-1 device, we have performed our experimental simulation of gaseous divertor. In the experiment, we found that when a plasma of $n_{e}<$ $10^{14} \mathrm{~cm}^{-3}$ and $T_{e}<5 \mathrm{eV}$ flows through a narrow cylinder into the collector chamber, it plugs the cylinder, preventing the back flow of neutral gas ( $\lesssim .5$ torr) from the collector chamber and allowing a large different in neutral gas pressure to be maintained.

4. Also in the QED-1 device, the dispersion relation of obliquely propagating whistler waves have been measured in exact agreement with theory. Furthermore the collisional damping of this wave have been investigated thoroughly.

\section{Plans and Milestones}

Project is closed.

Major Recent Publications (Excluding meeting abstract)

1. G. Allen, D. Owens, S. Seiler, M. Yamada, H. Ikezi, and M. Porkolab, Phys. Rev. Lett. 41, 1045 (1978).

2. S. Seiler and M. Yamada, Nucl. Fusion 19469 (1979).

3. M. Nishi, M. Yamada, S. Suckewer and E. Rosengaus, PPPL-1521, April 1979.

4. D. K. Owens and M. Yamada, PPPL-1520, February 1980.

5. H. Eubank et al., Plasma Phys. Conf. Nucl Fusion (Proc. 7th Int. Conf. Insbruck, 1978) IAEA-CN-37-C-3. 
Experimental Plasma Research

University of California at Los Angeles

Category .PP

Project

Large Axisymmetric Mirror Experiment (LAMEX)

A. Y. Wong

FY79 \$125K op $\quad$ FY80 $\$ 150 \mathrm{~K}$ op

$30 \mathrm{~K} \mathrm{eq} \quad 40 \mathrm{~K}$ eq

\section{Purpose}

1. Produce an axisymmetric, MHD stable mirror confined plasma of large diameter and uniform density.

2. Study confinement with high mirror ratio.

3. Study properties of loss cone instabilities and their effect on confinement.

\section{Approach}

An average minimum $|\mathrm{B}|$ magnetic field configuration is produced by combining a surface magnetic field with a simple mirror field. This produces a region of large axial $(100 \mathrm{~cm})$ and radial $(60 \mathrm{~cm})$ dimensions with uniform field strength. Low central field strength $(200 \mathrm{G})$ allows high mirror ratio at a moderate mirror throat field $(4 \mathrm{kG})$. The uniform field region will allow detailed study of loss cone instabilities. Moderate plasma parameters $\left(\mathrm{n}<10^{11} \mathrm{~cm}^{-3}, \mathrm{~T}_{\mathrm{i}}<100 \mathrm{eV}\right)$ allow detailed, local probing of the plasma. The magnetic field is DC allowing relatively high repetition rate and rapid data acquisition.

\section{Progress}

The required plasma parameters, mentioned above, have been achieved with axial injection from a washer stack gun source. MHD stabilization of this axisymmetric mirror confined plasma hy the average minimum $|\mathrm{B}|$ surface field has been demonstrated. In the MHD stable plasma, loss is through the mirror throat at a rate determined by ion-ion and charge exchange collisions. The equilibrium plasma pressure radial profile has been studied as a function of field configuration. The maximum plasma radius that has been observed is $\mathrm{R}_{\mathrm{p}} / \rho_{\mathrm{ci}}=10$. In some cases, an increase in confinement time with increasing mirror ratio has been observed $(2<\mathrm{R}<20)$. Density fluctuations at a frequency near $\omega_{c i}$ have been observed $\left(\omega / \omega_{c i} \approx .7, \delta \mathrm{n} / \mathrm{n} \lesssim 10 \%\right)$, possibly indicating the presence of a loss cone instability. An increase in confinement time and fluctuation level was observed after the addition of titanium gettering.

\section{Plans}

1. Evaluate the effectiveness of a surface magnetic field in stabilization of a simple mirror. 
2. Verify the presence of a loss cone ion velocity distribution. Study the effect of mirror ratio and micro instability level on confinement and velocity distribution.

3. Study the properties of the drift cyclotron loss cone instability.

\section{Milestones}

1. Initial confinement of MHD stable plasma: March 1979.

2. Plasma density and temperature goal achieved: June 1979.

3. Observation of ion cyclotron fluctuations: October 1979.

4. Begin study of instability properties and study of large plasma diameter stabilization of the drift cyclotron loss cone instábilliry: January 1980.

5. Study dependence of plasma parameters on mirror ratio: April 1980.

Graduate Students (\% DOE support)

P. Cheung (0), C. Darrow (0), W. DiVergilio (0), D. Eggleston (0), J. Ferron (50), G. Hockney (0), K. Jones (50), K. L. Lam (50), H. Quevedo (0), J. Santoru (0), P. Straus (0), H. Stephanian (0), P. Young (50).

\section{Graduates (Year)}

R. Schumacher (1979), P. Leung (1979).

\section{Other Professional Staff}

G. Dimonte, H. Goede, H. M. Lai, B. Leikind, P. Leung, R. Schumacher, K. Yatsu.

\section{Major Recent Publications}

1. "Fast Ion Beam-Plasma Interactions System", R. A. Breun, J. R. Ferron, Rev. Sci. Inst. 50, 862 (1979).

2. "Formation of Double Layers," A. Y. Wong, P. Leung and B. H. Quon, to be published in Physics of Fluids.

3. “Experimental Observations of Highly Nonlinear States in Plasmas," A. Y. Wong, UCLA PPG-400, accepted for publication in Comments on Plasma Physics and Controlled Fusion. 


\section{Project}

Study of Hot Plasma Transport and Heating in Toroidal Geometry

K. MacKenzie, R. J. Taylor

FY79 \$425K op

$25 \mathrm{~K}$ eq

FY80 \$500K op

20K eq

\section{Purpose}

Research under this project is geared towards studying the properties of particle transport of clean plasmas and plasma-wall regions under ohmic and RF heated conditions and making such plasmas available to other users," such as FIR scattering groups and diagnostic developers.

\section{Approach}

Plasmas are produced in Microtor and Macrotor tokamaks by using capacitor banks with up to $2 \mathrm{MJ}$ of stored energy. Fields of up to $25 \mathrm{kG}$ in Microtor and $4 \mathrm{kG}$ in Macrotor are used. The dimensions are $\mathrm{R}=30 \mathrm{~cm}$ and a chamber cross section of $20 \times 25 \mathrm{~cm}$ for Microtor, and $\mathrm{R}=90 \mathrm{~cm}$ with a $90 \times 150$ $\mathrm{cm}$ chamber for Macrotor. Plasma densities are $10^{12}<\mathrm{N}$ (Microtor) $<5 \times 10^{14} / \mathrm{cc}$ and $10^{11}<\mathrm{N}$ (Macrotor) $<2 \times 10^{13} / \mathrm{cc} . \mathrm{T}_{\mathrm{e}}$ (Macro $)=150 \mathrm{ev}, \mathrm{T}_{\mathrm{e}}($ Micro $)=600 \mathrm{ev}$.

\section{Progress}

1. Macrotor has operated for two years at $2 \mathrm{kG}$ and at $4 \mathrm{kG}$ December, 1979.

2. Suppression of high-Z impurity influx by cold electron injection (which changes the sheath potential) has been demonstrated. Microtor/Macrotor has shown $\mathrm{na}^{2}$ scaling, at all operating conditions.

3. Microtor has operated at $20 \mathrm{kG}$ August, 1978 and at $25 \mathrm{kG}$ - December, 1979.

\section{Plans}

1. To study power balance and its dependence on internal electric and magnetic fluctuations.

2. To study high beta effects and plasma control requirements.

3. To study transport in the presence of RF and use RF for transport controls, e.g., as related to ash removal in reactors. 


\section{Milestones}

1. Issue report on density clanıping and drop due to RF by September, 1980.

Graduate Students (\% DOE support)

D. Whelan (50\%, summer; 25\%, academic year) plus students from Professor Luhmann's group.

\section{Graduates}

A. Semet (Professor Luhmann)

\section{Other Professional Staff}

J. Garter

F. Sohwirzke (consultant)

F. Tenescu

S. Talmadge

S. Zwẹhen

\section{Major Recent Publications}

Measurements of Wall Impurity Concentrations During Tokamak Discharge, R.J. Taylor, Lena Oren, F. Schwirzke, Department of Navy Post Graduate School, Navy, August 1978. Lecture, Varenna, Italy, September, 1978. Published Pergamon Press Ltd., Oxford, UK, Proceeds of Course.

Trapping and Removal of Oxygen in Tokamaks, L. Oren, R.J. Taylor, Nucl. Fus. 17, 1143 (1977).

Phenomenology of Metal Influx in Micro/Macrotor Tokamaks, L. Oren. R.J. Taylor and F. Schwirzke, Center for Plasma Fusion Engineering, UCLA Report, Journal of Nuclear Materia's, $76 \& 77,412$ (1978).

Suppression of Metallic Impurities by Electron Injection in Macrotor, R.J. Taylor, Lena Oren, Physical Review Letter, 42, 446 (1979).

Surface Interactions and Conditioning Techniques in Tokamaks, R.J. Taylor, Plasma Physics, J. Nucl. Mater, 76 \& 77, 412 (1978), Invited Paper.

Vacuum Photodiode Detector Array for Broadband UV Detection in a Tokamak Plasma, S.J. Zweben, C.R. Menyuk, and R.J. 'Taylor, Am. Inst. Physics, PPG 375, April, 1979.

Small Scale Magnetic Fluctuations Inside the Macrotor Tokamak, S.J. Zweben. C.R. Menyuk a.d R.J. Taylor, PPF 383, January, 1978.

Laser Induced Desportion from the Macrotor Tokamak Walls, F. Schwirzke, Lena Oren, S. Talmadge and R.J. Taylor, Phys. Rev. Lett. 40, $1181,1978$. 
Experimental Plasma Research

University of California, Irvine

\section{Project}

Simple Mirror Stabilization and Confinement

Nathan Rynn, Heinrich Boehmer

FY79 AF $\quad$ FY80 $\$ 180 \mathrm{~K}$ op

\section{Purpose}

To stabilize a simple mirror confined plasma against flute instabilities by surrounding it with an outer blanket of cold plasma that is line-tied to an electron-emitting conductor.

\section{Approach}

A simple mirror, about the size of Constance II at MIT, but without the stabilizing bars, will be built. The mirror will be filled with a plasma with a temperature of the order of $10 \mathrm{eV}$ or higher. Then the plasma will be surrounded with a blanket of colder plasma that is line-tied to an electron- : emitting conductor.

\section{Progress}

1. The stabilization scheme has been tested and proven effective in a Q-machine mirror configuration.

2. Optical diagnostic techniques for detecting radial and azimuthal plasma motion have been developed. In addition, we have the capability of measuring ion velocity distributions in space and time.

3. The theory of the stabilization mechanism has been tested in a curved magnetic field geometry.

\section{Plans}

1. Fabricate the simple mirror.

2. Trap $10 \mathrm{eV}$ plasma in simple mirror. Observe fluting.

3. Determine the motion of a flute-unstable core both with and without the conducting blanket.

4. Repeat these measurements using a barium plasma and optical diagnostics to measure the heat loss from the core to the tenuous plasma blanket. 


\section{Milestones}

1. Complete fabrication of the simple mirror - June 1980.

2. Begin trapping plasma and flute studies - July 1980.

3. Begin making optical measurements in Ba plasma - September 1980.

\section{Graduate Students}

S. Fornaca (100\%), M. Wickham (100\%).

\section{Graduates}

None

\section{Other Professional Staff}

H. Boehmer (25\%).

\section{Major Recent Publications}

S. Fornaca, Y. Kiwamoto, and N. Rynn, "Experimental Stabilization of Interchange Mode by Surface Line-tying," Phys. Rev. Lett. 42, 772 (March 1979). 
Experimental Plasma Research

Columbia University

Category PP

\section{Project}

High-Beta Plasma Research - Torus I and Torus II.

Robert A. Gross

FY79 (5 month) $\$ 185 \mathrm{~K}$ op $\quad$ FY80 $\$ 450 \mathrm{~K}$ op

$65 \mathrm{~K} \mathrm{eq} \quad 0 \mathrm{~K}$ eq

\section{Purpose}

To investigate plasma equilibrium and stability of high-beta axisymetric toroidal configurations.

\section{Approaches}

Torus $I$ is an axisymetric, rectangular cross section experimental device $\left(R_{0}=22.5 \mathrm{~cm}, R_{0} / a=3\right.$, $\mathrm{h}=45 \mathrm{~cm}$ ), which operates as a belt pinch or elongated high-beta tokamak. Operating parameters are: $\mathrm{B}_{\mathrm{O}} \sim 10 \mathrm{kG}, \mathrm{n} \sim 10^{16} \mathrm{~cm}^{-3}, \mathrm{~T} \sim 10 \mathrm{eV}, \mathrm{I}_{\mathrm{p}} \sim 100 \mathrm{kA}, \mathrm{q}(\mathrm{a}) \gtrsim 3,<\beta>\sim 10 \%$.

Torus II is an axisymetric, rectangular cross section, high-beta tokamak $\left(R_{\mathrm{O}}=22.5 \mathrm{~cm}, \mathrm{R}_{\mathrm{O}} / \mathrm{a}=3\right.$, $\mathrm{h}=30 \mathrm{~cm}$ ) heated initially by a high power $(50 \mathrm{GW}, 1.7 \mu \mathrm{sec})$ toroidal field reversal technique. Operating parameters are: $\mathrm{B}_{\mathrm{o}} \sim 10 \mathrm{kG}, \mathrm{n} \sim 10^{15} \mathrm{~cm}^{-3}, \mathrm{~T} \sim 100 \mathrm{eV}, \mathrm{I}_{\mathrm{p}} \lesssim 80 \mathrm{kA}, \mathrm{q}(\mathrm{a}) \gtrsim 2$, $<\beta>\sim 10 \%$.

\section{Progress}

Torus I: Completed study of belt pinch dynamics and plasma properties. Machine is now being used to develop high-beta toroidal diagnostics. Optical schlieren techniques are being explored to obtain instantaneous complete radial density profiles.

Torus II: Experimental research in this machine began in May 1978. High-beta tokamak equilibrium configurations have been ohtained with $\beta(0) \sim 30 \%,\langle\beta\rangle \sim 10 \%$, b/a $\sim 2$, and they appear macroscopically stable. During radiative cooling there is some evidence of density fluctuation growth at the plasma outer edge, suggestive of the start of ballooning instability. Stable operation is believed to be in the second, high-beta tokamak regime with dimensionless parameters of shear $s \sim 0.5$, and pressure gradient $G \sim 4$. Completed spectroscopic study of physics of initial high power (12 and $25 \mathrm{GW}$ ) field reversal heating. Vacuum UV spectroscopy and $\mathrm{CO}_{2}$ laser scattering systems installed and working.

\section{Plans}

Torus I: Complete evaluation of optical schlieren diagnostic for high-beta toroidal research and then terminate Torus I operation.

Torus II: Measure plasma properties as a function of space and time and evaluate $\beta(r, t)$ for different initial heating powers: Search for ballooning modes and limits of high-beta tokamak stability. Operate with $\mathrm{H}_{2}$ as well as $\mathrm{He}$, perform tests at higher initial heating power (to $50 \mathrm{GW}$ ), and extend experimental pulse length time. 


\section{Milestones}

1. Began detailed studies of Torus II plasma properties, summer 1978.

2. Obtained detailed poloidal flux plots of Torus II, (12 GW initial heating) Sept., 1979.

3. Obtained first vacuum UV data for Torus II, Sept. 1979.

4. $\mathrm{CO}_{2}$ scattering diagnostic in operation; Nov. 1979.

5. Completed visible spectroscopic study of Torus II plasma; G. Georgiou Ph.D. thesis, Dec. 1979.

6. Thomson scattering diagnostic to begin operation; Feb. 1980.

7. Search for ballooning modes and high-beta tokamak stability limits; 1980 .

\section{Graduate Students (\% DOE Support)}

G. Georgiou (100\%); C. Kostek (100\%); A. Kashani (100\%); F. Levinton (100\%); M. Machida (100\%);

S. Paul (100\%); E. Schamiloglu (100\%).

\section{Graduates (Year)}

G. Georgiou (1979).

\section{Other Professional Staff}

Professor T.C. Marshall Dr. P.G. Weber

Professor G.A. Navratil

\section{Major Recent Publications}

1. High-Beta Tokamaks by Pinch Techniques; C.K. Chu, R.A. Gross, Proc. Finite-Beta Workshop, Varenna, Italy, CONF-7709167, pg. 187 (1977).

2. Columbia Torus II, A High-Beta Tokamak; R.A. Gross, P.G. Weber, T.C. Marshall; Proc. IEEE Workshop, Moisterey, CA pg. 107-123 (1978).

3. Experimental and Theoretical Studies of High-Beta Tokamaks; A. Aydemir et al., IAWA-CN37/U1, 7th International Conlerence on Plasma Physics and Controlled Nuclear Fusion Research, Innsbruck, Austria, Vol. II, pg. 105 (1979).

4. Experiments on High-Beta Tokamak Stability, P.G. Weber, T.C. Marshall, R.A. Gross; Proc. 9th European Conf. on Controlled Fusion \& Plasma Physics, Oxford, England, EP3, 144 (1979).

5. Study of Turbulent Heating Effects in the High-Beta Tokamak Torus II; G.E. Georgiou, T.C. Marshall, P.G. Weber, Sub. to Phys. Fluids (1979). 
6. Implications of Recent High-Beta Tokamak Research, R.A. Gross and T.C. Marshall; Comments on Plasma Physics \& Controlled Fusion; to be published 1980.

7. Nuclear Energy; Fission \& Fusion; R.A. Gross, 3 chapters in book: Energy for Survival; Ed. H. Messel; Pergamon Press, 1979.

8. Spectroscopic Study of Turbulent Heating in the High-Beta Tokamak - Torus II; G.E. Georgiou; Columbia University Ph.D. thesis 1979. 
Experimental Plasma Research

University of Iowa

Category PP

\section{Project}

Experimental Studies of Cusp Confinement and of CTR Plasmas

Noah Hershkowitz

FY79 \$70K op (10 month) FY80 \$125K op

$0 \mathrm{~K} \mathrm{eq} \quad 50 \mathrm{~K}$ eq

\section{l'urpose}

To investigate plasma confinement associated with electrostatic and multi-dipole magnetic fields.

\section{Approaches}

Epot: A multi-dipole device with each cusp covered by a pair of positive electrodes. Magnetic fields provide electron confinement. Electric fields provide ion confinement.

MagPi I and II: Used to study the extent to which self-consistent electric fields can be used to reduce secondary electron emission at end walls of magnetic mirror machines.

Picket Fence: A current produced multi-dipole magnetic field.

Double Layer: A triple plasma device is used to produce magnetic field alligned electrostatic "sheath". All devices are steady state, low temperature $(<10 \mathrm{eV})$, low density $\left(<10^{12} \mathrm{~cm}^{-3}\right)$ devices.

\section{Progress}

Epot: Electrostatic potential wells which confine ions have been achieved. Plasma density is improved by application of bias voltage. Wall secondary electrons are directly observed.

MagPi I and II: Plasma confinement is observed at "parallel" cusps. Self-consistent electrostatic ion confinement is found to be important. Potential minima favorable for secondary electron suppression are observed. Straight line cusps and ring-point cusps behave essentially the same. Ion Cyclotron waves driven by cross field ion beams, were identified.

Picket Fence: An efficient and accurate emissive probe technique has been developer. $\overrightarrow{\mathrm{E}} \times \overrightarrow{\mathrm{B}}$ drifts have been observed. A "trapped electron" source has been developed.

Double Layer: Large double layers $\left(\Delta \Phi / \mathrm{T}_{\mathrm{e}} \leq 20\right)$ have been achieved with magnetic fields where $\omega_{\mathrm{pe}} / \omega_{\mathrm{ce}} \leq 1$. Two dimensional measurements were made of the electric potential.

\section{Plans}

Epot: Plasma confinement will be optimized.

MagPi I and II: Complete study of plasma confinement. 
Picket Fence: Begin laser fluorescence studies to determine ion distribution functions. Carry out higher $\left(\leq 10^{13} \mathrm{~cm}^{-3}\right)$ density measurements.

Double Layers: Make use of a new triple plasma device to study the ability of potential barriers to provide thermal insulation for electrons in order to test the use of thermal barriers on tandem mirrors.

\section{Milestones}

1. Electrostatic Confinement: Complete preliminary study of secondary electron emission March 1980.

2. MagPi Experiments: Complete preliminary study on the details of secondary emission in MagPi II - March 1980.

3. Picket Fence: (1) Begin laser fluorescence studies to determine ion distribution functions September 1979. (2) Complete high density experiment - December 1980.

4. Electrostatic Sheaths: Complete measurements on the time dependence of double layers September 1979.

5. Thermal Barrier Studies: (1) Complete device fabrication - December 1979. (2) Begin thermal barrier studies with and without magnetic field - January 1980. (3) Complete thermal barrier studies without magnetic field - July 1980.

Graduate Students (\% DOE Support)

P. Coakley (30\%); J. Glanz (100\%); S. Cartier (100\%); C. Chan (20\%).

Graduates (Year)

T. Romesser (1975), T. Christensen (1977), J.R. Smith (1978), F. Ze (1979).

\section{Other Professional Staff}

Professor G. Joyce Professor G. Payne

Professor S.W. Nicholson James R. DeKock

Professor G. Knorr

\section{Major Recent Publications}

1. Electrostatic Self-Plugging of a Picket Fence Cusped Magnetic Field, Noah Hershkowitz, John R. Smith and Hideo Kozima, Phys. Fluids, 22, 122-125, 1979.

2. Negative Plasma Potential Produced by Supplemental Electron Emission, Noah Hershkowitz, Frederic Ze, and Hideo Kozima, Phys. Fluids, 22, 338-346, 1979. 
3. The Inflection-Point Method of Interpreting Emissive Probe Characteristics, J.R. Smith, N. Hershkowitz, and P. Coakley, Rev. Sci. Instrum., 50, 210-218, 1979.

4. Laboratory Double Layers, Peter Coakley and Noah Hershkowitz, Phys. Fluids, 22, 1171-1181, 1979.

5. Strong Laboratory Double Layers in the Presence of a Magnetic Field, Peter Coakley, Lloyd Johnson and Noah Hershkowitz, Phys. Lett., 70A, 425-428, 1979.

6. Spatial Plasma Potential Variations in a Multi-dipole Device, Noah Hershkowitz, John R. Smith and James R. DeKock, Plasma Phys., 21, 823-826, 1979.

7. Surface Trapping of Primary Electrons by Multi-Dipole Magnetic Fields, N. Hershkowitz, J.R. DeKock, P. Coakley and S.L. Cartier, Rev. Sci. Instrum., to be published January 1980. 
Experimental Plasma Research

University of Maryland

Category PP

\section{Project}

Production of Thermonuclear Plasmas in High Beta Devices

H.R. Griem, A. DeSilva, C. Chin-Fatt, and G. Goldenbaum

FY79 \$425K op FY80 \$47K op

$0 \mathrm{eq} \quad 0 \mathrm{eq}$

\section{Purpose}

To study the heating of high beta plasmas.

\section{Approach}

Deuterium plasmas are produced and heated in a toroidal theta pinch by the application of fast rising $(\mathrm{t} / 4 \widetilde{<} \cdot 1 \mu \mathrm{s})$, high voltage $(600 \mathrm{kV})$, pulses which are crowbarred at peak current and decay with an $\mathrm{L} / \mathrm{R}$ time of $30 \mu \mathrm{s}$. A post-implosion "quasi-equilibrium" phase is attained by programming an additional capacitor bank to drive toroidal plasma currents.

\section{Progress}

Recent experiments have concentrated on plasmas formed in high ( $~ 800$ gauss) parallel and antiparallel bias fields. In the antiparallel case a deep $(\beta \sim 1)$ magnetic well is formed and drifts in about $6 \mu \mathrm{sec}$ to the outer wall. With parallel bias, the plasma diamagnetism is small and the plasma drifts more rapidly to the wall. Spatially resolved measurements of the magnetic field, electron density, and temperatures provided strong evidence for the role of microinstability-heating in the current sheath. X-ray and Thomson scattering measurements revealed a bi-Maxwellian electron distribution with the bulk of the electrons at temperatures up to $1.5 \mathrm{keV}$ and a smaller hot component at $\mathrm{T} \approx 5 \mathrm{keV}$. Ion temperatures from neutron yields and Doppler broadening of impurity spectral lines are $>1 \mathrm{keV}$, at $\mathrm{n} \simeq 10^{15} \mathrm{~cm}^{-3}$.

\section{Plans}

The high bias field results will be compared with parallel and antiparallel low bias field ( 200G) conditions. The magnetic field structure will be probed at several azimuthal positions and at various positions in the minor cross section, to search for evidence of tearing or ballooning modes. An attempt will be made to drive a greatly increased toroidal current to arrest the toroidal drift.

\section{Milestones}

1. Complete magnetic probe studies of MHD stability, May 1980. 
2. Installed and tested increased toroidal current drive - June 1980.

3. Terminate experiments - September 1980.

\section{Graduate Students}

R. Merlino (100\%), D. Murphy (100\%).

\section{Graduates}

Nunte

\section{Other Professional Staff}

Dr. Y.P. Chong, Research Associate

Dr. R.A. Hess, Research Associate

\section{Major Recent Publications}

Plasma Heating in a High-Voltage Toroidal $\theta$ Pinch, Y.G. Chen, et al., Phys. Rev. Lett. 38, 1400 (1977).

Experimental and Theoretical Studies of High-Beta Tokamaks, A. Aydemir, et al., 7th IAEA Conf. on Plasma Physics and Controlled Nuclear Fusion Research, Innsbruck, Austria, 1978. 


\section{Project}

TERP: Toroidal Experimental Research Plasma

G.C. Goldenbaum

$\begin{array}{rrr}\text { FY79 } & \$ 175 \mathrm{~K} \text { op } & \text { FY80 } \\ 20 \mathrm{~K} \mathrm{eq} & \$ 190 \mathrm{~K} \text { op } \\ 20 \mathrm{~K} \mathrm{eq}\end{array}$

\section{Purpose}

To investigate high beta plasma properties (instabilities and transport) in a noncircular cross section tokamak configuration and compare with numerical calculation.

\section{Approach}

Energy efficient, pulsed power techniques are used to produce the tokamak configuration via fast rising fields.

\section{Progress}

Kink instabilities have been studied in the linear and nonlinear phases and compared with time dependent computer codes. Linear growth rates and dependencies agree well, details in the nonlinear phase agree less well.

The experiment has been modified to increase the field magnitude and prolong the pulse time to allow slowly growing modes (ballooning and tearing) to be studied.

Transport in a collisional, stable plasma has been investigated, and an MHD regime in which crossed temperature and density gradients coexist has been found.

\section{Plans}

Measurements of field and density profiles during instability growth will be compared with linear initial value computer code calculations for high beta conditions.

\section{Milestones}

1. Complete field and density measurements showing evolution of motion in high $q(q>1)$ plasmas - March 1980.

2. Install Thomson scattering system to measure temperature profiles during instability June 1980.

3. Install forward scattering system to investigate microinstability controlled transport June 1981. 


\section{Graduates}

A.W. Allen (1978)

\section{Other Professional Staff}

Researç Associate

\section{Major Recent Publications}

1. Experimental Observations of the Equilibrium and Stability of a Noncircular Cross Section Toroidal Plasma, A.W. Allen, University of Maryland Technical Report No. 78-051.

2. Observation of the Nonlinear Phase of a Noncircular Crnss Ser.tinn Toroidal Kink Instability, A.W. Allen and G.C'. Golden baum, Phys. Fluids 22, 795 (1979).

3. Observations of a Highly Collisional Toroidal Plasma Equilibrium, A.W. Allen, J.A. Antoniades, and G.C. Goldenbaum, Phys: Fluids 22, 1979.

4. Experimental and Numerical Studies of Magnetohydrodynamic Stability Properties of a Rectangular Cross Section Finite $\beta$ Toroidal Plasma, A.W. Allen, F.L. Cochran, G.C. Goldenbaum, and P.C. Liewer, Phys. Rev. Lett. 39, 404 (1977). 
Experimental Plasma Research

Massachusetts Institute of Technology

\section{Project}

Mirror Instabilities - Constance I

L.D. Smullin

FY79 27K op $\quad$ FY80 80K op

$5 \mathrm{~K} \mathrm{eq} \quad 7 \mathrm{~K} \mathrm{eq}$

\section{Purpose}

To study problems relevant to Hot Electron suppression of DCLC instabilities.

\section{Approach}

There are three sub-projects during FY80.

1. Study the properties of the Ti washer gun and of the plasma stream it produces.

2. Build and test a pulsed gas washer gun to replace the Ti washer plasma gun now in use.

3. Study of electron gun design to optimize the efficiency of beam-plasma interaction (BPI).

\section{Results}

1. Extensive measurements have been made on the washer gun plasma. In the $2 \mathrm{kG}$ guide field, there is a 200-300 amp electron'beam flowing through a plasma of $n \gtrsim 10^{13} \mathrm{~cm}^{-3}$. The full voltage (after breakdown) falls to about 150-250, but the electron stream has components with $\mathrm{W}_{\|} \rightarrow 600-800 \mathrm{ev}$. Microwave and UHF emissions have been observed and cataloged, as have the low frequency flute-like fluctuations.

2. A fast acting ( $\sim 1 \mathrm{~ms})$ gas valve has been designed and built for the washer plasma gun.

3. The SLAC electron beam computer code (written by Dr. W. Harmannsfeld) has been set up on the computer here, and is being used to analyze the electron flow pattern from magnetron injection guns. The code will be used to analyze the space change limited magnetron guns we have been using in past experiments; and it will serve as a guide for the design of more efficient guns.

4. Constance I has been refurbished and will be used as an E-beam test facility as well as a plasma gun test facility.

Plans

1. A study (numerical and analytical) has begun of various beam-plasma interaction modes to try to relate theoretical predictions to the phenomena observed in the output of the plasma washer gun. 
2. Test the pulsed gas gun to determine whether the extra degree of freedom (separate control of gas evolution) allows production of a hotter plasma than is possible with the Ti washer gun.

3. Continue the numerical study of electron trajectories and test several designs experimentally.

\section{Milestones}

1. Test pulsed gas gun starting February, 1980. If results are promising, install on Constance II.

2. Begin experimental E-beam studies, January, 1980.

3. Plot trajectories to the spread in $V_{\perp}$ and $\bar{V}_{\perp} / V_{I I}$, begin February, 1980.

Graduate. Students (\% DOF. Sunport)
A. Ezzedine (50\%)
P. Rymer ( $100 \%$ NSF)
S. Voldman (100\%) 
Experimental Plasma Research

The Pennsylvania State University

Category PP

\section{Project}

A Study of Flow and Loss Processes at the Ends of a Linear Theta Pinch

T.M. York and E.H. Klevans

$\begin{array}{rrr}\text { FY79 } & \$ 33 \mathrm{~K} \text { op } & \text { FY80 } \\ & \$ 25 \mathrm{~K} \text { eq } & \$ 158 \mathrm{~K} \text { op } \\ & \$ 7 \mathrm{~K} \text { eq }\end{array}$

\section{Purpose}

Investigate the physics of particle and energy loss from the ends of a theta pinch, including identification of mechanisms governing the loss and expansion of plasma in the field lines, and methods of inhibiting loss to improve confinement. Compact torus RFP configurations are used to study confinement; loss plasmas typical of Mirror and Tokamak machines are generated for plasma guiding and wall-interaction studies.

\section{Approach}

With a $50 \mathrm{~cm}$ long $10 \mathrm{~cm}$ dia. coil, the pinch discharge will produce source plasmas up to $\mathrm{n}_{\mathrm{e}}=10^{16}$, $\mathrm{T}_{\mathrm{e}}=200 \mathrm{eV}$ that can be studied to understand mechanisms involved in particle-field interaction, confinement in closed and open field lines, and dynamics of loss into expanding field lines with wall interactions. New diagnostic development is presumed and planned.

\section{Progress}

1. With a $25 \mathrm{~cm}$ long coil, and $110 \mu \mathrm{F}$ bank, the study of transient ( $\sim 5 \mu \mathrm{sec}$ ) loss from a RFP at low $\mathrm{T}$ which is strongly influenced by diffusion was carried out. Transients in reversed trapped field geometries were studied with $0.1 \mu \mathrm{sec}$ resolution diagnostics.

2. A Twyman-Green interferometer was developed and used to determine the history of axially integrated plasma behavior in a pinch coil.

3. Two new Thomson scattering diagnostic systems have been conceived, designed, and are undergoing evaluation:

a. Velocity diagnostic which incorporates an optimized $\mathrm{S} / \mathrm{N}$ procedure.

b. Low electron density diagnostic which utilizes doubled frequency Nd-glass light.

4. Prediction and generation of mirror fields at the ends of a theta discharge coil have been evaluated. Analytical predictions of fields were carried out with new techniques, and experimental field production has been compatibly evaluated. 
5. Development of a $50 \mathrm{~cm}$ long expt. with $10.5 \mathrm{~cm}$ coil and $7.62 \mathrm{~cm}$ discharge tube was carried out and used for studies of particle and energy loss. Unique identification of radial and axial $\mathrm{n}_{\mathrm{e}}, \mathrm{T}_{\mathrm{e}}$ gradients has been completed. This data allowed comparison with analytical models.

6. A new concept crowbar technique has been developed, evaluated and reported. It is used for main bank row crowbar and crowbar of coils at ends.

7. O-D codes to predict loss from open-ended theta pinches have been developed and successfully used to describe experiments.

8. A 1-D code to predict thermal and particle loss from open-ended theta pinches was developed and used to identify. loss physics.

9. O-D codes to predict pinch behavior with rotation and trapped fields were developed and used.

10. A O-D code to predict plasma properties in RFP devices was developed and used for FRX-B (LASL).

Plans

1. Alter main capacitor bank to achieve low inductance configuration, install new design crowbar, install new vacuum system to generate reproducible RFP plasmas which will be used for diagnostic and physics studies.

2. Demonstrate proof-of-principle of velocity diagnostic on $11 \mathrm{~cm}$ long $10.5 \mathrm{~cm}$ diam. test bed the ta pinch.

3. Conduct evaluation studies of frequency doubling Nd-glass lasers with cooperating laboratories (ARGUS group LLL).

4. Procure and test frequency doubling Nd-glass diagnostic system.

5. Carry out test-bed evaluation of Fizeau interferometer for low density diagnostics.

6. Experimental and analytical study of plasma loss from RFP and convection to wall interaction regions with parallel guiding fields.

7. Experimental and analytical study of plasma convection, diffusion, and guiding in expanding field lines with subsequent low density wall interactions to study thermal barriers.

\section{Milestones}

1. Experimental evaluation of electron velocity diagnostic technique using Thomson scattering on $10 \mathrm{~cm}$ long pinch. March 1980

2. Experimental evaluation of doubled frequency Nd-glass Thomson scattering diagnostic. June 1980

3. Alteration of existing $50 \mathrm{~cm}$ long theta pinch configuration to RFP with new vacuum system and new crowbar installation. June 1980. 
4. Experimental evaluation of Fizeau interferometer for low density diagnostics. December 1980

5. Preliminary data on flow guiding in B fields and interaction of RFP loss plasma with end walls in parallel fields. November 1980

Graduate Students (\% DOE Support)

B. Jacoby (50\%), R. McCowan (50\%), F. Mead (50\%), A. Peterson (50\%), K. Holsopple (Hourly).

Graduates

R. Freeman (1977), A. Awwad (1978), J. Véglia (1979). J. Heidrich (1980), E. Stover (1980)

\section{Other Professional Staff}

J.W. Robinson (15\%), Associate Professor of Electrical Engineering

\section{Major Recent Publications}

1. E.K. Stover, E.H. Klevans and T.M. York, "Computer Modeling of Linear Theta Pinch Machines," Phys. Fluids 21, 2090, 1978.

2. B.A. Jacoby, T.M. York and R.A. Mollo, "A Doubled Nd-Glass Laser System for Incoherent Thomson Scattering from Low Density Plasma," submitted to Applied Optics.

3. B.A. Jacoby and T.M. York, "A Method of Measuring Directed Electron Velocities in Flowing Plasmas Using the Incoherent Regions of Laser Scattering," accepted for publication in Applied Optics.

4. E.H. Klevans, "A Zero-Dimensional Model of a Reversed-Field Theta Pinch," presented at the US-Japan Joint Symposium on Compact Toruses and Energetic Particle Injection, December 12-14, 1979, at Princetur University.

5. E.H. Klevans and S.P. Gary, "Particle and Energy End Loss from a Collisionless Plasma," submitted to Physics of Fluids.

6. B.A. Jacoby and T.M. York, "A High Voltage SCR Trigger Circuit," submitted for publication in Rev. Sci. Instr.

7. J.W. Robinson, "A Self-Triggered Crowbar Switch," submitted for publication in Rev. Sci. Instr. 
Experimental Plasma Research

University of Texas

\section{Project}

Initial Phases of a Tokamak Discharge

Roger Bengtson

FY79 AF

FY80 \$170K op

oK eq

\section{Purpose}

The primary purpose is to characterize the initial formation of plasma in a tokamak. Major emphasis will he plared nn stundying the cool outer edgoo of the plamma for compaisun will mudeling codes and for knowledge of conditions around rf waveguide arrays.

A second purpose is to investigate the interaction of higher power waves in the frequency range 2-15 MHz using either ion cyclotron or Alfven waves. The possibility of if assisted currents will also be investigated.

The third objective is the development and check-out of various systems to be used on TFXT.

\section{Approach}

A research tokamak with $\mathrm{B}_{\mathrm{T}}=10-20 \mathrm{kG}, \mathrm{R}=51 \mathrm{~cm}, \mathrm{r}=17 \mathrm{~cm}, \mathrm{n}_{\mathrm{e}} \approx 0.1-5 \times 10^{13} \mathrm{~cm}^{-3}$ and usable test time of $50 \mathrm{msec}$ is used. The vacuum chamber has four full length diagnostic windows, $34 \mathrm{~cm}$ long, $15 \mathrm{~cm}$ wide, and a tangential port. Diagnostics include laser scattering, microwave interferometer, spectroscopic instrumentation and electric and magnetic probes.

\section{Progress}

Tokamak fabrication complete. Diagnostics installed and operating include Thomson scattering, microwave interferometer, soft $\mathrm{X}$-ray diode array, $\mathrm{X}$-ray spectroscopy and electron cyclotron emission. Typical conditions are $\mathrm{T}_{\theta_{\text {peak }}} \sim 250 \mathrm{eV}, \mathrm{N}_{\mathrm{c}} \sim 10^{13}, \mathrm{I}_{\mathrm{p}} \sim 40-50 \mathrm{k \Lambda}$.

\section{Plans}

1. Complete experiments on initial phases of a tokamak discharge and compare with theoretical models.

2. Begin Alfven wave heating and current drive experiments.

\section{Milestones}

1. Complete experiments to characterize initial current formation - March 1980.

2. Begin Alfven wave and current drive experiments - July 1980. 


\section{Graduate Students (\% DOE Support)}

J. Benesch (100), S. Eckstrand (100), R. Gandy (100), S. Lin (100), S. McCool (100), T. Kochanski (100), R. Mitchie (0), J. Watkins (0), G. Joyce (0).

\section{$\therefore$ Other Professional Staff}

Dr. Akira Hasegawa, Bell Laboratories

Dr. P. Phillips

Dr. W. Rowan 
Experimental Plasma Research

University of Wisconsin - Madison

Category PP

\section{Project}

Tokapole

J.D. Callen, R.N. Dexter, G.A. Emmert, D.W. Kerst, R.S. Post, S.C. Prager, J.C. Sprott, K.R. Symon, J.R. Conrad

FY79 (8 mo) \$266K op

$\$ 17 \mathrm{~K}$ eq

FY80 \$425K op

$\$ 35 \mathrm{~K}$ eq

\section{Purpose}

To study basic physics of equilibrium, stability heating, and transport in a torus.

\section{Approach}

Tokapole: A four-node poloidal divertor tokamak configuration is created by positioning octupole rings for dee, inverse dee, and square cross sections. When operated without toroidal field, a pure octupole with similar plasma parameters is obtained.

\section{Progress}

1. Square, dee and inverse dee poloidal divertor equilibria obtained, and compared with numerical calculations.

2. Axisymmetric instability observed and studied in detail.

3. Impurity content and radiated losses monitored spectroscopically in detail.

4. Adiabatic containment zones calculated for typical ion energies.

5. $1 \mathrm{MW}$ ICRH source installed and operating.

6. Advantages of ECRH preionization documented.

7. Wave coupling to shear Alfven resonances observed.

\section{Plans}

1. Study effect of divertor plate on stability.

2. Correlate onset and behavior of q-related helical MHD instabilities with current density profile.

3. Understand and control neutral wall reflux. 
4. Understand ion cyclotron heating rates and limitations.

5. Investigate high power Alfven wave heating.

6. Study effectiveness and limitations of poloidal ohmic heating.

\section{Milestones}

1. Correlate MHD helical instability with the current density and q-profile - October 1980.

2. Complete ICRH experiments - August 1980.

3. Understand limitations of poloidal ohmic heating - December 1980.

4. Compare shear Alfven resonances with 2-D theory - December 1980.

\section{Graduate Students (\% DOE support)}

A. Biddle (100\%), C. Fortgang (100\%), D. Holly (100\%), R. Moyer (100\%), L. Peranich (0\%), P. Smith (100\%), J. Twichell (100\%), D. Witherspoon (100\%), N. Brickhouse (100\%), C. Burton (100\%), H. Garner (100\%), J. Halle (100\%), A. Kellman (100\%), T. Osborne (100\%), S. Painchaud (100\%), M. Phillips (100\%), E. Rose (100\%), M. Sengstacke (100\%), D. Shepard (100\%), C. Strawitch (100\%), M. Zarnstorff (100\%).

\section{Graduates}

J. Rudmin (1974), A. Cavallo (1975), J. Greenwood (1975), G. Schmidt (1975), G. Navratil (1976), R. Richards (1976), C. Armentrout (1977), T. Casper (1978), A. Butcher-Ehrhardt (1978),

R. Groebner (1979). B. Lipschultz (1979), E. Strait (1979), D. Brouchous (1979), K. Wong (1975), R. Breun (1975), R. Raymond (1975), R. O’Doherty (1976), W. Guss (1976), J. Barter (1976), J. Etzweiler (1977), T. Owens (1979).

\section{Other Professional Staff}

E. Strait, B. Lipschultz, R. Torti

\section{Major Recent Publications}

1. Experimental Demonstration of $\vec{E} \times \vec{B}$ Plasma Divertor, E.J. Strait, D.W. Kerst, and J.C. Sprott, Phys. Fluids 21, 2342 (1978).

2. Experimental Study of Axisymmetric Instability of Inverse-Dee and Square Tokamak Equilibria, B. Lipschultz, S.C. Prager, T.H. Osborne, J.C. Sprott, and M. Phillips, Phys. Rev. Letters 43, 36 (1979). 
3. Observation of the Effect of Shear on Vortex Diffusion in a Collisional Plasma, G. Navratil, R.S. Post, and A.B. Ehrhardt, Phys. Fluids 22, 241 (1979).

4. Stable Confinement of High Beta Toroidal Plasma, S.C. Prager, J.H. Halle, R.S. Post, and J. Twichell, submitted to Nuclear Fusion.

5. Ion Cyclotron Heating in the Wisconsin Toroidal Octupole, J.D. Barter, and J.C. Sprott, Plasma Physics 19, 945 (1977).

6. Observations of Neoclassical and Anomalous Resistivity in Toroidal Discharges, J.G. Etzweiler and D.A. Brouchous; submitted to Phys. Fluids. 


\section{PLASMA HEATING (PH) PROGRAM}

The function of the APP plasma heating program is to study and test the physics of methods to heat fusion plasmas and to drive plasma current. Various heating techniques have been tested in the past, such as compression, turbulence, shock, neutral-beam, and rf, with the most recent program emphasis being on neutral-beam and rf techniques. The APP sponsored research can be divided into two basic categories: exploratory experiments using novel heating techniques, and - basic studies with established techniques. The latter type tend to be complimentary to the larger heating programs sponsored in the confinement systems program. The smaller APP experiments have some advantages over the larger experiments in that only modest powers are required to significantly increase the temperatures; for example ICRF heating power to tokamak ohmic heating power can be 10 or more for a reasonable cost, and many ideas or variations can be tried in a short time.

The specific goal of the APP plasma heating program is to establish the viability, effectiveness, and bases for a variety of heating techniques in fusion devices and for driving toroidal plasma current with rf energy. 


\section{Progress - Plasma Heating}

- The Naval Research Laboratory has designed and developed a $100 \mathrm{kw}, 35 \mathrm{Ghz}, 10-15 \mathrm{~ms}$ gyrotron for Electron Cyclotron resonance frequency (ECRF) studies. The tube has been operated on ISX-B for both pre-ionization and heating experiments. In the pre-ionization experiments the rf is used to initially breakdown the neutral gas. Preliminary results show that rf pre-ionization reduces the total volt-seconds required by $10-15 \%$ compared to the normal ohmic heating breakdown; a significant reduction. In the electron cyclotron resonance heating experiments the electron temperature on axis was raised from $850 \mathrm{eV}$ to $1250 \mathrm{eV}$. The tokamak operated at $N_{\mathrm{e}} \sim 10^{13}, \mathrm{~B}=12.5 \mathrm{kG}, \mathrm{I}=100 \mathrm{kA}$. The gyrotron produced about $100 \mathrm{~kW}$ for 10-15 msec. The electron temperature rise was linear with rf power, about $4 \mathrm{eV} / \mathrm{kW}$, with no apparent saturation at the $100 \mathrm{~kW}$ level.

- Experimental evaluation of optimal antenna designs for ion cyclotron rosonance freüuency (IC'KF') heating has been accomplished nn Microtor at UCL $\Lambda$. Thesc results have been utilized in fabricating the antennas used on Macrotor.

- Stochastic ICRF heating in Macrotor has raised the ion temperature from $50 \mathrm{eV}$ to $200 \mathrm{eV}$. While the rf power has been increased to $500 \mathrm{~kW}$, approximately 5 times larger than the ohmic heating power. At these power levels a severe density drop is observed which is attributed to the drop in the particle confinement time from $5 \mathrm{~ms}$, without $\mathrm{rf}$, to $1 \mathrm{~ms}$ with rf.

Progress in containing the density at Macrotor's low magnetic fields ( $3 \mathrm{kG}$ ) in the presence of rf heating has been made with the use of $\bar{a}$ powerful negative bias applied to the periphery of the discharge from filaments. This process seems to trap ions (including high-Z). The trapped ions slow down the transport of electrons enough so that the rf induced density loss is not observed under this condition. The rf power will be increased to $5 \mathrm{MW}$ as a clearer picture of the heating mechanism the deleterious density drop evolves. 
Experimental Plasma Physics

Princeton Plasma Physics Laboratory

Category PH

\section{Project}

ACT-1/L-3: Radio-Frequency Plasma Heating and Current Generation Studies.

K.L. Wong, M. Ono

FY79 \$468K op

$17 \mathrm{~K}$ eq

FY80 \$390K op

$\mathrm{OK}$ eq

\section{Purpose}

The purpose of the ACT-1/L-3 program is:

1. To study the linear and nonlinear interaction of waves and particles in toroidal (ACT-1) and linear (L-3) magnetic fields;

2. To investigate current generation by the damping of unidirectional plasma waves and the application of this concept to steady-state tokamaks;

3. To measure the plasma heating and transport resulting from high frequency electromagnetic interactions;

4. To compare experimental conclusions with existing theory and to rescale relevant results to larger-scale experiments on hot tokamak plasmas and

5. To explore new concepts and develop new diagnostic systems and techniques.

\section{Approach}

ACT-1 (Advanced Concepts Torus - 1) has been in operation since August 1979. The machine parameters are: major radius $=59 \mathrm{~cm}$, minor radius $=10 \mathrm{~cm}$, magnetic field on minor axis $-5.5 \mathrm{kG}$, steady-state plasma density $\simeq 10^{12} \mathrm{~cm}^{-3}$, electron temperature $\simeq 10 \mathrm{eV}$, ion temperature $\sim 0.5 \mathrm{eV}$. It is a highly adaptable test-bed for advanced concept experiments as it features enormous access to the plasma through 26 port sections. For plasma heating and current generation studies, RF power up to $100 \mathrm{~kW}$ will be available from a $160-220 \mathrm{MHz}$ power amplifier. L-3 is a linear machine dedicated to the investigation of nonlinear propagation and coupling of lower hybrid waves. The waves are excited by a multiple-ring slow wave structure which can be operated at 1 $\mathrm{kW}$ power level and they are detected by probes connected to RF interferometers, spectrum analyzers and boxcar integrators.

\section{ACT-1}

\section{Progress}

1. Construction of ACT-1 has been completed. The plasma can be produced by emitting tungsten filaments and by electron cyclotron heating. A steady-state plasma of $\mathrm{n} \sim 2 \times 10^{12} \mathrm{~cm}^{-3} \mathrm{can}$ be produced at a neutral pressure of $10^{-4}$ torr. The diagnostics on ACT- 1 consists of $8 \mathrm{~mm}$ microwave interferometer for density measurements, NaI x-ray detector with multi-channel analyzer, electrostatic ion-energy analyzer and various RF probes. Using ion-acoustic waves 
as test waves, the plasma drift velocity were found to be less than $10 \%$ of the ion-acousuc speed. The plasma equilibrium is apparently maintained by a vertical plasma current flowing to the limiter to complete its electrical circuit. Test wave measurements show that the ion temperature is about $0.5-1.0 \mathrm{eV}$, depending on the operating conditions.

2. Construction of the $20 \mathrm{kV}$ power supply for the $100 \mathrm{~kW}, 200 \mathrm{MHz}$ power amplifier has been completed. The 8-terminal $90^{\circ}$ phased power divider for the current generation experiment has been assembled. The high power slow wave structure is being fabricated and the fault detective circuit for the $20 \mathrm{kV}$ power supply is being installed.

\section{Plans}

1. To investigate lower hybrid wave propagation in a toroidal plasma at low power levels $(<1 \mathrm{~kW})$.

2. To investigate lower hybrid wave heating and current generation at high power levels $(<100$ $\mathrm{kW}$ ).

3. To set up a $\mathrm{CO}_{2}$ laser scattering system to detect the lower hybrid waves and other density fluctuations.

4. Theoretical calculations show that a high density ion Bernstein mode would be ideal for heating tokamak reactors. A small scale experiment is being planned to test this idea.

\section{Milestones}

1. Complete the installation of the $100 \mathrm{~kW}$ power amplifier and the wave launching antenna April 1980.

2. Understand the lower hybrid wave propagation in a tornidal plasma at low power levels September 1980.

\section{L-3}

\section{Progress}

The trajectory modification of a focused resonance cone due to ponderomotive force effects was investigated in L-3. At high driving power the strong localized electric fields modify the density through the ponderomotive force on the electrons, leading to a modification of the resonance cone trajectory. The cone is seen to bend in towards the axis, in agreement with the nonlinear selfconsistent theory. The density perturbation at the focus propagates away and excites ion-acoustic waves. The wave dispersion relation was verified in $\mathrm{He}^{+}, \mathrm{Ne}^{+}, \mathrm{Ar}^{+}$and $\mathrm{Kr}^{+}$plasmas. Electron heating was observed which is consistent with collisional heating.

\section{Plans}

To investigate experimentally the nonlinear lower hybrid wave coupling efficiency near the plasma surface due to ponderomotive force effects. 
Milestone

1. Understand the ponderomotive force effect on the lower hybrid wave coupling efficiency September 1980.

\section{ACT-1, L-3}

\section{Graduate Students}

1. Project students (\% DOE support; degree, years to complete): James R. Wilson (100, PhD, 1), Robert Horton (100, PhD, 2); Glen Wurden (100, PhD, 3).

2. Graduated during past three years (year, employed in fusion): Masayuki Ono (1978, yes). 


\section{Project}

ECRH with a Gyrotron Oscillator Michael E. Read

$\begin{array}{rrr}\text { FY79 } \$ 218 \mathrm{~K} \text { op } & \text { FY80 } & \$ 200 \mathrm{~K} \text { op } \\ \text { OK eq } & \$ 40 \mathrm{~K} \text { eq }\end{array}$

\section{Purpose}

Design, build and test a $200 \mathrm{~kW}, 10 \mathrm{~ms}, 35 \mathrm{GHz}$ gyromonotron oscillator, then use this device in joint experiments on electron cyclotron heating on Tokamaks and/or other magnetically confined plasma devioos.

\section{Approaches}

1. Extend the theory and designs for a short pulse gyrotron oscillator developed with DoD funding in order to build a $200 \mathrm{~kW} 10 \mathrm{~ms}$ oscillator at a frequency of $35 \mathrm{GHz}$.

2. Design and fabricate systems for the linear polarization and transmission of the radiation. It is expected that approximately 125 to $175 \mathrm{~kW}$ will be injected into a given Tokamak.

3. Use the oscillator on Tokamaks and other magnetically confined plasma geometrics to test theories of electron cyclotron heating. The Tokamaks proposed are:

A. ISX-B, at ORNL. This larger Tokamak will allow the study of $\mathrm{ECH}$ in a high temperature $(>1 \mathrm{KeV})$ plasma, where significant single pass absorption is predicted for either mode. Bulk healing will be measurable. with the present gyrotron power and pulse length. Studies will concentrate on preionization and profile control. A full complement of Tokamak diagnostics will be available.

B. Versator II, at MIT. This machine is suited for long term detailed experiments on ECH, due to its acccssibility and design. The large vacuum ports will allow easy injection of the microwave power. The ohmic heating and gyrotron powers will be roughly equal, so significant bulk heating is expected. It is expected that experiments on this machine will address in detail questions raised but not answered, on previous experiments. In particular the gyrotron output will be linearly polarized, allowing the separation and identiflcation of the effects of extraordinary and ordinary waves.

\section{Progress}

The gyrotron has been developed and tested. A maximum power of $150 \mathrm{~kW}$ has been obtained, and a $100 \mathrm{~kW}$ has been achieved with a pulse length of $20 \mathrm{~ms}$. The device has been operated for approximately two months at these levels, and appears to be a reliable research tool.

The ECH experiments previously planned at microtor were canceled, due to temporal constraints. 
The experiments on ISX-B, at ORNL, have been completed, with very encouraging results. With $85 \mathrm{~kW}(15 \mathrm{~ms})$ delivered to the Tokamak, an increase of $400 \mathrm{eV}$ in the electron temperature was seen. Preionization studies showed a significant $(\sim 40 \%)$ decrease in the initial Tokamak loop voltage.

Plans

Perform ECH experiments on Versator II, at MIT.

Explore feasibility of early significant experimental studies of ECH in tandem mirrors.

\section{Milestones}

1. Complete ISX-B experiments - December, 1979

2. Ship and assemble power supply (MIT) - March, 1980

3. Install gyrotron at MIT - April, 1980

4. Begin experiments on Versator II - May, 1980

5. Complete experiments on Versator II - January, 1981

\section{Graduate Students}

None

\section{Other Professional Staff}

Dr. V.L. Granatstein

Dr. Kwo Ray Chu

\section{Major Recent Publications}

1. M.E. Read, R.M. Gilgenbach, R. Lucey, Jr., K.R. Chu, and V.L. Granatstein, "Spatial and Temporal Coherence of a $35 \mathrm{GHz}$ Gyromonotron Using the $\mathrm{TE}_{01}$ Circular Mode." Submitted to IEEE-MIT.

2. R.M. Gilgenbach, M.E. Read, K.E. Hackett, R. Lucey, B. Hui, V.L. Granatstein, K.R. Chu, A.C. England, C.M. Loring, O.C. Eldridge, H.C. Howe, A.G. Kulchur, E. Lazarus, M. Murakami, and J.B. Wilgen, "Heating at the Electron Cyclotron Frequency in the ISX-B Tokamak." Submitted to Physical Review Letters.

3. R.M. Gilgenbach, M.E. Read, K.E. Hackett, R. Lucey, V.L. Granatstein, A.C. England, C.M. Loring, J.B. Wilgen, Y.K. Peng, K.E. Burrel, O.C. Eldridge, M. Hacker, R. Isler, P. King, E. Lazarus, and M. Murakami, "Electron Cyclotron Resonance Preionization in the ISX-B Tokamak." Submitted to Physical Review Letters. 
Experimental Plasma Research

California Institute of Technology

Category PH

\section{Project}

Wave Heating and Diagnostics for Fusion Plasmas

R.W. Gould

FY79 \$80K $\quad$ FY80 \$235K

\section{Purpose}

Investigate wave interactions with plasmas as they apply to heating and diagnostics of low beta toroidal plasmas.

\section{Approach}

Plasma turbulence in the $0-10 \mathrm{MHz}$ range is studied using magnetic and electric probes to obtain frequency spectra, spatial dependence, cross-correlation, etc. Studies of wave launching, mode structure, and energy deposition in the ion cyclotron range of frequencies are conducted. These studies are conducted in a research tokamak with $R=45 \mathrm{~cm}, a=15 \mathrm{~cm}, I>30 \mathrm{kA}, \mathrm{B}=5 \mathrm{~T}$.

\section{Progress}

1. Prior studies of electrostatic fluctuations have been extended to magnetic fluctuations by using spatially separated magnetic probes. It is found that the r.m.s. value of the radial component of the fluctuation is 1-5 Gauss (up to one percent of the steady poloidal field), poloidal correlation lengths less than about $5 \mathrm{~cm}$, decay of the spectral density with increasing frequency (roughly an inverse fourth power), and the radial component of the fluctuations greater than the poloidal component at high frequencies.

2. With gas puffing a growing coherent $m=2$ oscillation at $22 \mathrm{kHz}$ is observed. When the density . begins to decay a multipeaked spectral structure is observed which is identified as harmonics of $\mathrm{m}-2$ and $\mathrm{m}-3$ modes.

3. Efficient coupling to the ICRF toroidal eisenmodes has been obtained through the use of a carefully designed antenna and matching network. Antenna input impedance is found to be sensitive to plasma conditions. Energy coupled into a toroidal eisenmode can be efficiently coupled out again with a similar antenna.

\section{Plans}

1. Study magnetic and electric fluctuations under varying plasma conditions. Attempt to identify modes through studies of the spatial dependence of spectra and cross-correlation. Attempt to relate fluctuation properties to transport.

2. Investigate ICRF ( $5 \mathrm{MHz}<\mathrm{f}<30 \mathrm{MHz}$ ) antenna structures and coupling under low and high (P $>50 \mathrm{~kW}>$ ohmic) conditions. 


\section{Milestones}

1. Comprehensive report on fluctuation studies - September 1980

2. Report on high power ICRF experiments - September 1980

Graduate Students (\% DOE Support)

B. Levine (100\%), M. Hedemann (100\%), G. Greene (100\%)

\section{Graduates}

C. Grabbe (1977), R. Kubena (1977), D. Hwans (1978), B. Levine (1980)

\section{Other Professional Staff}

P. Bellan (20\%)

\section{Major Recent Publications}

B. Levinc, G.J. Greene, and R.W. Gould "Focusing Resonance Cones" Phys Fluids 21, 1116-1119, July, 1978

C.L. Grabbe "Damping of Resonance Cones in Lower Hybrid Mode Conversion" Phys. Fluids 21, 1976-1978, Nov. 1978

C.L. Grabbe "Resonance Cones in a Bounded Plasma for a Finite Source" Phys. Fluids 21, 1661-1662, Sept. 1978

D.Q. Hwans and R.W. Gould "Measurements of the Complex Plasma Loading Impedance of the Magnetosonic Cavity Modes" Phys. Fluids (accepted) 1980 
Experimental Plasma Research Branch

Category PH

University of 'California at Los Angeles

\section{Project}

Study of Hot Plasma Transport and Heating in Microtor/Macrotor

K. MacKenzie, R.J. Taylor

FY79 \$225 op FY80 \$260 op

$$
5 \mathrm{eq} \quad 20 \mathrm{eq}
$$

\section{Purpose}

To study RF heating using both resonant and non-resonant modes and to compare ICRF, ECRF and $\mathrm{LH}$ techniques. To increase beta and to study diffusion in the presence of heating.

\section{Approach}

Plasmas are produced in Microtor and Macrotor tokamaks by using capacitor banks up to $2 \mathrm{MJ}$. Fields of up to $25 \mathrm{kG}$ in Microtor and $4 \mathrm{kG}$ in Macrotor are used. The dimensions are $\mathrm{R}=30 \mathrm{~cm}$ and a chamber cross section of $20 \times 25 \mathrm{~cm}$ for Microtor, and $\mathrm{R}=90 \mathrm{~cm}$ with a $90 \times 150 \mathrm{~cm}$ chamber for Macrotor. Plasma densities are $10^{12}<\mathrm{N}$ (Microtor) $<2 \times 10^{14} / \mathrm{cc}$ and $10^{11}<\mathrm{N}$ (Macrotor) $<$ $2 \times 10^{13} / \mathrm{cc}$. $\mathrm{T}_{\mathrm{e}}($ Macro $)=150 \mathrm{ev}, \mathrm{T}_{\mathrm{e}}($ Micro $)=600 \mathrm{ev}$.

\section{Progress}

1. $0.5 \mathrm{MW}$ of RF power has been delivered to Macrotor, August, 1979.

2. Observations have been made on the generation of fast neutrals with an observed hcating of ions from $50 \mathrm{ev}$ to $250 \mathrm{ev}$.

3. Developed techniques to reduce both impurities to acceptable levels.

4. ICRF power studies in Microtor were begun in December, 1979.

\section{Plans}

1. To study ICRF power disposition.

2. Tó study antenna region.

3. To increase efficiency at high power by eliminating the density drop.

4. Localize origin of fast neutrals. 


\section{Milestones}

Generate a comprehensive report in ICRF by August, 1980.

Graduate Students (\% DOE support)

David Whelan (50\% summer, 25\% academic year), plus students from Professor Luhmann's group.

\section{Graduates}

\section{A. Semmet (Professor Luhman)}

\section{Other Professional Staff}
J. Carter
E. Tenescu
F. Schwirzke (consultant)
S. Zweben
S. Talmadge

Major Recent Publications

R.J. Taylor and G.J. Morales, ICRF Heating Studies in the Macrotor Tokamak (an invited paper presented at the International Symposium on Heating in Toroidal Plasmas, held in Grenoble, France). 
Experimental Plasma Research

Massachusetts Institute of Technology

Category PH

Project

Tokamak Research on Versator II

George Bekefi

FY79 \$110K op $\quad$ FY80 $\$ 303 \mathrm{~K}$ op

\section{Purpose}

To study RF heating and current drive of Tokamak Discharges at the lower hybrid frequency, and rf heating and profile shaping at the electron-cyclotron frequency.

\section{Approaches}

1. RF power of $150 \mathrm{~kW}$ having a frequency of $800 \mathrm{MHz}$ is injected into the tokamak discharge via four and six waveguide grills.

2. RF power of $100 \mathrm{~kW}$ having a frequency of $35 \mathrm{GHz}$ is injected into the tokamak near the gyrofrequency.

\section{Progress}

1. Equilibrium Studies. The tokamak operates on a routine daily basis with the following repeatable discharge characteristics: toroidal magnetic field of $12-15 \mathrm{kG}$; plasma current of $40-50 \mathrm{kA}$; current flat top of 20-25 msec duration.

2. RF Studies at the Lower Hybrid Frequency. The four and six waveguide grills have been constructed and are being tested. For details, see M. Porkolab - Lower Hybrid RF Studies.

3. RF Studies at the Electron-Cyclotron Frequency. (In collaboration with the Naval Research: I.xlini inlug.)

a. Several types of microwave antenna systems for injection into Versator II have been designed and tested.

b. The. NRL gyrotron powei supply is being upgraded and installation ol the system on Versator II will begin in January 1980.

\section{Plans and Milestones}

1. Begin electron-cyclotron heating - June 1980.

2. Begin combined ECRH and lower Hybrid heating experiments - January 1981. 


\section{Graduate Students}

Alan. S. Fisher (100\%), Kirk E. Hackett (100\%), F.S. McDermott (100\%), Burton Richards (100\%).

\section{Graduates}

David S. Stone, Ph.D. Physics 1979.

Other Professional Staff

None

Major Recent Publications

None 
Experimental Plasma Research

Massachusetts Institute of Technology

Category PH

Project

Lower-Hybrid R.F. Heating of Versator II

M. Porkolab

FY79 \$193,000 op

$25,000 \mathrm{eq}$

FY80 \$192,000 op

17,000 eq

\section{Purpose}

To study the physics of rf heating and rf current drive in tokamak discharges at the lower-hybrid frequency.

\section{Approach}

A maximum of $150 \mathrm{~kW}, 10 \mathrm{~m} \mathrm{sec}$ long pulsed power at $800 \mathrm{MHz}$ will be injected through four and six wave-guide grills with variable relative phasing.

\section{Progress}

The installation of the high-power rf equipment has been completed. The necessary theoretical work for the waveguide design has been completed. The construction of one 4-waveguide grill and one 6 -waveguide grill is complete. Initial coupling experiments at low rf power $(0 \underset{<}{\mathcal{2}} \widetilde{<} 10 \mathrm{~kW})$ and at several different phases with both grills have been completed. Certain discrepancies between the Brambilla theory and the experimental results have been noted. Conditioning of the windows to achieve high power levels $(P \widetilde{>} 100 \mathrm{~kW})$ using the 6-waveguide grill are in progress.

\section{Plans and Milestones}

1. Raise power level of 6 -waveguide grill to $P \widetilde{ } \sim 100 \mathrm{~kW}, \tau_{\text {pulse }}=10 \mathrm{msec}$ and obtain initial results on rf current drive at $\omega>\omega_{\ell \mathrm{h}}: 3 / 15 / 80$.

2. Install 4-waveguide grill, raise power to $P \widetilde{>} 100 \mathrm{~kW}$, and obtain initial ion heating results at $\omega \simeq \omega_{\ell h}: 6 / 15 / 80$.

3. Install second grill to test rf current drive (4-waveguide, new dimensions): $10 / 1 / 80$.

4. Install third grill to optimize current drive at $\tau_{\text {pulse }} \sim 20 \mathrm{msec}$ (4 or 6-waveguide, new dimensions): $2 / 1 / 81$.

5. Return to the 4-waveguide experiment and obtain the efficiency during the ion heating experiments at $\omega \simeq \dot{\omega}_{\ell h}: 6 / 1 / 81$. 
6. Complete the studies of rf current drive, including the efficiencies. Also, combine ECRF and LHRF current-drive to maximize the current: September '81.

\section{Graduate Students}

Stephen Knowlton, 100\%; David Hinshelwood, $100 \%$.

\section{Graduates}

None

\section{Other Professional Staff}

Kuo-in Chen, 100\%; Stanley Luckhardt, $100 \%$.

\section{Major Recent Publications}

None 
Experimental Plasma Research

Physics International Company

Category PH

Project

REB Current Drive

Vernon L. Bailey

FY80. \$500K op

\section{Purpose}

To inject an intense relativistic electron beam (REB) into a well-diagnosed tokamak to demonstrate current drivo cupubility.

\section{Approach}

Ship an REB generator, which is now in service at Phipers International, and injection system to UCLA and inject and trap an REB in the tokamak, Macrotor. The injected REB parameters will be: kinetic energy $\leq 800 \mathrm{keV}$, injected current $\leq 140 \mathrm{kA}$ and injection time $\approx 60 \mathrm{~ns}$. Macrotor is a large $\left(R_{0}=0.9 \mathrm{~m}, 2 \mathrm{a} \times 2 \mathrm{~b}=0.9 \mathrm{~m} \times 1.5 \mathrm{~m}\right)$, rectangular cross-section, low-field tokamak $\left(B_{\mathrm{T}}=2 \mathrm{kG}\right)$.

\section{Progress}

Began program 14 December 1979. Completed preliminary design of the magnetically insulated transmission line (MITL) and vacuum interface to connect the REB generator to Macrotor.

Plans

Experimental: Construct a magnetically insulated transmission line (MITL) and vacuum interface to connect the REB to Macrotor. Design and construct a plasma-filled diode and plasma gun to inject the REB into the Macrotor plasma. Design and construct diagnostics to study the interaction of the beam in the Macrotor plasma. Characterize the REB generator, MITL, plasma-filled diode, and plasma gun in a simulated Macrotor B-field environment.

Provide a suitably modified relativistic electron beam generator for experiments at UCLA. The generator to be provided is PI's $225 \mathrm{~W}$ generator. Disassemble, crate, and ship the REB system to UCLA. Reassemble and suitably mount at UCLA. Install temporary oil storage facility. Inject the REB into a pre-existing Macrotor plasma discharge to increase current or extend discharge. Investigate the effect of the beam on the plasma current, temperature, and stability using the Macrotor plasma diagnostics. Diagnose the beam temporal behavior and trajectory using magnetic and X-ray imaging diagnostics. Study the effects of varying plasma and beam parameters.

Theoretical: Assist in the design of the magnetically insulated transmission line and plasma diode. Calculate (pretest and post-test) the motion of the REB during the injection and trapping, and compare the predictions with the experimental data. Calculate (pretest and post-test) the increase in toroidal current and plasma heating, and compare the predictions with the experimental data. Assist in the data reduction and analysis. Investigate the cause of any discrepancies between the theoretical predictions and experimental data. Extend the theoretical models of REB current-drive for use in scaling to a larger experiment and the tokamak fusion reactor regime. 


\section{Milestones}

1. Complete fabrication and integration of MITL, vacuum interface, diode, and diagnostics March 1980.

2. Complete characterization of the REB generator, MITL, plasma-filled diode, and plasma gun in a simulated Macrotor B-field environment - June 1980.

3. Begin current drive experiments on Macrotor - August 1980.

\section{Other Professional Staff}
H. Helava
R. Cooper
B. Ecker
D. Dakin
T.S.T. Young
S. Putnam
M. Di Capua
J. Creedon

\section{Major Recent Publications}

1. "Electron Beam Driven Fusion Reactors," V. Bailey, et al., Proc. of the Third International Topical Conference on High Power Electron and Ion Beam Research and Technology, Novosibirsk, USSR, July 1979 (to be published).

2. "Electron Beam Driven Tokamaks," V. Bailey, et al., Proc. of the 8th Symposium on Engineering Problems of Fusion Research, San Francisco, November 1979 (to be published). 


\section{PLASMA DIAGNOSTICS (PD) PROGRAM}

The Plasma Diagnostics Program has four functions: to provide advanced diagnostic techniques for the measurement of parameters not presently directly detected, e.g., current density; to develop and upgrade instrumentation for more sophisticated measurements, e.g., spatial and temporal resolution; to provide data and evaluation for instrumentation that will function reliably amidst tritium and neutrons in a reactor environment; and to standardize the instrumentation and techniques so that advanced diagnostics become routine.

The ncw gonoration of larger and hotter confinement devices has made some diagnnstics very difficult or inadequate, e.g., ion temperature measurements through charge exchange. Moreover, there are still some parameters that cannot be measured directly, the most impurtanl of which is current density. New diagnostic techniques are required in both of these situations.

Recent advances in such areas as spectroscopic instrumentation and lasers have made possible much better spatial and temporal resolution of a number of parameters. Higher resolution instruments and the deployment of arrays of detectors for imaging offer the promise of improved accuracy.

The ultimate goal of the Plasma Diagnostics Program is the adoption of a standardized diagnostic and instrumentation package along with data processing methods that would permit the rapid, and unambiguous comparison and contrasting of data from machine to machine. 


\section{Progress - Plasma Diagnostics}

- In work on neutron diagnostics, the spectrum of neutrons generated in the TFTR plasma has been calculated under a variety of conditions and the results are being used to model the performance of various neutron detection systems used to measure plasma parameters.

A neutron counter/spectrometer was installed on a TMX end plug, and the first neutron spectrum measurements on a mirror confined plasma wave mode. (LLL)

- The first simultaneous measurements of the electron density and poloidal field-induced Faraday rotation of a tokamak discharge have been made on ISX-B. The measurement was performed along 4 chords extending over one half the plasma column using a $0.381-\mathrm{mm}$ wavelength submillimeter laser. The time-resolution of this measurement was sufficient to observe changes in the poloidal field correlated with a current ramp in the discharge. Theoretical predictions of the Faraday/electron density profiles based on the Thomson scattering data are in excellent agreement with the measurements. Work is now being done to unfold the Faraday profiles to obtain actual current density profiles. (ORNL)

- Design and construction of two compact, transportable cw FIR laser packages has been completed. The lasers, for FIR diagnostic applications at PPPL and UCLA, have $45 \mathrm{~mW} \mathrm{cW}$ output power at $\lambda=214.7 \mu \mathrm{m}$ using $\mathrm{CH}_{2} \mathrm{~F}_{2}$ with long term stability of $\pm 10 \%$ over a 2 hour period.

- Broadband x-ray spectra were used to analyze emission from Alcator A and Constance I at MIT. A method of observing and monitoring disruptions also has been developed. The techniques are forerunners of a two-dimensional x-ray imaging system currently being constructed for Alcator C and being studied for TMX. Partly as a result of the interest stimulated by this program, efforts are now underway to utilize 2-D x-ray imaging on both Macrotor at UCLA and ISX-B at ORNL. (American Science \& Engineering)

- A successful drift wave cw FIR laser scattering experiment was carried out on the Microtor tokamak using $447 \mu \mathrm{m}$ and $1222 \mu \mathrm{m}$ lasers, following a demonstration laboratory scattering measurement from driven ion acoustic waves. (UCLA)

- Calibration capability for radiometric standard detectors has been extended to wavelengths as short as $50 \AA$ ( $240 \mathrm{eV}$ photon energy). The new range between 50 and $3200 \AA$, with accuracies from 6 to 10 percent, fills the previously existing gap in radiometry between the $\mathrm{x}$-ray and near ultraviolet spectral regions, allowing radiometric diagnostics to be used over the full range from $x$-ray to infrared wavelengths. The expertise gained through this effort is providing instrument calibration for groups at both PPPL and Johns Hopkins. (National Bureau of Standards)

- A laser injection system is being used with a multispatial detector system to study impurity transport in the Alcator A tokamak. Modeling of the measured profiles and impurity decay times have provided estimates of the diffusion rates as a function of radius. Soft $x$-ray radiative losses from Alcator $A$ have also been determined using a grazing incidence monochromator. (Johns Hopkins) 
- Extreme ultraviolet intensity measurements have been used to estimate the electron temperature in the center cell of TMX at LLL. Spatially resolved measurements of the center cell and plug are underway. (Johns Hopkins)

- Pioneering work on heavy ion beam-probes has been continuing. A primary beam is directed into the plasma and multiply charged secondary ions, created by electron impact or charge exchange, are observed emerging from the plasma. The toroidal field separates the secondary ions according to their creation point, thereby providing 3-D spatial resolution. The difference in energy between the primary and secondary ions provides a direct measurement of the space potential, and the intensity of the various secondary ion species can provide a measurement of the electron density and temperature. Results of this development program were so encouraging that Mirror Systems extended financial support to provide beam probe systems for TMX and EBT which have yielded important information on the operation of these devices. (Rensselaer Polytechnic Institute). 
Experimental Plasma Research

LASL

Project

Diagnostics Development

F.C. Jahoda

FY79 \$195K op

FY80

$\$ 300 \mathrm{~K}$ op

$25 \mathrm{~K} \mathrm{eq}$

$35 \mathrm{~K}$ eq

\section{Purpose}

Development of diagnostics, pertinent to programs at LASL and other fusion-energy laboratories, requiring longer lead times and less certain of fruition than the tasks undertaken by the project groups.

\section{Approach}

Extension of laser scattering techniques to encompass both multi-time and multi-space point coverage on a single discharge.

Determination of plasma internal magnetic fields by far-infrared Faraday rotation, and exploration of means for localized measurements.

\section{Progress}

Optical design and construction of apparatus for scattered light collection over a $40 \mathrm{~cm}$ path through a $5 \mathrm{~cm}$ aperture on ZT-40, dispersion and presentation to an $1.8 \mathrm{~cm}$ silicon intensified target tube for space resolved $\mathrm{T}_{\mathrm{e}}$ measurement.

Development of a 500 microsecond duration mode-locked ruby laser oscillator for time resolved Thomson scattering.

Development of far-infrared Faraday rotation measurement apparatus incorporating a phase comparison of two circular polarizations separated $1 \mathrm{MHz}$ in frequency by Doppler shift.

\section{Plans}

Installation on ZT-40 and CT experiments of automated versions of above experiments.

Initiation of laboratory exploratory phase on localized magnetic field measurements by 1) dye-laser excited lithium beam fluorescence and $b$ ) resonantly enhanced nonlinear laser scattering. 


\section{Milestones}

Far-Infrared Faraday rotation on ZT-40, January 1980

Space-resolved Thomson scattering on ZT-40, March 1980

Time-resolved Thomson scattering on ZT -40 , September 1980

Graduate Students

None

\section{Graduates}

None

Other Professional Staff

(part-time)

P.R. Forman

K.B. Freese

P.G. Weber

\section{Major Recent Publications}

1. "New Techniques in Plasma Density Profiling", Richard Kristal in Diagnostics for Fusion Experiments. Varenna, Italy, 416 September 1978, E. Sindoni, C. Wharton eds., p. 617-637 (Pergamon Press, 1979).

2. "Far Infrared Faraday Rotation Measurement on ZT-40", M.D. Bausman, P.R. Forman, F.C. Jahoda, and K.W. Peterson, Fourth International Conference on Infrared and Near-Millimeter Waves (Miami Beach, Florida, 10-15 December 1979) (in press). 


\section{Project}

Fast Neutron Diagnostics for Advanced Thermonuclear Experiments

D.R. Slaughter, R.W. Bauer

$\begin{array}{rrr}\text { FY79 } \$ 100 \mathrm{~K} \text { op } & \text { FY80 } & \$ 150 \mathrm{~K} \text { op } \\ 30 \mathrm{~K} \text { eq } & 80 \mathrm{~K} \text { eq }\end{array}$

\section{Purpose}

Review and evaluate existing techniques, and develop new techniques for fast neutron diagnostics in advanced magnetic confinement experiments. These efforts focus on techniques which allow time resolved measurements on time scales of interest in advanced experiments. Promising techniques will be implemented on MFTF for diagnostic measurements.

\section{Approach}

Scintillation spectrometers containing crystals, liquid, or gas are being studied for use in neutron spectroscopy at very high count rates. Concurrently, an electronic system for pulse height analysis at event rates in the range $10^{6}-10^{7} \mathrm{cps}$ is under development so that time resolved energy spectra may be obtained. In all cases, the requirements for collimation and shielding against scattered background are being studied through calculations and experimental simulations of the diagnostic environment.

\section{Progress}

1. Characterized various stilbene and NE213 scintillators, ${ }^{3} \mathrm{He}$ proportional counters, and a ${ }^{3} \mathrm{He}$ ionization chamber with regard to efficiency, energy resolution, interference due to photons, and count rate capability.

2. Demonstrated pulse height analysis and $n-\gamma$ discrimination at a $5 \times 10^{5} \mathrm{cps}$ data rate. Accumulated neutron spectra with good energy resolution during a 1-s acquisition period.

3. Designed and calibrated spectrometer systems with energy resolution of 160 to $200 \mathrm{keV}$ at $2.5 \mathrm{MeV}$ and 550 to $700 \mathrm{keV}$ at $14 \mathrm{MeV}$. Energy resolution is not degraded appreciably at data rates of $\sim 5 \times 10^{5} \mathrm{cps}$.

4. Developed a data reduction program that runs on a LSI-11 micro-computer. The program (or variations of it) executes in a few seconds and is now in use on Alcator-A and PLT.

5. Developed and calibrated a high-sensitivity, wide-dynamic-range silver activation counter whose response is the same for $2.5-$ and $14-\mathrm{MeV}$ neutrons. This counter is now manufactured by a commercial vendor.

6. Assembled a gas scintillation spectrometer capable of spectroscopy at data rates up to $10^{7} \mathrm{cps}$. Insertion of fissionable foils makes it a neutron monitor with energy threshold in the $\mathrm{MeV}$ region. It is insensitive to radiation other than neutrons. 
7. Used computer simulations of TFTR neutron spectra to show that neutron spectral data with energy resolution of $200 \mathrm{keV}$ at $2.5 \mathrm{MeV}$ or $600 \mathrm{keV}$ at $14 \mathrm{MeV}$ might be used to measure $\mathrm{Z}_{\mathrm{eff}}$ during neutral-beam injection.

8. Used neutron transport calculations to show that a neutron pinhole imaging device may be constructed of water and polyethylene. Spatial resolution of a few centimeters at an object plane $6 \mathrm{~m}$ away is attained and spectral degradation in the regions of interest is negligible.

9. Installed a neutron counter/spectrometer on a TMX end plug and made the first neutron spectrum measurement on a mirror confined plasma.

\section{Plans}

1. Investigate improvements in light collection for scintillators which fluoresce in either the visible or $u-v$ spectrum so that better energy resolution may be obtained with very fast spectromelers.

2. Investigate the use of ${ }^{3} \mathrm{He}$ or $\mathrm{Ne}$ in a gas scintillation spectrometer and evaluate the response to a fission foil in a gas scintillator.

3. Investigate methods of photo-tube stabilization, fast linear amplification, pulse pile-up rejection, and fast digitization and storage of pulse height data in order to allow time-resolved energy spectroscopy.

4. Investigate, via calculations and experimental simulations, the neutron and photon environment near an MFTF diagnostic access port and study appropriate collimation and shielding for neutron diagnostic instruments.

\section{Milestones}

1. Complete construction and preliminary evaluation of gas scintillation chamber - June 1980 .

2. Complete first prototype pulse height analysis system for event rates in the range $10^{6}-10^{7} \mathrm{cps}$ September 1980.

3. Complete construction of one collimated spectrometer/counter system for MFTF September 1980.

\section{Graduate Students}

None

\section{Graduates}

None 


\section{Other Professional Staff}

J. McQuaid, D. Obrien, H. Spracklen

\section{Major Recent Publications}

Dennis R. Slaughter, William L. Pickles, “A Highly Sensitive Silver-Activation Detector for Pulsed Neutron Sources," Nuc. Inst. Meth 160, 87-92 (1979).

Dennis R. Slaughter, "Plasma Neutron Diagnostic Techniques With Good Spatial and Energy Resolution,” IEEE Trans. Nuc. Sci., NS-26, No. 1, Feb. 1979.

D.R. Slaughter, "A Neutron Diagnostic That Measures $Z_{\text {eff }}$ in a Neutral-Beam-Heated Tokamak," IEEE International Conference on Plasma Science, June 46, 1979, Montreal Canada (also UCRL 82158).

G.F. Hunt, R.C. Kaifer, D.R. Slaughter, R.E. Strout II, D.W. Rueppel, “A Microprocessor-Controlled Portable Neutron Spectrometer," IEEE Trans. Nuc. Sci. NS-27, No. 1 Feb. 1980.

D. Slaughter, "Neutron Yield Measurements on a TMX Endplug," Bull. Amer. Phys. Soc. 24, No. 8, 1018 (1979), (also UCRL 83174). 
Experimental Plasma Research

Oak Ridge National Laboratory

Category PD

\section{Project}

Diagnostics of High Temperature Plasmas

C.F. Barnett, D.P. Hutchinson, J.A. Ray, P.A. Staats, K.L. Vander Sluis, D.M. Thomas

FY79 $\$ 350 \mathrm{~K}$ op $\quad$ FY80 $\$ 320 \mathrm{~K}$ op

$25 \mathrm{~K}$ eq $\quad 37.5 \mathrm{~K} \mathrm{eq}$

\section{Purpose}

Demonstrate far infrared diagnostic techniques for the next generation of plasma experiments where increased density, temperature, and size will limit active and passive probing measurements.

\section{Approach}

Submillimeter lasers are used to measure (1) the spatial ion temperature of a tokamak by Thomson scattering; (2) electron density. by interferometric techniques; and (3) current density profile in a tokamak plasma utilizing Faraday rotation of a linearly polarized, modulated beam. A new approach to ion temperature measurements will be made using a liquid oxygen cell to measure D-D neutron transmission.

\section{Prógress}

1. A two-chord DCOOD $(381-\mu \mathrm{m})$ interferometer was installed on ISX-B at radii of 0 and $15 \mathrm{~cm}$. The interferometer was able to follow density changes before, during, and after plasma disruptions, during gas puffing, during $\mathrm{H}_{2}$-pellet injection, and during neutral-beam injection. In addition, the interferometer followed the ISX plasma density osciliations during $\mathrm{m}=2$ instability growths up to disruption.

2. The line-averaged electron density and Faraday rotation signals were measured simultaneously along four chords in the ISX tokamak. The radial current profiles obtained are in agreement with computations using. $\mathrm{I} \mathrm{e}_{\mathrm{e}}$ and $\mathrm{n}_{\mathrm{e}}$ profiles obtained from Thomson scattering.'

3. Studies of a dielectric waveguide submillimeter transmission system for the Faraday rotation experiment have been completed.

4. The ion Thomson scattering system has been redesigned and fabricated using only a $\mathrm{CO}_{2}$ puinp and linear oscillator.

5. Two particle analyzers have been constructed, calibrated, and placed into operation: (1) a mass-energy analyzer to analyze negative ion beams, and (2) a neutral particle analyzer to measure beam species composition in intense neutral beams.

6. A low energy analyzer is being calibrated to determine the mass, angle, and energy dependence of neutral particle fluxes incident on tokamak walls in the energy range 10 to $200 \mathrm{eV}$. 


\section{Plans}

1. Install five vertical and five horizontal submillimeter channels on ISX or TEXT for Faraday rotation measurements.

2. Expand the number of channels on ISX to eight.

3. Increase power of the $\mathrm{cw}$ submillimeter laser so that one laser is sufficient for several channels.

4. Continue development of $\mathrm{D}_{2} \mathrm{O}$ laser and detection electronics for Thomson scattering measurements.

5. Develop low energy (10-200 eV) neutral particle spectrometer for tokamaks.

6. Improve Faraday modulator to operate at high frequencies so that fast magnetic fluctuations may be observed.

\section{Milestones}

1. Have Thomson scattering apparatus assembled and on a tokamak - January 1981.

2. Install eight vertical channels on ISX and have in routine operation - July 1981.

3. Complete low energy neutral measurements from tokamak plasma - September 1981.

4. Install five vertical and five horizontal Faraday rotation channels on a tokamak - July 1983.

\section{Graduate Students}

D.M. Thomas

\section{Graduates}

None

\section{Other Professional Staff}

C.H. Ma

\section{Major Recent Publications}

1. C.H. Ma, D.P. Hutchinson, and K.L. Vander Sluis, "A Modulated Submillimeter-Laser Polarimeter for the Measurement of the Faraday Rotation by a Plasma," Appl. Phys. Lett. 34, 218 (1979). 
2. D.P. Hutchinson, P.A. Staats, K.L. Vander Sluis, and J.B. Wilgen, "A Multichannel Submillimeter Interferometer for Tokamak Density Measurements," ORNL/TM-7015, September 1979.

3. J.A. Ray, C.F. Barnett, and B. Van Zyl, "Absolute Measurements of Low Energy Ho Fluxes by a Secondary Emission Detector,” J. Appl. Phys. 50, 65 1.6 (1979).

4. D.A. Brisson, F. Baity, B. Quon, J.A. Ray, and C.F. Barnett, "Low Energy H Atom Analyzer Using a Cesium Heat Pipe," Rev. Sci. Instrum. (accepted for April 1980).

5. D.P. Hutchinsun, C.H. Ma, P.A. Staats, and K.L. Vander Sluis, "The Simultaneous Measurement of Electron and Current Density Profiles in the ISX-B Tokamak," (in preparation for Phys. Rev. Lett.). 
Experimental Plasma Research

Category PD

The Aerospace Corporation

\section{Project}

Far Infrared Laser Development

E.J. Danielewicz, D.T. Hodges

$\begin{array}{ccc}\text { FY79 } \begin{array}{c}\$ 120 \mathrm{~K} \text { op } \\ 0 \text { eq }\end{array} & \text { FY80 } & \$ 130 \mathrm{~K} \text { op } \\ & & \text { OK eq }\end{array}$

\section{Purpose}

Develop cw FIR laser sources for application to the diagnostics of thermonuclear plasmas.

\section{Approaches}

1. Develop new molecular laser systems for increasing the efficiency and spectral coverage of optically pumped FIR lasers.

2. Incorporate state of the art features into a well engineered FIR laser package suitable for on site diagnostics of thermonuclear tokamak plasma devices.

\section{Progress}

1. Discovery of the new $\mathrm{CH}_{2} \mathrm{~F}_{2}$ and cis $\mathrm{C}_{2} \mathrm{H}_{2} \mathrm{~F}_{2}$ laser molecules yielding 10 new FIR laser lines in the $\lambda=100-400 \mu \mathrm{m}$ region with efficiency exceeding the best previous FIR lasers.

2. Construction of two compact and transportable cw FIR laser packages, with preliminary performance data of $45 \mathrm{~mW} \mathrm{cW}$ output power at $\lambda=214.7 \mu \mathrm{m}$ using $\mathrm{CH}_{2} \mathrm{~F}_{2}$ with long term stability of $\pm 10 \%$ over a $2 \mathrm{hr}$. period.

\section{Plans}

1. Complete laboratory characterization of the cw FIR laser package including performance optimization and reliability testing.

2. Actively stabilize the $\mathrm{CO}_{2}$ pump laser to improve temporal stability.

3. Measure the FIR laser noise spectral purity and frequency stability using a Schottky diode mixer.

4. Evaluate the promising new $382.9 \mu \mathrm{m}$ line of $\mathrm{CH}_{2} \mathrm{~F}_{2}$ as a local oscillator for the pulsed $\mathrm{D}_{2} \mathrm{O}$ laser. 
5. Demonstrate the transportability, stability and control features of the FIR laser package in an actual plasma diagnostic measurement.

6. Evaluate potentially efficient FIR laser candidate molecules.

\section{Milestones}

1. Complete laboratory characterization of the cw FIR laser package - April 1980.

2. Perform preliminary diagnostic measurement on an actual Tokamak device to field test the FIR laser package - July 1980.

3. Make available the aerospace cw FIR laser package and design as a diagnostic tool for other Tokamak laboratories - August 1980.

Graduate Students (\% DOE support)

C. Young UCLA (10\%)

E. Gamble UCLA (Start Feb. 1980, 100\%)

\section{Graduates}

None

\section{Other Professional Staff}

T.A. Galantowicz on a 1 yr. sabbatical leave during FY79.

\section{Major Recent Publications}

"A Review of Advances in Optically Pumped Far Infrared Lasers," D.T. Hodges, Infrared Phys., 18,375 (1978).

"Characteristics of Non-Diffusion-Limited Optically Pumped cw Lasers; Experimental Results for $\mathrm{CH}_{2} \mathrm{~F}_{2}$," T.A. Galantowicz, E.J. Danielewicz, F.B. Foote, and D.T. Hodges, in Proceedings of the International Conference on Lasers '78, V.J. Corcoran, ed. (STS Press, McLean, Virginia, 1979).

"High Performance at New FIR Wavelengths from Optically Pumper $\mathrm{CH}_{2} \mathrm{~F}_{2}$," E. I. Danielewicz, T.A. Galantowicz, F.B. Foote, R.D. Reel, and D.T. Hodges, Opt. Lett., 4, 280 (1979).

"New Far Infrared cw Optically Pumped cis- $\mathrm{C}_{2} \mathrm{H}_{2} \mathrm{~F}_{2}$ Laser," E.J. Danielewicz, R.D. Reel, and D.T. Hodges, IEEE J. Quantum Electron. (in press) 
Experimental Plasma Research

American Science and Engineering, Inc.

Category PD

\section{Project}

Spatially, Spectrally and Temporally Resolved X-Ray Imaging Systems for Magnetically

Confined Plasma (with specific applications to Alcator Tokamaks).

R. Petrasso, F.H. Seguin, M. Gerassimenko, R. Krogstad, R. Chase

FY79 \$250K op FY80 \$300K op

\section{Purpose}

To develop soft X-ray imaging techniques and instrumentation that can be used to monitor, with high/time resolution, the spatial and braodband spectral characteristics of magnetically confined plasmas; to use this system to (a) reconstruct X-ray emissivity structures associated with MHD activity in tokamaks, with particular emphasis on that activity which immediately precedes major disruptions; (b) to determine, by measurements and radiative modeling, the general spectral qualities and power content of plasma radiation in the soft and ultra-soft X-ray range.

\section{Approach}

A 2-view X-ray imaging system has been built to image the Alcator $\mathrm{C}$ plasma from the side and bottom at one toroidal position. Both the in-out and up-down motion of the plasma, and the evolution of X-ray emissivity profiles can be monitored with high/time resolution $(-10 \mu \mathrm{sec})$. An on-line computer and graphics display system allows immediate post-shot analysis of the discharge. More difficult computations, such as tomographic reconstructions and radiative modeling, are accomplished off-line.

\section{Progress}

1. A two-view X-ray imaging system has been designed and built for the Alcator $\mathrm{C}$ tokamak.

2. Preliminary data have been obtained with the bottom X-ray array mentioned in.(1).

3. Tomographic reconstructions of the Alcator A X-ray emissivity structures, associated with magnetic island structures, have been obtained. These reconstructions have been possible in the circumstance where saturated islands rigidly rotate past the X-ray detector array.

4. Spectral studies of the Alcator A plasma show that the plasma radiation becomes more like hydrogen bremsstrahlung as the plasma density increases.

5. Electron temperature profiles of the Alcator A plasma have been obtained immediately preceding and following internal disruptions, and compared to theoretical models of the process. 


\section{Plans}

1. Obtain data from the Alcator $\mathrm{C}$ tokamak using the two-view X-ray imaging system, and use this data for:

a. Reconstructing $\mathrm{X}$-ray emissivity structures;

b. Comparing the reconstructions, mentioned in (a), to theoretical predictions of the amplitude and overlap of magnetic island structure.

c. Comparing radiative data to the predictions of radiative models.

\section{Milestones}

1. Alcator A radiative studies - February 1980.

2. Development of tomographic reconstruction techniques for machines such as TMX and Alcator - April 1980.

3. Reconstruction of Alcator A X-ray emissivity features - March 1980.

4. Completion of the two-view X-Ray Imaging System for Alcator C - June 1980.

Graduate Students (\% DOE Support)

None

\section{Graduates}

None

\section{Other Professional Staff}

B. Holmes

P. Gauthier

\section{Major Recent Publications}

Accepted for publication in Keview of Scientific Instruments: A Soft X-Kay Imaging Instrument for the ALcator A Tokamak.

Submitted for publication: Magnetic Island Structure in the Alcator A Tokamak; Radiative Studies of the Alcator A Tokamak Plasma; Studies of the Hot Electron Population in an Electron Beam Stabilized Mirror Confined Plasma. 
Experimental Plasma Research

University of California at Los Angeles

Category PD

\section{Project}

FIR Diagnostics

Luhmann

FY79. $\$ 225 \mathrm{~K}$ op

$40 \mathrm{~K}$ eq

FY80 \$230K op

$40 \mathrm{~K}$ eq

\section{Purpose}

Development of new far-infrared diagnostic methods for use on large tokamak and mirror devices. Current emphasis is on the development of a cw ion temperature measurement system suitable for use on TFTR and MFTF, and measurement of tokamak fluctuations in the presence and absence of $\mathrm{rf}$ heating.

\section{Approach}

Fusion plasma ion temperatures and fluctuation spectra will be determined via submillimeter wave Thomson scattering, Present emphasis is on the determination of tokamak ion temperature by cw FIR laser scattering from externally launched electrostatic ion cyclotron waves. Similar FIR scattering systems will be employed to scatter from fluctuations produced by ICHF and lower hybrid heating.

\section{Progress}

1. Development of first low noise FIR receiver suitable for ion temperature measurement.

2. Use of quasi-optical receiver to measure high harmonic synchrotron radiation from runaway electrons in Microtor tokamak.

3. Development of $1 \mathrm{~W}$, long pulse (50-150 $\mathrm{s}$ ) FIR local oscillator for low noise hetrodyne receiver in Thomson scattering diagnostic.

4. Successful completion of first collective scattering measurements in the far-infrared. Radiation at both $875 \mu \mathrm{m}$ and $447 \mu \mathrm{m}$ was scattered from driven ion acoustic waves in an unmagnetized laboratory plasma system and sensitivity, k-resolution and spatial resolution measured.

5. First tokamak far-infrared scattering successfully completed on Microtor tokamak using 447 $\mu \mathrm{m}$ and $1222 \mu \mathrm{m}$ lasers. Fluctuations in drift wave frequency region studied.

6. Discovery of new far-infrared pumping mechanism in $\mathrm{C}^{13} \mathrm{H}_{3} \mathrm{~F}$ molecule: collisionally coupled, two photon absorption. This resulted in the discovery of new lasing lines at $388 \mu \mathrm{m}$ and $412 \mu \mathrm{m}$. 


\section{Plans}

1. Undertake an ion temperature measurement on Microtor via cw FIR laser scattering from antenna launched electrostatic ion cyclotron waves.

2. Determine the effect of ICRF heating on low frequency microturbulance in Microtor.

3. Attempt cw FIR scattering from lower hybrid waves in Microtor.

4. Resume short wavelength $(\lambda<500 \mu \mathrm{m})$ pulsed laser development.

5. Continue FIR ring laser studies.

6. Employ $385 \mathrm{GHz}$ carcinotron in tokamak scattering.

\section{Milestones}

1. CW FIR laser scattering from driven ion cyclotron waves in Microtor. Installation and Initiation of Experiment - May 1980. 
Experimental Plasma Research

General Atomic Company

Category PD

\section{Project}

Current Profile Diagnostic Development

R. Fisher, E.S. Ensberg

FY79 $\$ 100 \mathrm{~K}$ op $\quad$ FY80 $\$ 200 \mathrm{~K}$ op

$50 \mathrm{~K}$ eq $\quad 40 \mathrm{~K}$ eq

\section{Purpose}

Develop a method of measuring the poloidal magnetic field profile in tokamak plasmas.

\section{Approaches}

A diagnostic beam of neutral atoms is passed through the plasma. Modulating the polarization of a collinear resonant dye laser beam, with phase-sensitive detection of the laser-excited fluorescence, permits determination of the instantaneous orientation of the magnetic field at each point on a minor radius through the plasma.

\section{Progress}

1. A review of proposed concepts for measuring current density profiles using the Zeeman effect in neutral atomic beam was completed and resulted in the selection of the collinear beam approach.

2. Construction of a numerical model of the evolution of the neutral beam in the presence of the laser beam and plasma-beam interactions led to the selection of a Li beam and showed that a $1 \mathrm{ma}, 100 \mathrm{KeV}$ beam with a $100 \mathrm{~mW}$ single mode dye laser would provide adequate signal-tonoise ratio in PLT or DIII plasma temperatures and densities.

3. Assembly of a laboratory demonstration of the feasibility of the concept has begun.

\section{Plans}

1. A laboratory apparatus will be completed including lithium beam source and beam optics, neutralizing cell, pulsed magnet, c.w. dye laser, Faraday rotator and fluorescence detection system. This apparatus will be used for fluorescence spectroscopy on atoms in a $30 \mathrm{KeV}$ beam at 2 to 3 Tesla.

2. Discussions have been initiated with the TEXT Project organization to clarify requirements for testing this current profile diagnostic on the TEXT machine soon after experimental operations on the machine begin. 


\section{Milestones}

1. Laboratory demonstration of $30 \mathrm{KeV} \mathrm{Li} \mathrm{beam} \mathrm{spectroscopy} \mathrm{-} \mathrm{August} 1980$.

2. Detailed design for TEXT installation - November 1980.

3. TEXT installation-April 1981.

\section{Graduate Students}

None

\section{Graduates}

None

Other Professional Staff

Dr. J.F. Baur

Dr. W.P. West

Major Recent Publications

None 
Experimental Plasma Research

Johns Hopkins University

Category PD

\section{Project}

Extreme Ultraviolet and Soft X-Ray Diagnostics of High Temperature CTR Plasmas

H.W. Moos, L. Armstrong, Jr.

FY79 \$333K op FY80 \$375K op

$25 \mathrm{~K}$ eq

\section{Purpose}

Determination of impurity distributions and other properties of high temperature plasmas through the application and improvement of spectroscopic diagnostic techniques.

\section{Approach}

Design, construct and test new spectroscopic instrumentation for diagnostics in the extreme ultraviolet (EUV) and soft $x$-ray (SXR) spectral region. Perform EUV and SXR spectroscopic diagnostics on high temperature plasmas in cooperation with DOE laboratories, and make theoretical calculations of transition energies and oscillator strengths for atoms and ions likely to be found in CTR plasmas.

\section{Progress}

A multispatial detector system is being used with a laser injection system to study impurity transport in the Alcator A tokamak. Modeling of the measured profiles and impurity decay times have provided estimates of the diffusion rates as a function of radius. Soft $x$-ray radiative losses from from the Alcator A tokamak have been determined using a grazing incidence monochromator calibrated against synchrotron radiation at the NBS SURF II facility. Similar determinations are in progress on the Alcator C tokamak. EUV intensity measurements have been used to estimate the electron temperature in the center cell of TMX at LLL. Spatially resolved measurements of the center cell and plug are under way. A multiple spectral element microchannel plate detector for normal incidence use has been constructed. A similar detector for grazing incidence use has been designed. Transition energies and oscillator strengths in the neon isoelectronic sequence have been evaluated, as have electron impact excitation rates in the rare gas isoelectronic sequences. Photoionization studies in chlorine have been completed.

Plans

1. Perform ultraviolet diagnostic studies at DOE plasma facilities; some of these experiments will utilize spatial resolution to determine impurity distributions and transport.

2. Design and construct new instruments for short wavelength diagnostics. 
3. Prepare instrumentation capable of looking at many spatial and/or spectral elements in a single plasma shot.

4. Evaluate Ml transition rates for ground configurations of first row isoelectronic sequences:

\section{Milestones}

1. Complete impurity transport measurement on Alcator A with spatial imaging detector system February 1, 1980.

2. Complete initial impurity emission measurements on TMX - March 1, 1980.

3. Begin transport studies on TMX - March 1, 1980.

4. Complete construction of multispectral element detection spectrograph systern - July 1, 1980 .

5. Complete analysis of impurity transport in Alcator A - September 1, 1980.

\section{Graduate Students}

1. Project students (\% DOE support, degree, years to complete):

S. Allen (100, Ph.D., 1), O. Strand (100, Ph.D., 1), J. Castracane (100, Ph.D., 1), R. Bell (100; Ph.D., 1), B. Stratton (25, Ph.D., 3); R. Holman (25, Ph.D., 3), J. Swanson (0, Ph.D., 1), W. Fielder (100, Ph.D., 1).

2. Graduated during past three years (year employed in fusion):

J. Terry (Ph.D., 1978, yes); R.K. Richards (Postdoctoral Fellow, 1976-78, yes); P. Drake

(Ph.D., 1979, yes); K.I. Chen (Ph.D., 1979, yes); D. Ton-That (Postdoctoral Fellow, 1977-79, no).

\section{Other Professional Staff}

Wm. G. Fastie, Adjunct Research Professor Physics; W.L. Hodge, Associate Research Scientist;

M. Finkenthal, R. Dukart, and M. Vajed-Samii, Postdoctoral Fellows.

\section{Major Recent Publications}

N.H. Lazar, K.H. Carpenter, J.M. Tyson, E.S. Warden, W.H. Moos, "Spatial distribution of impurities and H neutrals in Elmo Bumpy Torus (EBT)," Nuclear Fusion, 19, 571 (1979).

R.P. Drake and H.W. Moos, "Evidence for neutral beam injected oxygen impurities in 2XIIB," Nuclear Fusion (lett.) 19, 407; 1979.

H.W. Moos, K.I. Chen, J.L. Terry, and W.G. Fastie, "Construction, calibration and application of compact spectrophotometer for EUV (300-2500 §) plasma diagnostics," Appl. Optics 18, 1209 (1979).

E.S. Marmar, D. Overskei, H. Helava, K.I. Chen, J.L. Terry, and H.W. Moos, "The effects of wall temperature on light impurities in Alcator," Nuclear Fusion letters, 19, 485 (1979). 
R.K. Richards, H.W. Moos, and S.L. Allen, "A Spatial Imaging Detector System for Pulsed Plasma Extreme Ultraviolet Diagnostics," Review of Scientific Instruments, 51, 0038 (1980).

R.P. Drake and H.W. Moos, "Extreme Ultraviolet Study of the 2XIIB Neutral-Beam-Heated Mirror Machine," to be published in Nuclear Fusion.

K.I. Chen, J.L. Terry, H.W. Moos, and E.S. Marmar, "Spatial Profiles of Light Impurity Ions in the Alcator A Tokamak Plasma," to be published in Nuclear Fusion.

W. Fielder, D.L. Lin, and D. Ton-That, "E1 and M2 Transitions in the Neon Isoelectronic Sequence," Phys. Review A, 19, 741 (1979).

W. Fielder and L. Armstrong, "Photoionization Cross Sections using the Multiconfiguration HartreeFock and Its Extensions," to be published in Phys. Scriptica. 
Experimental Plasma Research

University of Maryland

Category PD

Project

Laser Sources for Vacuum Ultraviolet Scattering in Fusion Plasmas

D.W. Koopman and R. Mahon

FY79 $\$ 85 \mathrm{~K}$ op $\quad$ FY80 $\$ 175 \mathrm{~K}$ op

$30 \mathrm{~K}$ eq

\section{Purpose}

To develop a diagnostic technique to make spatially resolved neutral $H, D$, and $T$ density measurements in magnetically confined fusion plasmas.

\section{Approach}

A tunable laser at $7296 \AA$ is to be built and the output wavelength converted to $1216 \AA$ (Ly-alpha) by frequency doubling and tripling techniques. Alternate/supplementary approaches will continue to be examined. The $1216 \AA$ beam will be used to achieve resonant scattering off neutral hydrogen atoms in a plasma.

\section{Progress}

1. A new ruby laser for pumping the $7296 \AA$ dye laser amplifiers has been integrated into the láborátóry system.

2. The use of beryllium vapor as a non-linear medium for producing Ly $\alpha$ radiation by twophoton resonant, four-wave sum mixing was demonstrated.

3. Phase matching of the krypton with both argon and xenon has been achieved.

\section{Plans}

1. Search for and understand the limitations on the efficiency of third harmonic generation in phase matched media.

2. Further redesign the newly purchased ruby laser to permit achievement of a smonthly varying spatial intensity distribution.

3. Construct a hydrogen discharge tube for an in-house fluorescence scattering experiment.

4. Plan for utilization of the diagnostic on a magnetically confined plasma device. 


\section{Milestones}

1. Achieve complete understanding of limitations on third harmonic generation in krypton phase-matched with argon/xenon (May 1980).

2. Complete in-depth analysis of a on-site fluorescence scattering experiment possibilities (September 1980).

Graduate Students (\% DOE support)

Y.M. Yui (100)

\section{Graduates}

None

\section{Other Professional Staff}

Research Associate (to be appointed)

\section{Major Recent Publications}

"Resonant Scattering of Lyman Alpha Radiation as a Neutral Density Diagnostic for Fusion Plasmas," D.W. Koopman, T.J. Mcllrath, and V.P. Myerscough, J.Q.S.R.T. 19, 555 (1978).

"Non-Linear Generation of Lyman-Alpha Radiation," R. Mahon, T.J. McIlrath, and D.W. Koopman, Appl. Phys. Letters 33, 4, 305 (1978).

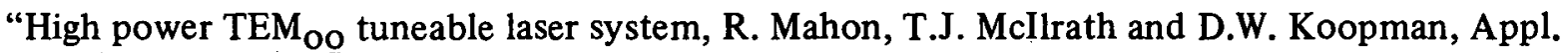
Opts 18, 6, 891 (1979).

"Third harmonic generation in argon, krypton and xenon: Bandwidth limitations in the vicinity of Lyman $\alpha$," R. Mahon, T.J. McIlrath, V.P. Myerscough and D.W. Koopman, IEEE, J. Quant. Elect., QE-15, 6, 444 (1979).

"Four-wave sum mixing in beryllium around hydrogen Lyman- $\alpha$," R. Mahon, T.J. McIlrath, F.S. Tomkins and D.E. Kelleher, Opt. Letts., 4, 11, 360 (1979).

"Effects of spatial modes on third harmonic generation", Y.M. Yiu, T.J. Mcllrath and R. Mahon, Pliys. Rev. A, Deccmbcr (1979). 
Experimental Plasma Research

University of Maryland

Category PD

Project

Far-Infrared Diagnostics

D.A. Boyd

FY80 \$80K op

$20 \mathrm{~K}$ eq

\section{Purpose}

To build up a sup plàsmàa devices.

\section{Approach}

The laboratory is being built around a large aperture Michelson Interferometer which has high resolution in the far infrared (100-5000 microns).

\section{Progress}

The polarizing grids for the interferometer have been acquired. A detector and several other components have been ordered. A data processing system which will perform the Fourier transforms required is being identified.

\section{Plans}

To acquire all the components of the interferometer system, assemble them, and put the system into operation on a large tokamak or mirror experiment.

\section{Milestones}

1. Begin acquisition of components - October 1979.

2. Complete acquisition - June 1980.

3. Put complete system into operation - September 1980.

Graduate Students (\% DOE Support)

None 


\section{Graduates (Year)}

None

Other Professional Staff

Dr. G. D. Tait

Major Recent Publications

None 
Experimental Plasma Research

Category PD

University of Maryland

Project

Mirror Diagnostics

D.A. Boyd

FY80 \$132K op

\section{Purpose}

Tu study electron cyclotron emission from a mirror confined plasma and to develop a diagnostic system for this type of measurement.

\section{Approach}

The Maryland Mirror Machine is a simple mirror machine. (Length between mirrors $40 \mathrm{~cm}$, radius $8 \mathrm{~cm}, \mathrm{~B}_{\mathrm{O}}<30 \mathrm{kG}$, risetime of field $1.6 \mathrm{msec}$, decay time of field $6 \mathrm{msec}$ ). A plasma is injected into the mirror field and its electron cyclotron emission is measured with a swept superheterodyne receiver.

\section{Progress}

A plasma source has been constructed and operated. Plasma has been trapped in the mirror field and the electron cyclotron radiation has been measured.

\section{Plans}

1. Complete an evaluation of the present system.

2. Construct a higher frequency superheterodyne receiver.

3. Construct a microwave interferometer for plasma density measurements.

4. Evaluate the electron cyclotron emission measurements for their diagnostic capabilities.

\section{Milestones}

1. Initiate experimental studies - October 1979

2. Complete initial experiments - February 1980

3. Create higher density plasma - June 1980

4. Begin studies with high frequency receiver and interferometer - September 1980 
Graduate Students (\% DOE Support)

None

Graduates (Year)

None

Other Professional Staff

Professor R. Ellis

Dr. C. Tsakiris

Mr. Wang

Recent Publications

None 
Experimental Plasma Research

University of Maryland

\section{Project}

EBT Experiment

D.A. Boyd

FY80 \$56K op

\section{Purpose}

In collaboration with Oak Ridge National Laboratory, to perform electron synchrotron radiation measurements on the relativistic electron rings in the EBT device in order to develop a diagnostic föt thesese ringes.

\section{Approach}

A high frequency swept superheterodyne receiver will be used to measure the emitted radiation (center frequency - $100 \mathrm{GHz}$ ).

\section{Progress}

Negotiations with Oak Ridge National Laboratory on the purchase of the receiver have been completed, and commitment for the purchase of the equipment has been made.

\section{Plans}

1. Specify the parameters of the superheterodyne receiver.

2. Acquire the receiver and test it with an optic system on an EBT cavity.

3. Begin initial measurements on the EBT device.

\section{Milestones}

1. Negotiate purchase of receiver by Oak Ridge National Laboratory - December 1979.

2. Acquire receiver - May 1980

3. Test optics and receiver on EBT cavity - August 1980

4. Install receiver and begin initial measurements - October 1980 
Graduate Students (\% DOE Support)

None

Graduates (Year)

None

Other Professional Staff

Dr. G. Tsakiris

Dr. V.K. Tripathi

Mr. C.S. Wang

Major Recent Publications

None 
Experimental Plasma Research

Massachusetts Institute of Technology

Category PD

\section{Project}

Development of High Power Submillimeter Lasers for Diagnostics of Tokamak Plasmas.

D.R. Cohn, B. Lax, H.C. Praddaude, P. Woskoboinikow, W. Mulligan

$\begin{array}{rrr}\text { FY79 } & \$ 200 \mathrm{~K} \text { op } & \text { FY80 } \\ 50 \mathrm{~K} \text { eq } & \$ 215 \mathrm{~K} \mathrm{op} \\ 30 \mathrm{~K} \mathrm{eq}\end{array}$

\section{Purpose}

Development of high power submillimeter (SMM) lasers and low noise SMM receivers and their utilization to establish the feasibility of Thomson scattering for ion temperature diagnostic of Tokamak plasmas.

\section{Approaches}

1. An optically pumped molecular gas SMM laser. A most suitable gas has been found to be $\mathrm{D}_{2} \mathrm{O}$, lasing at $385 \mu \mathrm{m}$, when pumped with a $\mathrm{CO}_{2}$ laser operating at the $9 \mathrm{R}(22)$ transition.

2. A specially developed Schottky barrier mixer diode, a quasioptical diplexer are assembled in a compact SMM receiver configuration.

\section{Progress}

1. Use of an etalon to provide single mode, tunable, high power $\mathrm{CO}_{2}$ laser pump radiation. This development has afforded an increased SMM laser efticiency, improved spectral purity, and decreased superradiance.

2. Production of $800 \mathrm{~kW}, 100 \mathrm{nsec}$ pulses of high spectral purity at $385 \mu \mathrm{m}$ from a $\mathrm{D}_{2} \mathrm{O}$ oscillator with a conversion efficiency better than $0.3 \%$ has been achieved.

3. Construction of a SMM receiver with a noise equivalent power of $2 \times 10^{19} \mathrm{~W} / \mathrm{Hz}$ (double sideband) is now complete.

4. Development of instrumentation necessary to obtain the power spectrum of the scattered radiation.

5. Submillimeter laser and associated optical system have been installed on Alcator C.

Plans

1. Complete ruggedization of SMM receiver for operation in a tokamak environment; initiate cyclotron emission measurements. 
2. Complete implementation and final testing of all components of the submillimeter laser Thomson scattering system on Alcator C.

3. Initiate Thomson scattering measurements.

\section{Milestones}

1. Initial cyclotron radiation measurements on Alcator C - May 1980

2. Initial scattering measurements on Alcator C - September 1980.

Graduate Students (\% DOE support)

None

\section{Major Recent Publications}

1. "High Power Optically Pumped Far Infrared Laser Systems," Z. Drozdowicz, P. Woskoboinikow, K. Isobe, D.R. Cohn, R.J. Temkin, K.J. Button, J. Waldman, IEEE J. Quan. Electronics QE13 (413), 1977.

2. "Schottky-Barrier Diodes for Submillimeter Heterodyne Detection," B.J. Clifton, IEEE Trans. Microwave MTT25 (457), 1977.

3. "Far-ir Heterodyne Radiometric Measurements with Quasioptical Schottky Diode Mixers," H.R. Fetterman, P.E. Tannenwald, C.D. Parker, J. Melngailis, R.C. Williamson,

P. Woskoboinikow, H.C. Praddaude, W.J. Mulligan, Applied Physics Letters 33 (151), 1978.

4. "High Power Tunable $385 \mu \mathrm{m} \mathrm{D} \mathrm{D}_{2} \mathrm{O}$ Vapor Laser Optically Pumped with a Single Mode Tunable $\mathrm{CO}_{2}$ TEA 2 Laser," P. Woskoboinikow, H. Praddaude, W. Mulligan, D.R. Cohn and B. Lax, (to be published in Journal of Applied Physics).

5. "Real Time Spectral Analysis of Far Infrared Laser Pulses Using a SAW Dispersive Delay Line," H.R. Fetterman, P.E. Tannenwald, C.D. Parker, J. Melngailis, R.C. Williamson, P. Woskoboinikow, H.C. Praddaude, and W.J. Mulligan, Appl. Phys. Lett. 34 (123) 1979.

6. "Saturable Gas Absorber for a $9 \mu \mathrm{m}$ Band $\mathrm{CO}_{2}$ Laser Amplifier," P. Woskoboinikow, H.C. Praddaude, and W.J. Mulligan, Optics Lett. 4 (199) 1979. 


\section{Project}

Ion Beam Probe Plasma Diagnostic System

R.L. Hickok

$\$ 244 \mathrm{~K}$ op

$25 \mathrm{~K}$ eq

\section{Purpose}

Develop diagnostic systems for making space and time resolved measurements in both open and closed confinement devices. Primary emphasis is the development and application of heavy ion beam probing.

\section{Approach}

A primary beam of heavy particles, either neutral or singly ionized, is directed into the plasma and multiply charged secondary ions created by electron impact or charge exchange are observed after they leave the plasma. The magnetic field separates the secondary ions according to their creation point thereby providing 3-D spatial resolution. The difference in energy between the primary and secondary ions provides a direct measurement of the space potential and the intensity of the various secondary ion species can provide a measurement of the electron density and temperature. The range in momentum of both the primary and secondary ions can provide information about internally generated magnetic fields. Since the measurements are continuous in time and provide 3-D spatial resolution, beam probing is ideally suited for carrying out fluctuation correlation studies. Specific techniques for carrying out these measurements are developed on small in-house facilities, such as RENTOR and ALEX, and then transferred to major confinement experiments. For example we are currently operating (supported by separate contracts) beam probe diagnostic systems on EBT-S and the center cell of TMX.

\section{Progress}

1. First secondary ion signals were obtained from the beam probe system on the RENTOR tokamak in August 1979.

2. First space potential measurements on RENTOR were obtained in December 1979.

3. A hollow cathode arc plasma was installed and is operational in the ALEX "Baseball" facility.

4. The neutral beam diagnostic system has been installed on ALEX.

Plans

1. Move RENTOR to new plasma laboratory in the Jonsson Engineering Center.

2. Refine space potential measurements on RENTOR to provide improved signal-to-noise ratio. 
3. Correlate space potential measurements in RENTOR with other diagnostics to establish the sensitivity of this parameter to Tokamak operating conditions.

4. Develop the capability of providing correlations between density and space potential fluctuations in RENTOR.

5. Establish space potential measurements in minimum B geometry with the neutral beam system on ALEX.

6. Continue experimental and theoretical development of electrostatic energy analyzers to provide increased noise immunity, better sensitivity, and improved angular acceptance.

\section{Milestones}

1. Obtain initial space potential meạsurements on Alex - May 1980.

2. Reestablish RENTOR operation in new Plasma Laboratory - July 1980.

3. Initiate fluctuation studies on RENTOR - September 1980.

Graduate Students (\% DOE Support)

C. Fiore (75), T. Price (75), P. Schoch (75), L. Solensten (75), M. Reed (50), K. Saadatmand (50), T. Matthew (50), K. Manoni (50), J. Kerns (50), S. Biron (25), J. Kolawole, K. Pourrezaei, A Chachich, D. Michael.

\section{Graduates}

P. Woskoboinikow (76), J. Pipkins (79).

\section{Other Professional Staff}

W.C. Jennings, Associate Professor

J.T. Woo, Associate Professor

K.A. Connor, Assistant Professor
A. Hershcovitch, Research Associate J.F. Lewis, Research Engineer J. Schatz, Engineering Assistant

\section{Major Recent Publications}

"Space Potential Measurements with Particle Beam Probes", R.L. Hickok, W.C. Jennings, K.A. Connor, and J.T. Woo, Proceedings of 9 th European Conference on Controlled Fusion and Plasma Physics (September 1979).

"The EBT Heavy Ion Probe", accepted for publication by Review of Scientific Instruments, F.M. Bieniosek, P.L. Colestock, K.A. Connor, R.L. Hickok, and S.P. Kuo. 
Experimental Plasma Research

Smithsonian Institution, Astrophysical Observatory

Category PD

\section{Project}

Development of a High Resolution, High Throughput Spectrometer

Suitable for Line Shape Diagnostics of X-Rays Emitted from Hot Plasmas

H.W. Schnopper, P.O. Taylor

$\begin{array}{rrr}\text { FY79 AF } & \text { FY80 } \\ & \text { 0K eq }\end{array}$

\section{Purpose}

Develop an instrument to provide high spectral resolution measurements of $\mathrm{x}$-ray line profiles and ionic charge state distributions in a time dependent (pulsed) hot plasma. The instrument will be particularly suited for measurements in the photon energy range above about $0.5 \mathrm{keV}$, where contributions from important impurity ions can be investigated.

\section{Approach}

Design and build curved crystal $x$-ray spectrometers with high resolution linear detectors. The range of Bragg angles subtended by the crystals are sufficient to reflect the resonance, forbidden and intercombination lines of the He-like series of heavy ion plasma impurities. The linear positionsensitive detector is coupled directly to a minicomputer data analysis system which also controls the spectrometer functions.

\section{Progress}

1. A $30 \mathrm{~cm} \times 2 \mathrm{~cm}$ position sensitive proportional counter was developed, tested and installed in the spectrometer. The spectrometer was tested with a Mo target $\mathrm{x}$-ray tube and resolved the MoL spectrum down to the natural line widths, ca $2 \mathrm{eV}$.

2. The spectrometer was transferred to MIT in July, 1979 and reassembled and tested. Necessary modifications have been made in the Alcator cell allowing the spectrometer to sit close to the Tokamak on the limiter port and the instrument is ready to be interfaced.

3. Work in continuing on obtaining and analyzing spectra taken with a flat crystal on both Alcator A and C. A new smaller curved crystal spectrometer has been designed for line profile diagnostics on $\mathrm{Cl} \mathrm{K}$ and $\mathrm{Fe} \mathrm{K}$ lines which have been observed. High resolution crystals have been specified. Three other new items, a somputer based multichannel analyzer, an $\mathrm{x}$-ray sensitive Reticon array with low noise electronics, and a high resolution proportional counter, will all be available for integration onto the spectrometers after testing.

Plans

1. Use the spectrometer to obtain wide band spectra and charge state distributions of Mo $L$ on Alcator C. 
2. Modify the Mo L spectrometer, and insert a new crystal, to obtain high resolution $\left(1 / 10^{4}\right)$ spectra and charge state distributions of FeK radiation from Alcator C and/or A.

3. Construct a new high resolution spectrometer for measurements of line profiles of He-like $\mathrm{CIK}$ and $\mathrm{FeK}$ omissions. This will be used as a routine ion temperature diagnostic on Alcator $\mathrm{C}$ and could also be reproduced on Alcator $\mathrm{A}$.

\section{Milestones}

1. Obtain first MoL spectra from Alcator C - May 1980.

2. Be prepared to obtain high resolution FeK spectra on Alcator - August 1980.

3. Complete construction of high resolution line profile spectrometer for $\mathrm{C} 1 \mathrm{~K}$ or $\mathrm{FeK}$ June 1980.

4. Operate line profile spectrometers - September 1980.

\section{Graduate. Students}

None

\section{Graduates}

None

\section{Other Professional Staff}

Elisabeth Kallne (50\%)

\section{Major Recent Publications}

"Focusing x-ray spectrograph for laser fusion experiments," B. Yaukobi, R.E. Turner, H.W. Schnopper and P.O. Taylor. Submitted to App. Phys. (Letter) 


\section{ATOMIC PHYSICS (AM) PROGRAM}

The Atomic Physics program provides atomic data on impurity ions for use in diagnosing fusion devices, and for determining the effects of impurities on radiative power losses and particle confinements. Projects are included that measure spectroscopic data for highly ionized, heavy impurities (wavelengths, energy levels, transition probabilities) and cross sections for excitation, ionization, and recombination of such ions. An important part of the activity is the operation of an atomic data center to compile and distribute data as it becomes available. Other projects in the AM program determine the important processes in ion sources for neutral beam injection systems. 


\section{Progress - Atomic Physics}

- Quasi-continuous spectral features from the ORMAK and the PLT tokamaks have been identified from theoretical calculations of the wavelengths as coming from tungsten and gold. Computations of the excitation rates from oscillator strengths have also permitted the tungsten content of the plasmas to be roughly estimated. The results confirm calculations which indicate that concentrations of heavy metals of the order of $10^{-4} n_{e}$ could prevent ignition of thermonuclear plasmas.

- As a result of the identification of heavy metals and of the severity of their radiative losses, the tungsten limiter of PLT was replaced with carbon. This change was largely responsible for the improvement of the energy confinement time which permitted the attainment of the highest temperatures achieved in a tokamak; viz., $\mathrm{T}_{\mathrm{i}}=6 \mathrm{keV}$. Present plans for TFTR now include carbon, rather than the originally contemplated tungsten limiters and armour plates.,

- Ion temperatures of six $\mathrm{keV}$ in PLT were measured at Princeton by four different methods, three of which depended critically on the knowledge of atomic data. In the first technique, the ion temperature was determined by Doppler width measurements of a long-wavelength forbidden line of $\mathrm{Fe} \mathrm{XX}$ at $2665.1 \AA$. This line in the ground state configuration was only recently identified in PLT with the assistance of other recent energy level data. A second approach again utilized Doppler line broadening measurements but this time based on the ls-2p K $\mathrm{K}_{\alpha}$ transition of the helium-like ion Fe XXV which is in the soft $\mathrm{x}$-ray region at $1.85 \AA$. In this case, the total observed width includes a significant contribution from natural broadening because of the extremely short lifetime of the upper state. To correct for this contribution to the width, the transition probability for spontaneous emission had to be known and applied. In the third approach, the ion temperature was determined by a charge exchange measurement of the escaping neutral deuterium which depends on the knowledge of absolute charge cross sections. Atomic data have clearly contributed prominently to the diagnosis of the beam-heated PLT plasma.

- Spectra for numerous ions of various heavy metals, including molybdenum and tungsten, have been obtained with very powerful ND:glass laser beams incident on metallic targets by NBS and NRL spectroscopy teams. Forty-five times ionized tungsten is the highest stage of ionization observed with diffraction grating instruments, and the new data have made possible extended systematic studies of the spectra of isoelectronic ions, especially for the important $\mathrm{Cu}$ and $\mathrm{Zn}$ isoelectronic sequences. These observations have led to numerous new line identifications and improved wavelengths for many highly ionized metal ions pertinent to tokamaks. A comprehensive analysis and interpretation of all these heavy ion spectra is in progress.

- Calculations for populating specific $\mathrm{n}$ - and $\ell$-states of $\mathrm{0}^{7+}$ due to charge exchange of $\mathrm{H}^{\circ}$ with $0^{8+}$ at $40 \mathrm{keV}$ have permitted the first direct measurement of fully ionized oxygen in a tokamak. This was accomplished by utilizing intensities of spectral lines excited selectively from a neutral heating beam passing through the plasma. The technique promises to be useful for tracking light impurities in the interior of large-diameter, hot plasmas where the normally radiating, nonstripped species are localized near the edge. 
- Measurement of the dielectronic recombination and ionization rates for $\mathrm{Fe}^{8+}$ and $\mathrm{Fe}^{11+}$ have been made in a small theta pinch. Effective rate coefficients for recombination at electron densities $\mathrm{N}_{\mathrm{e}} \approx 3 \times 10^{16} \mathrm{~cm}^{-3}$ have been found to be equal to or smaller than presently accepted expressions for low density plasma. The rate coefficient for ionization also appears to be smaller than theoretical values. The total rate of dielectronic recombination has been calculated for $\mathrm{Mo}^{+32}$ to form $\mathrm{Mo}^{+31}$ on the basis of the fundamental atomic physics of this process, and using accurate atomic data calculated for these particular ions. The agreement with simple analytical expressions is good in the high temperature range. Considerable disagreements are also found when the details of the process, i.e., different recombination channels, are considered.

- The application of reaction rate data of electron interactions with atomic and molecular hydrogen indicated that the production rate of $\mathrm{H}^{-}$was 2-3 orders of magnitude less than that observed in ion sources. Recent theory, which has been confirmed by experiment, indicates that the dissociative attachment cross section $\left(\mathrm{e}+\mathrm{H}_{2} \rightarrow \mathrm{H}^{-}+\mathrm{H}\right.$ ) in the electron energy range $0-5 \mathrm{eV}$ increases by four orders of magnitude when the rotational quantum number increases from $v=0$ to $j=7$. Similar inereases have been observed in $D_{2}$ with a five orders of magnitude increase from $v=0$ to $v=5$. These dramatic increases that are obtained by increasing the $\mathrm{H}_{2}$ or $\mathrm{D}_{2}$ gas temperature account for the $\mathrm{H}^{-}$production rate in negative ion sources.

- Recent measurements of the equilibrium $\mathrm{D}^{-}$yield from alkali or alkaline-earth vapors have provided quantitative data to reduce the uncertainties in producing intense $\mathrm{D}^{-}$beams by charge exchange collisions. Previously, projection of $\mathrm{D}^{+}$through $\mathrm{Cs}$ vapor at energies less than $1 \mathrm{keV}$ was believed to be the optimum system. Designs have been altered to project $10 \mathrm{keV} \mathrm{D}^{+}$through $\mathrm{Na}$ vapor cell to maximize the $\mathrm{D}^{-}$that will be available after acceleration to several hundred $\mathrm{keV}$.

- An experimental/theoretical model of negative hydrogen ion production at surfaces bombarded by low-energy ions has been developed. The model can be used to predict yields in surface-production negative-ion sources for efficient neutral beam injectors.

- Extensive tables of critically evaluated atomic transition probabilities for all available stages of ionization of $\mathrm{Fe}, \mathrm{Co}$, and $\mathrm{Ni}$, comprising about 4000 lines, have been completed. For the highly ionized species of these elements, where very few data are available, techniques to utilize regularities along isoelectronic sequences have been extensively applied to predict additional transition probability data. With this approach, fairly reliable results for the principal lines of highly ionized $\mathrm{Fe}$ and $\mathrm{Ni}$, important for tokamak impurity studies, could be derived. Publication of this NBS table is expected in the Journal of Physical and Chemical Reference Data for early 1980. 


\section{Project}

Electron Impact Excitation and Ionization of Heavy Ions

K.W. Jones, D.C. Gregory, and B.M. Johnson

$\begin{array}{llll}\text { FY79 } & 30 \mathrm{~K} \text { op } & \text { FY80 } & \begin{array}{l}\text { Funds for operation are provided } \\ \text { by Basic Energy Sciences. }\end{array}\end{array}$

Purpose

To measure cross sections for electron excitation and ionization of highly charged heavy ions of $\mathrm{Ti}, \mathrm{Fe}, \mathrm{Cr}$, and $\mathrm{Ni}$.

\section{Approach}

A high current electron beam will be crossed with heavy ion beams produced by the Brookhaven National Laboratory Tandem Van de Graaf Accelerator Facility. These accelerators can produce beams of essentially any element in the periodic table with ionization states which can be selected by appropriate choice of beam energy. Typical maximum states of ionization are Fe XX, Mo XVIII, and Au XXXVIII. Beams of a single charge state will be produced by charge state analysis just before the interaction region. Cross sections for ionization will be determined from a second charge state measurement after the interaction region. Cross sections for excitation will be determined from observation of the interaction region with an appropriate spectrometer.

\section{Progress}

The basic experimental apparatus has been designed and most of the hardware has been ordered and received. Cleaning of the components for ultra-high vacuum use and the assembly of the system have been started.

\section{Plans}

Assembly of the experimental apparatus is expected before May 1980. Additional high vacuum pumps which are required will also be ordered during this period. Initial trials of the equipment will start after May 1980.

\section{Milestones}

1. Order high vacuum pumps as available funds permit - January 1980 .

2. Complete assembly of experimental apparatus - April 1980. 
3. Test electron gun, and ion beam charge state analyzing systems and detection system July 1980.

4. Start Experimental Program using solid or gas targets on the crossed-electron beams July 1980 .

Graduate Students (\% DOE Support)

None

Graduates (Year)

None

Other Professional Staff

None

Major Recent Publications

None 
Experimental Plasma Research

Category AM

LBL

Project

Atomic Physics (Experimental)

R.V. Pyle, K.H. Berkner

$\begin{array}{rrr}\text { FY79 } \$ 272 \mathrm{~K} \text { op } & \text { FY80 } & \$ 270 \mathrm{~K} \text { op } \\ 30 \mathrm{~K} \text { eq } & 35 \mathrm{~K} \mathrm{eq}\end{array}$

\section{Purpose}

Investigate atomic physics phenomena related to neutral-beam injection systems; production of $\mathrm{H}^{-}$, $\mathrm{D}^{-}$, and $\mathrm{He}^{-}$ions in gases and vapors, and on surfaces; charge transfer and ionization of hydrogen atoms and molecules in collision with heavy highly stripped (trapped impurity) ions; neutralization of fast $\mathrm{D}^{-}$in a plasma target; and neutralization, excitation, ionization, and dissociation of ions, atoms, and molecules found in neutral-beam lines (for diagnostic purposes).

\section{Approach}

Products of particle collisions in gases and plasmas, and at surfaces are studied with the aid of three ion accelerators ( $200 \mathrm{eV}-25 \mathrm{keV}, 500 \mathrm{eV}-30 \mathrm{keV}, 2 \mathrm{keV}-300 \mathrm{keV}$ ) and a hydrogen-atom source in conjunction with gas and metal-vapor target cells (including a heat-pipe target and a high-temperature vapor cell), plasma targets, appropriate vacuum systems, and beam analysis and detection systems. The Super-HILAC heavy-ion accelerator (a source of highly stripped ions) is used in conjunction with a large $20 \mathrm{kG}$ magnet and appropriate target and analysis chamber.

\section{Progress}

1. Measurements of $\mathrm{H}^{-}$and $\mathrm{D}^{-}$formation on clean and cesiated surfaces bombarded by thermal atoms from an oven were completed. This work is related to negative ion formation processes in sources for neutral beam systems. By varying the oven temperature it was shown that the negative ion production probability is small at thermal energies, but rises rapidly with energy.

2. The range of validity of an experimental/theoretical scaling rule for electron loss from hydrogen atoms colliding with highly stripped heavy ions has been extended with $\mathrm{Nb}^{+\mathrm{q}}$ ions up to $\mathrm{q}=36$ and carbon ions in the E/q range 50 to $280(\mathrm{keV} / \mathrm{amu}) \div \mathrm{q}$.

3. The $\mathrm{D}^{-}$yield from charge transfer in a sodium vapor target over the energy range 0.4 to $10 \mathrm{keV}$ has been measured; the equilibrium yield has a broad maximum of about $10 \%$ at $3 \mathrm{keV}$. The $\mathrm{D}^{-}$ yield for $\mathrm{D}_{2}^{+}$incident on sodium vapor has also been measured; a very thick target $\left(5 \times 10^{16}\right.$ $\mathrm{cm}^{-2}$ ) is required to dissociate the $D_{2}^{+}$.

4. The first measurements of ${ }^{3} \mathrm{He}^{-}$and ${ }^{4} \mathrm{He}^{-}$on surfaces bombarded by low energy $(\sim 300 \mathrm{eV})$ atoms and ions have been made. $\mathrm{He}^{-}$sources are important in the development of diagnostic beams for measurement of $\alpha$ energies in $d-t$ plasmas. 
5. $\mathrm{H}^{-}$and $\mathrm{D}^{-}$yield measurements as well as work functions for thin coverage of $\mathrm{Cs}$ on $\mathrm{Ca}, \mathrm{Ni}, \mathrm{Mo}$ and $\mathrm{W}$ substrates have been continued, as well as $\mathrm{Li}$ and $\mathrm{Cu}$ on W. Significantly higher yields for thin coverage vs thickness have been obtained. A model to describe negative ion formation at surfaces based upon probabilities of reflection, $\mathrm{H}^{-}$formation at the surface, and $\mathrm{H}^{-}$survival leaving the surface has been demonstrated. The model fits the data for all the alkali metal targets and for both $\mathrm{H}$ and $\mathrm{D}$ incident. The model also correctly predicts the $\mathrm{H}^{-}$yield from a $\mathrm{Cu}$ target with thin $\mathrm{Na}$ coverage, based upon the thick $\mathrm{Na}$ results.

\section{Plans}

1. Complete experimental/theoretical determinations of $\mathrm{H}^{-}$and $\mathrm{D}^{-}$yields when low-workfunction surfaces are bombarded by low-energy hydrogen and deuterium atoms and ions.

2. Measure thick-target negative hydrogen and deuterium yields and cross sections in calcium vapor.

3. Measure $\sigma_{-0}$ and $\sigma_{0_{-}}$, and neutralization efficiency from interactions of $50-300 \mathrm{keV} \mathrm{D}^{-}$ions in cesium and hydrogen plasmas.

4. Measure charge-transfer and target ionization cross sections for very heavy, highly ionized ions in molecular hydrogen $(\mathrm{eg} . \mathrm{Pb}+\mathrm{q})$.

5. Measure collision cross sections of impurity ions, eg $\mathrm{D}_{2} \mathrm{O}^{+}$, found in neutral beam lines.

6. Measure yields of $\mathrm{He}^{-}$ions formed by double charge exchange of high-current helium beams in $\mathrm{Na}$ vapor, and on low-work function surfaces.

7. Determine the atomic processes producing negative hydrogen ion within discharges.

8. Develop low-energy (50-500 eV) atomic hydrogen beams for metal vapor and surface studies.

9. Measure relative Balmer line emission cross sections for $\mathrm{D}^{+}, \mathrm{D}_{2}^{+}, \mathrm{D}_{3}^{+}$in $\mathrm{H}_{2}$.

Milestones (numbered by Plans items)

1. Complete experimental/theoretical determinations of $\mathrm{H}^{-}$and $\mathrm{D}^{-}$yields. March 1980

2. Measure trick-target negative hydrogen and deuterium yields and cross sections in calcium vapor. September 1980

4. Measure charge-transfer and target-ionization cross sections of a very heavy, highly ionized ion (probably $\mathrm{Pb}$ ) in hydrogen gas. February 1980

5. Obtain first (preliminary) results for dissociation of $10-150 \mathrm{keV} \mathrm{D} \mathrm{O}^{+}$ions in $\mathrm{H}_{2}$. July 1980

6. Complete first measurements of ${ }^{3} \mathrm{He}^{-}$and ${ }^{4} \mathrm{He}^{-}$on surfaces and in a sodium vapor jet. January 1980

9. Obtain first (preliminary) relative Balmer line emission cross sections for $\mathrm{D}^{+}, \mathrm{D}_{2}^{+}, \mathrm{D}_{3}^{+}$in $\mathrm{H}_{2}$. May 1980 
Graduate Students (\% DOE support)

P.J. Schneider (100\%), S.E. Savas (100\%), K.R. Stalder (100\%), K. Jimbo (50\%), M. Wada (50\%), and J. Trow (50\%).

\section{Graduates}

None

\section{Other Professional Staff}

W.G. Graham, A.S. Schlachter, J.W. Stearns, and J. Tanis

\section{Major Recent Publications}

"Negative-Hydrogen-Ion Production by Low energy Hydrogen Atom Bombardment of Surfaces", W.G. Graham, Phys. Lett. A, (July 1979).

"Negative-Hydrogen-Ion Production by Backscattering from Alkali-Metal Targets", P.J. Schneider, K.W. Berkner, W.G. Graham, R.V. Pyle, and J.W. Stearns, LBL-9992 to be published in the Proceedings of the Workshop on Hydrogen Recycling, Dublin, CA October 17-18, 1979.

" $\mathrm{D}^{-}$Formation by Charge Transfer of 0.3 to $10-\mathrm{keV}$ Deuterium Ions and Atoms in Cesium, Rubibium, and Sodium Vapors," A.S. Schlachter, K.R. Stalder, and J.W. Stearns, in "Eleventh International Conference on the Physics of Electronic and Atomic Collisions" (Kyoto, 1979), p. 526.

"Charge-State Dependence of Electron Loss from $\mathrm{H}$ by Collisions with Heavy, Highly-Stripped Ions," K.H. Berkner, W.G. Graham, R.V. Pyle, A.S. Schlachter, and J.W. Stearns, "Eleventh International Conference on the Physics of Electronic and Atomic Collisions" (Kyoto, 1979), p. 596.

"A Model for $\mathrm{H}^{-}$Production from Sodium Surfaces, J.R. Hiskes", Proceedings of the Workshop on Hydrogen Recycling, Dublin, Ca. October 17-18, 1979.

"Negative Ion Production by Backscattering From Alkali Metal Surfaces Bombarded by Ions of Hydrogen and Deuterium", P.J. Schneider, Ph.D. Thesis. 
Project

Neutral Beam Plasma Research

W.B. Kunkel, C.F. Burrell, C.F. Chan, W.S. Cooper

FY79 \$100K op FY80 \$125K op

$30 \mathrm{~K}$ eq $\quad 15 \mathrm{~K} \mathrm{eq}$

\section{Purpose}

To understand the relevant physics required to optimize the performance parameters of neutral injector ion sources and beams for present and planned OFE experiments. The immediate goal is to maximize the fraction of full-energy deuterium atoms in the beam (a very cost effectiveimprovement) and to minimize the beam divergence.

\section{Approach}

The program develops diagnostic instrumentation (pulsed Langmuir probes, spectroscopy, mass spectrometry), analysis techniques (direct digital data acquisition, Fast Fourier Transform waveform analysis), and computer models to study the plasma properties of LBL ion sources, and the characteristics of the resulting neutral beams. When sufficient understanding is achieved, suggestions are made for modifications to improve the performance of neutral beam systems.

\section{Progress}

1. A computer model for standard ("field-free") LBL source plasmas has been developed that includes ten coupled rate equations and wall interactions. The model computes the electron energy distribution and the flux of atomic and molecular ions to the walls. The model predictions of electron temperatures and ion beam composition are in good agreement with the measured performance of 4 different sources, running on both hydrogen and deuterium.

2. A "bucket" source (which uses rows of permanent magnets on the walls of the source chamber to enhance primary electron confinement) has been built to conduct the studies required to extend the model to include this type of source.

3. A broadband digital spectral analysis system has been used to investigate superthermal potential fluctuations in the source plasma. These fluctuations are caused by ion acoustic waves, driven by a not yet understood interaction between the plasma and the periodically spaced tungsten filaments that serve as cathodes. The fluctuation amplitude levels are found to be insufficient to cause significant ion heating (which would increase the beam divergence).

4. An experimental study has begun of the plasma generated in the neutralizer gas cell by the fast ion beam. Interest in this topic is because spectroscopic measurements indicate an apparent increase in the divergence of the ion beam as it penetrates this plasma; an increase that occurs after the beam is accelerated, and may be sufficient to double the beam divergence. 


\section{Project}

Atomic and Molecular Physics

C.F. Barnett, C. Bottcher, H.J. Kim, F.W. Meyer, R.A. Phaneuf

FY79 \$375K op FY80 \$470K op

$25 \mathrm{~K} \mathrm{eq} \quad 37.5 \mathrm{~K}$ eq

\section{Purpose}

To measure atomic data needed in understanding the heating, cooling, loss, and diagnostics of high temperature plasmas.

\section{Approach}

Monoenergetic particle beams in the energy range $20 \mathrm{eV}$ to $10 \mathrm{MeV}$ are passed through static gas cells or crossed with an energetic neutral or charged beam to determine absolute cross sections. Facilities available include six accelerators: (1) $0.01-2.0 \mathrm{keV}$; (2) $1-50 \mathrm{keV}$; (3) $20-600 \mathrm{keV}$; (4) 1-15 MeV tandem; (5) 5-150 keV multicharged ion; and (6) 10-100 keV Ho accelerator. In addition to the usual electronic and vacuum equipment, two beam-scattering chambers are available to perform crossed-beams experiments in 10-10 Torr vacuums.

\section{Progress}

1. Using the ORNL-PIG multicharged ion source, measurements of total electron capture cross sections for $\mathrm{C}^{5+}, \mathrm{Oq}^{+}(\mathrm{q}=2-6), \mathrm{Arq}^{+}(\mathrm{q}=2-9), \mathrm{Feq}^{+}(\mathrm{q}=5,6)$, and $\mathrm{Xeq}^{+}(\mathrm{q}=2-12)$ in $\mathrm{H}$ and $\mathrm{H}_{2}$ have been made in the energy range $3 \leqslant \mathrm{E} \leqslant 6 \mathrm{keV} / \mathrm{charge}$. These measurements were made in collaboration with D.H. Crandall of Basic Energy Sciences.

2. Theoretical analysis has been completed of the electron capture into the $n$ state of multicharged ions reacting with $\mathrm{H}$ or $\mathrm{H}_{2}$. These theoretical and experimental data indicate that the cross section ratio for $\mathrm{H}_{2}$ target gas to $\mathrm{H}$ target gas is not 2 over the entire energy or velocity range.

3. Measurements of charge-changing collisions involving $\mathrm{H}^{+}, \mathrm{H}^{\circ}$, and $\mathrm{H}^{-}$incident on $\mathrm{Cs}$ in the $\mathrm{H}$ energy range 50 to $200 \mathrm{eV}$ are being completed.

4. Improvements have been made in the laser ion source. Electron capture cross sections of $\mathrm{C}^{\mathrm{q}}$ $(q=3-5)$ have been made in $\mathrm{H}_{2}$ down to energies of $100 \mathrm{eV} / \mathrm{amu}$. Measurements are underway using $\mathrm{Fe}$ ions incident on both $\mathrm{H}_{2}$ and $\mathrm{H}$.

5. Crossed-beams experiments, where total electron loss (capture plus ionization) cross sections are studied, have determined the relative excited state distribution in the $\mathrm{H}^{\mathrm{O}}$ beam for principal .. quantum numbers $q \leqslant n \leqslant 25$ has the expected $a / n^{3}$ dependence. The total cross section is dominated by collisions with the highly excited states, and the weighted cross section shows an $\mathrm{n}^{3}$ scaling, not the $\mathrm{n}^{2}$ scaling expected from classical calculations. 


\section{Plans}

1. Complete total electron loss cross section (ionization plus capture) of $\mathrm{H}(1 \mathrm{~s})$ and $\mathrm{H}(\mathrm{n} \ell)$ with multicharged ions.

2. Extend electron capture cross section measurements of $\mathrm{Fe}^{q^{+}}$or $\mathrm{Ti}^{q^{+}}$in $\mathrm{H}$ or $\mathrm{H}_{2}$ target gas to cover the energy range 0.1 to $10 \mathrm{keV} / \mathrm{amu}$.

3. Extend measurements to higher charge states in the relevant range of 0.01-20 keV/amu. The goal is to make measurements with $\mathrm{Fe}^{22+}$ using one of two methods:
A. An upgrade of the present laser ion source.
B. A merged-beams technique using either the ORNL Heavy Ion Accelerator or the Tandem Van de Graati.

4. Determine electron capture cross sections of $\mathrm{O}^{8+}, \mathrm{O}^{7+}, \mathrm{C}^{6+}$, and $\mathrm{C}^{5+}$ in $\mathrm{H}$ into $\mathrm{n}, \ell$ states in the energy range $\leqslant 100 \mathrm{keV} / \mathrm{amu}$.

\section{Milestones}

1. Use present laser ion source to determine electron capture cross section of $\mathrm{Fq}^{\mathrm{q}^{+}}$or $\mathrm{Ti}^{\mathrm{q}^{+}}$in $\mathrm{H}_{2}$ and $\mathrm{H}$ for energies less than $1 \mathrm{keV} / \mathrm{amu}$ - July 1980.

2. Determine feasibility of upgrading laser ion source to produce high charge states of $\mathrm{Fe}$ and $\mathrm{Ti}$ energies less than $10 \mathrm{keV} / \mathrm{amu}$ - September 1980.

3. Construct apparatus to measure the cross section for capture into excited $n, \ell$ states for $\mathrm{C}^{5+}$, $\mathrm{C}^{6+}, 0^{7+}$, and $0^{8+}-$ September 1981 .

4. Complete measurements of effect of highly excited $\mathrm{H}^{\circ} \mathrm{n}$ states on the total electron loss cross section in collisions with multicharged ions (50-200 keV/amu) - July 1980.

5. Determine total electron loss cross section of $\mathrm{H}(1 \mathrm{~s})$ with multicharged ions $(50-200 \mathrm{keV} / \mathrm{amu})$ July 1981 .

6. Initiate measurements of electron capture collisions of $\mathrm{H}^{+}, \mathrm{He}^{+}$, and $\mathrm{He}^{2+}$ with multicharged ions - July 1981.

\section{Graduate Students}

None

\section{Graduates}

None 


\section{Other Professional Staff}

None

\section{Major Recent Publications}

1. D.H. Crandall, R.A. Phaneuf, and D.C. Gregory, "Electron Impact Ionization of Multicharged Ions," ORNL/TM-7020, September 1979.

2. D.H. Crandall, R.A. Phaneuf, B.E. Hasselquist, and D.C. Gregory, "Measured Cross Sections for Ionization of $\mathrm{C}^{3+}, \mathrm{N}^{4+}$ and $0^{5+}$ Ions with Contribution Due to Excitation-Autoionization," J. Phys. B 12, L249 (1979).

3. F.W. Meyer, R.A. Phaneuf, H.J. Kim, P. Hvelplund, and P.H. Stelson, "Single Electron-Capture Cross Sections for Multiply Charged $\mathrm{O}, \mathrm{Fe}, \mathrm{Mo}, \mathrm{Ta}, \mathrm{W}$, and $\mathrm{Au}$ Ions Incident on $\mathrm{H}$ and $\mathrm{H}_{2}$ at Intermediate Velocities," Phys. Rev. A 19, 515 (1979).

4. D. Gregory, G.H: Dunn, R.A. Phaneuf, and D.H. Crandall, "Absolute Cross Sections for 2s-2p Excitation of $\mathrm{N}^{4+}$ by Electron Impact," Phys. Rev. A 20, 410 (1979).

5. H.J. Kim and F.W. Meyer, "Electron Loss from Rydberg States of $\mathrm{H}^{\mathrm{O}}$ in Collisions with $\mathrm{N}^{3+}$," submitted to Physical Review Letters, November 1979.

6. H.J. Kim and E.W. Meyer," $n$-Scaling of Electron-Loss Cross Sections for Fast $\mathrm{H}(\mathrm{n})^{\mathrm{O}}+\mathrm{N}^{3+}$ Collisions," p. 962 in Abstracts of the XIth ICPEAC, Kyoto, Japan, K. Takayanagi and N. Oda, Eds., Society for Atomic Collision Research (Japan), 1979.

7. D.H. Crandall, R.A. Phaneuf, and F.W. Meyer, "Electron Capture by Slow Multicharged Ions in Atomic and Molecular Hydrogen," Phys. Rev. A 19, 504 (1979).

8. T.J. Morgan, C.F. Barnett, J.A. Ray, and A. Russek, "Ionization of Nonadiabatic Ettects in Molecular Hydrogen Rydberg States by Electric Field Ionization," Phys. Rev. A 20, 1062 (1979).

9. C. Cisneros, I. Alvarez, R. Garcia, C.F. Barnett, J.A. Ray, and A. Russek, "Electron Capture into $\mathrm{D}_{3}{ }^{-\prime}$ and $\mathrm{D}_{3}{ }^{\circ}$ Repulsive States by $\mathrm{D}_{3}{ }^{+}$in Cs." Phys. Rev. A 19, 631 (1979).

10. D.H. Crandall and R.A. Phaneuf, "Electron Impact Iònization of Oxygen Ions $-0^{3+}, 0^{4+}, 0^{5+}$," p. 226 in Abstracts of the XIth ICPEAC, Kyoto, Japan, K. Takayanagi and N. Oda, Eds., Society for Atomic Collision Research (Japan), 1979.

11. F.W. Meyer and H.J. Kim, "Measurement of H Atom Rydberg-State Population by a Transmission Method," p. 552 in Abstracts of the XIth ICEPAC, Kyoto, Japan, K. Takayanagi and N. Oda, Eds., Society for Atomic Collision Research (Japan), 1979. 
Experimental Plasma Research ORNL

\section{Project}

Controlled Fusion Atomic Data Center

C.F. Barnett, B.J. Farmer, S.W. Hawthorne, M.I. Kirkpatrick

\begin{tabular}{|c|c|}
\hline 179 & $\begin{array}{r}\$ 170 \mathrm{~K} \text { op } \\
0 \mathrm{~K} \text { eq }\end{array}$ \\
\hline
\end{tabular}

\section{Purpose}

To evaluate published data and to publish in the form of handbooks and newsletters those atomic dala of inlerest lu OFE.

\section{Approach}

Search refereed and report literature, perform evaluations, and compile data consistent with the needs of magnetic fusion energy research.

\section{Progress}

1. Continued publication of bimonthly newsletter, "Atomic Data for Fusion," in cooperation with NBS.

2. Evaluated the ORNL-NBS newsletter and the corresponding IAEA newsletter to determine the feasibility of terminating the U.S. publication. Because the findings indicated that the IAEA newsletter was not adequate to fulfill the needs of the fusion community, the ORNL-NBS nèwsletter will continue.

3. Searched literature on a continuing basis.

4. Completed new computer input-output program for storing and retrieving bibliographical data. The 1978 bibliography has been published using this format.

5. Developed a computer program to produce our numerical and graphical data compilations using computer graphics techniques.

6. Completed computer programs to convert cross section data to reaction rates and polynomial fits as functions of plasma temperature or the energy of any beam injected into a Maxwellian plasma.

7. Completed numerical evaluation and compilation of some experimental cross sections of impurity ions interacting with $\mathrm{H}$ or $\mathrm{H}_{2}$. Unsuccessful attempts were made to put confidence levels on theoretical computations. 
8. Produced and distributed the 1976 and 1977 bibliography.

9. Published four bibliographies covering the period 1950-75; included are bibliographies on molecular dissociation, atomic and molecular excitation, ionization and stripping, and electron transfer.

Plans

1. Continue update of the compilation Atomic Data for Controlled Fusion Research, Vols. I, II, and III.

2. Continue in cooperation with NBS the publication of "Atomic Data for Fusion" with emphasis on newly acquired data.

3. Complete publication of cross sections of impurity.ions found in magnetically confined plasmas. Attempts will be made to merge theoretical estimates with experimental data.

4. Complete an atlas or catalog of all strong optical lines that have been observed in tokamaks and compute the excitation cross section or reaction rates of these lines using either closecoupling or distorted-wave methods. Results will be published as a handbook.

5. Continue with routine search and evaluation as needs arise.

6. Publish public relations booklet describing the work of the Atomic and Plasma Physics Research Program at Oak Ridge National Laboratory:

\section{Milestones}

1. Update compilation of evaluated data - continuing effort.

2. Publish 1979 bibliography - July 1980.

3. Merge reaction rate data with cross section data - September 1980.

4. Catalog tokamak optical lines and excitatiơn rate calculations - October 1981.

5. Complete publication of experimental impurity ion publication - September 1980 .

6. Evaluate theoretical data - January 1981 .

\section{Graduate Students}

None

Graduates

None 
Other Professional Staff

D.H. Crandall

F.W. Meyer

H.B. Gilbody

T.J. Morgan

H.J. Kim

E.W. McDaniel

R.A. Phaneuf

R.H. McKnight

J.A. Ray

E.W. Thomas

G.S. McNeilly

\section{Major Recent Publications}

1. C.F. Barnett and W.L. Wiese, “Atomic Data for Fusion”, Vol. 5, 1979.

2. E.W. Thomas, S.W. Hawthorne, F.W. Meyer, and B.J. Farmer, Atomic Data for Controlled Fusion Researrh. Revisions and Additions to Sertions $n$. 1 ,Sputtering, $D .5$ Ion Reflection from Surfaces, and D.6 Trapping, ORNL-5207/R1, November 1979.

3. S.W. Hawthorne, Controlled Fusion Atomic Data Center (public relations brochure), 1979.

4. S.W. Hawthorne, E.W. McDaniel, C.F. Barnett, D.H. Crandall, H.B. Gilbody, M.I. Kirkpatrick, R.A. Phaneuf, and E.W. Thomas, Bibliography of Molecular Dissociation in Heavy Particle Collisions 1950-75, ORNL-5500, February 1979.

5. S.W. Hawthorne, E.W. Thomas, C.F. Barnett, D.H. Crandall, H.B. Gilbody, M.I. Kirkpatrick, E.W. McDaniel, and R.A. Phaneuf, Bibliography of Atomic and Molecular Excitation in Heavy Particle Collisions 1950-75, ORNL-5501, February 1979.

6. S.W. Hawthorne, E.W. Thomas, D.H. Crandall, H.B. Gilbody, M.I. Kirkpatrick, R.A. Phaneuf, and E.W. Thomas, Bibliography of Ionization and Stripping in Heavy Particle Collisions 1950-75, ORNL-5503, February 1979.

7. S.W. Hawthorne, C.F. Barnett, H.B. Gilbody, M.I. Kirkpatrick, E.W. McDaniel, R.A. Phaneuf, and E.W. Thomas, Bibliography of Electron Transfer in Heavy Particle Collisions 1950-75; ORNL-5502, February 1979.

8. Bibliography of Atomic and Molecular Processes, 1978, to be published.

9. Bibliography of Atomic and Molecular Processes, 1976-77, prepared, as yet unpublished.

10. S.W. Hawthorne, Atomic and Plasma Physics Research Program (public relations booklet), 1979. 
Experimental Plasma Research

National Bureau of Standards

Category AM

\section{Project}

The Determination of Atomic, Molecular and Nuclear Data Pertinent to the Magnetic Fusion Energy Program

W.L. Wiese

\begin{tabular}{|c|c|}
\hline & $\begin{array}{r}\$ 744 \mathrm{~K} \text { op } \\
33 \mathrm{~K} \text { eq }\end{array}$ \\
\hline
\end{tabular}

\section{Purpose}

To develop the atomic, molecular and nuclear physics data base required for: Plasma diagnostics and plasma modeling, analysis of heavy ion impurity physics, study of plasma heating and cooling mechanisms, and neutral beam injection systems.

\section{Approach}

Electron-ion collision cross sections, radiative transition probabilities, dielectronic recombination and collisional transition rates and the wavelengths of prominent spectral lines are experimentally and theoretically determined. Wavelength and energy level data are also critically evaluated, compiled and tabulated. Far UV and soft $\mathrm{x}$-ray radiometric standards are developed to provide radiometric calibrations for laboratory instruments throughout the fusion energy program. The d-t fusion reaction cross section is determined through a measurement of its inverse reaction $n+$ $\mathrm{He} \rightarrow \mathrm{d}+\mathrm{t}$, using high resolution neutron time-of-flight techniques.

\section{Progress}

1. Line identification work for highly ionized species resulted in great progress for ions in the $\mathrm{Na}, \mathrm{Mg}, \mathrm{Cu}, \mathrm{Zn}, \mathrm{Ag}$, and $\mathrm{Pd}$ isoelectronic sequences. With the aid of observations with a powerful Nd/glass laser at Los Alamos, ambiguities in earlier identifications for Mo XXXI (a Mg-like ion) and Mo XXXII (Na-like) were removed. The $\mathrm{Zn}$ and $\mathrm{Cu}$ sequences were extended through W XLV and W XLVI, respectively. These results provided reference wavelengths for a number of lines used in Tokamak diagnostics. Collaborative work with NRL and LASL has provided results on resonance transitions of Mo XIII-XVIII.

2. Spectral analysis work on the Pd and $\mathrm{Ag}$ sequences has resulted in a new interpretation of $\mathrm{W}$ spectra for ORMAK and PLT. The dominant stage of ionization was shown to be W XXVIII, rather than W XXXI-XXXV, as was previously believed.

3. Critical compilations of energy levels for all spectra of aluminum, potassium, calcium, titanium, and vanadium were published and similar compilations for magnesium and scandium were completed. A bibliography on atomic energy levels and spectra (June 1975 through July 1979) was submitted for publication. The literature on all atomic spectra is monitored and references supplied for each issue of the newsletter "Atomic Data for Fusion." 
4. On the theta-pinch facility the heavy elements of titanium, iron and nickel have been introduced into the plasma by a coaxial discharge source. Measurements of the temporal histories of the spectral lines of Ti V through Ti XII irons have been performed in preparation to determine ionization rate coefficients of titanium ions.

5. A basic theory of dielectronic recombination including several previously neglected aspects has been developed. This theory is being used to investigate various approximations usually made in dielectronic recombination calculations. The atomic data necessary to compute the dielectronic recombination of Mo XXXII to form Mo XXXI is being generated.

6. Measurements of the cross section for the excitation of the $4^{2} \mathrm{P}$ and $5^{2} \mathrm{~S}$ levels of $\mathrm{Zn}$ II were completed. Cross section measurements were completed for ionization of $\mathrm{Zn} \mathrm{II} \mathrm{and}$ $\mathrm{Ga}$ II, and special care given to delineating the role of excitation-autoionization which dominates the low energy portion of the cross section curve. Preliminary measurements have been made of the cross section for excitation of the $4^{1} \mathrm{P}$ level of Ga II.

7. The Second Conference on "Atomic Processes in High Temperature Plasmas" was successfully organized and hosted at JILA, January 1979.

8. Radiometric transfer standard photodiodes calibrated down to $5 \mathrm{~nm}$ have been supplied to users. A study of various photocathode materials used by plasma diagnosticians has been completed. Monochromators have been calibrated at SURF for The Johns Hupkins University diagnostic group. In November 1979, the third workshop on the use of XUV and X-ray radiometry in plasma diagnostics was held. A collaboration with the Princeton spectral diagnostics group has been established on the development of new diagnostic XUV spectrometer systcms and the refurbishment of a transfer grazing-incidence monochromalor.

9. The measurement techniques for calibration of high leakage current detectors have been accomplished and a double wheel $\mathrm{x}$-ray filter assembly has been constructed which has the necessary throughput for calibration of a $3 \mathrm{~mm} \mathrm{x} 25 \mathrm{~mm}$ detector. An optical alignment system has been attached to the $x$-ray target chamber to enable quick and accurate alignment of x-ray scatter baffles and detector systems which are being calibrated. Absolute measurements of the K-line flux densities have been completed on targets of carbon and aluminum, 2\%7 and 1487 $\mathrm{eV}$, respectively, and L-line flux densities of iron and copper, 723 and $930 \mathrm{eV}$, respectively.

10. Measurements of the neutral total cross section for ${ }^{4} \mathrm{He}$ were completed with the best energy resolution to date and were found to be in agreement with earlier measurements.

\section{Plans}

1. Continue efforts to extend the observations of the Ag and Pd sequences to W XXVIII and W XXIX with our $2.2 \mathrm{~m}$ grazing incidence spectrograph. Continue data reduction for the $\mathrm{Na}$, $\mathrm{Mg}, \mathrm{C} \mathrm{u}$, and $\mathrm{Zn}$ sequences. Start major program on very accurate measurements of resonance lines of highly ionized iron group elements (Ti-Ni) to predict reliably forbidden transitions used for temperature measurements (by observations of Doppler broadening) in Tokamak plasmas. Start design of instrumentation for observations of forbidden lines on TEXT.

2. Critical evaluations and compilations for all sodium and nickel ionic spectra are planned. 
3. Following the determination of the spatial and temporal plasma parameters of electron temperature and density by Thomson scattering and interferometry, the ionization rates of several titanium ions will be determined. Start preparations for a proposed experiment on TEXT to study Be-like dielectronic satellites to Li-like ions.

4. An investigation with the goal of deriving an analy tic formula for the total rate of dielectronic recombination will be carried out. The effects of various plasma-atom interactions on the dielectronic recombination process will be examined.

5. The role of configuration mixing in Be-like ions will be determined by measurements of excitation cross sections of resonance lines and other lines from levels most likely to mix with the resonance level. Work will be done at JILA and at ORNL (when ion source move is complete). Ionization of Be-like ions will be measured, as well as species having large numbers of $\mathrm{d}$ shell electrons.

6. Transfer standard detectors will be further developed and supplied as required. Diagnostic spectrometer systems will be calibrated as needed. Collaboration with the Princeton diagnostic group on diagnostic instruments and a transfer instrument will be continued.

7. Advanced techniques will be applied to the present steady state $x$-ray source to significantly improve the long term stability of the x-ray flux density. A high purity fluorescent $\mathrm{x}$-ray source is scheduled for completion in June 1980 which has an expected beam purity. of greater than $90 \%$ for $x$-ray beams in the energy range of from 0.3 to $1.5 \mathrm{keV}$. For future low energy $x$-ray detector calibration requirements, alternate $x$-ray sources will be explored, e.g., (1) a synchrotron facility with high flux capabilities and (2) conversion of the NBS $1.5 \mathrm{MeV}$ dynamitron to a positive ion accelerator.

\section{Major Milestones}

1. Accurate measurements of the spectra of Fe XVI-XX and Ti XIV-XX - October 1980.

2. Spectral observations of Ag I and Pd I sequences to W - June 1980.

3. Complete energy-levels compilation for Ni I through Ni XX - September 1980.

4. Measurement of ionization rates of several titanium ions - July 1980.

5. Analytic dielectronic recombination formula - October 1980.

6. Measure cross sections for excitation of $2 p^{2}{ }^{3} \mathrm{P}, 2 \mathrm{p}^{2}{ }^{1} \mathrm{D}$ and $2 \mathrm{p}^{2}{ }^{1} \mathrm{~S}$ levels of B II - August 1980.

7. Measure cross sections for ionization of B II - June 1980.

8. Activate diagnostic spectrometer calibration facility - June 1980.

9. Supply standard detectors and calibrate instruments calibrated as requested - Continuing.

10. Finalize NBS-Princeton PPL radiometric transfer methods - September 1980. 
11. Distribute description of NBS standard x-ray beams to user community - July 1980 .

12. Investigate synchrotron radiation sources as alternate $\mathrm{x}$-ray calibration source $(0.1-10 \mathrm{keV})$ August 1980.

Graduate Students (\% DOE support)

W. Rogers (60\%)

\section{Graduates}

W. Rogers - January 1980, Ph.D. Physics

\section{Other Professional Staff}

Dr. C.D. Bowman

Dr. A.D. Carlson

Dr. G.H. Dunn

Dr. E.J. Knystautas

Dr. R.P. Madden

Dr. W.C. Martin

Dr. J. Reader
Dr. J.R. Roberts

Dr. L.J. Roszman

Dr. E.B. Saloman

Mr. J.H. Sparrow

Dr. J. Sugar

Dr. W.L. Wiese

Dr. R. Zalubas

\section{Major Recent Publications}

1. Spectrum and Energy Levels of Thirteen-Times Ionized Molybdenum (Mo XIV), J. Reader, G. Luther, and N. Acquista, J. Opt. Soc. Am. 69, 144 (1979).

2. Spectrum and Energy Levels of Eleven-Times Ionized Zirconium (Zr XII), J. Reader and N. Acquista, submitted to J. Opt. Soc. Am.

3. Energy Levels of Aluminum, Al I through Al XIII, W.C. Martin and R. Zalubas, J. Phys. Chem. Ref. Data 8, 817-864 (1979).

4. Energy Levels of Titanium, Ti I through Ti XXII, C. Corliss and J. Sugar, J. Phys. Chem. Ref. Data 8, 1.62 (1979).

5. Energy Levels of Vanadium, V I through V XXXIII, J. Sugar and C. Corliss, J. Phys. Chem. Ref. Data 7, 1191-1262 (1978).

6. One-electron Spectrum of Xe VIII, J.R. Roberts, E.J. Knystautas, and J. Sugar, J. Opt. Soc. Am. 69, 1620 (1979).

7. Dielectronic recombination rate of Mo XXXIII, L.J. Roszman, Phys. Rev. A 20, 673 (1979).

8. Absolute Emission Cross Section for Electron-Impact Excitation of $\mathrm{Li}^{+}$to the $\left(2{ }^{3} \mathrm{P}\right)$ Level, W.T. Rogers, J. $\emptyset$. Olsen, and G.H. Dunn, Phys. Rev. A 18, 1353 (1978). 
9. Absolute Cross Sections for $2 s-2 p$ Excitation of $\mathrm{N}^{4+}$ by.Electron Impact, D. Gregory, G.H. Dunn, R.A. Phaneuf, and D.H. Crandall, Phys. Rev. A 20, 2 (1979).

10. Electron Impact Ionization of C IV and N V, D.H. Crandall, R.A. Phaneuf, and P.O. Taylor, Phys. Rev. A 18, 1911 (1978).

11. Measured Cross Sections for Ionization of C IV, N V, and O VI İons with Contributions Due to Excitation-Autoionization, D.H. Crandall, R.A. Phaneuf, B.E. Hasselquist, and D.C. Gregory, J. Phys. B.: Atom. Molec. Phys. 12, L249 (1979).

12. The Use of Synchrotron Radiation for Detector Calibrations, E.B. Saloman, Proceedings of Conference on Synchrotron Radiation Instrumentation, to be published in supplement to Nucelar Instrumentation and Methods.

13. Evaluation of High Efficiency $\mathrm{Cu} I$ and Cs I Photocathodes for Soft X-ray Diagnostics, E.B. Saloman, J.S. Pearlman, and B.L. Henke, to be published in March 1, 1980 issue of Applied Optics.

14. Practical Photocathode Quantum Efficiencies and Filter Window Absorption Coefficients from $20 \mathrm{eV}$ to $10 \mathrm{KeV}$, R.H. Day, P. Lee, E.B. Saloman, and D.J. Nagel, submitted to Journal of Applied Physics.

15. Evaluation of Proposed Fusion Materials Irradiation Test Facility Neutron Dosimetry System; C.D. Bowman, report for Dr. W. McElroy, Westinghouse Hanford Company (1979).

16. Neptunium Fission Cross Section Measurements in the MeV Energy Range. A.D. Carison and B.H. Patrick, Proceed. Nuclear Cross Sections and Technology Conference (Oct. 1979). 
Experimental Branch

Naval Research Laboratory

\section{Project}

Charge Capture Experiments for Plasma Ions and Neutral Atoms

R.C. Elton, R.H. Dixon

FY79 \$70K $\quad$ FY80 \$30K

\section{Purpose}

The goal of this project is to demonstrate in a controlled experiment the significance of resonance charge transfer as an ionization/recombination processs in a plasma medium. In particular, elestron transfers from neutral atoms to specific excited levels and sublevels of various impurity ions are measured. Neutralization of helium ions (fusion products) by charge transfer is also studied.

\section{Approach}

Ionized atoms are formed near the surface of a laser-irradiated disc. A buffer gas surrounding the target interacts with the initial expanding plasma and creates the proper ion-neutral conditions for resonance charge transfer. Spectroscopic observations of the plasma determine spectral line enhancement which defines the specific excited ion level(s) participating in electron capture. The dynamic formation and transport of neutral atoms and ions are mapped with time-resolved spectroscopic techniques.

\section{Progress}

With a carbon disc and using grazing incidence spectroscopy in the $30-300 \AA$ region, anomalous emission originating on the $n=4,5$ levels in $C^{4+}$ and $C^{5+}$ ions have been associated with population by resonance charge transfer from neutral atoms.

Time-resolved density and velocity measurements,scoupled with numerical modeling, result in a charge transfer cross section consistent with theory. An early efflux of neutrals is associated with neutralized fast ions from the target. Results are reproduced with $\mathrm{Li}, \mathrm{B}$, and $\mathrm{N}$ target elements. Excited target neutrals are suppressed with increased gas density. Hydrogen is injected for $\left(\mathrm{C}^{\mathrm{n}}, \mathrm{H}\right)$ reactione:

\section{Plans}

1. Add temporal resolution to spatially resolved soft $x$-ray measurements.

2. Repeat preliminary Li measurements indicating transfer into $n=3$.

3. Measure ground state neutral density for accurate cross section. 
4. Map path of helium-ion neutralization.

5. Extend to heavier ions with larger laser (available).

\section{Milestones}

1. Complete time-resolved soft x-ray emission - March 1980.

2. Repeat lithium charge transfer theory test - January 1980.

3. Improve accuracy with ground state neutral measurement - July 1980.

4. Measure helium-ion charge transfer neutralization - September 1980.

5. Extend to heavier "impurity" elements - December 1980.

Graduate Students (\% DOE support)

None

Graduates (Year)

None

Other Professional Staff

Dr. John F. Seely

\section{Major Recent Publication}

"Short Wavelength Population Enhancement Associated with Charge Transfer in Laser-Produced Plasmas", in Laser Interaction and Related Plasima Phenomena (Plenurn Press, 1980). 
Experimental Plasma Research

Category AM

Naval Research Laboratory

\section{Project}

X-UV Spectroscopy in Support of the CTR Program

P.G. Burkhalter and D.J. Nagel

FY79 \$70K op $\quad$ FY80 \$85K op

\section{Purpose}

To provide wavelength data in the $x$-ray and ultraviolet region (2-300 $\AA$ ) from metallic elements ( $\mathrm{Ti}, \mathrm{Fe}$ and $\mathrm{Mo}$ ) and inert gases (Ar, $\mathrm{Kr}$ and $\mathrm{Xe}$ ) excited in high temperature plasmas (1-3 keV); these data will be used for analyses of Tokamak impurity, injection gas and wall reactants.

\section{Approach}

Radiation from high density plasmas in exploded wires, focused-laser sources and gas puff or vacuum discharge devices, is measured with $\mathrm{x}$-ray diffracting crystals and grating spectrographs. $\mathrm{Ab}$ initio calculations and isoelectronic extrapolation are used to classify the resulting spectra.

\section{Progress}

1. The L-series satellites in $\mathrm{Fe}$ and $\mathrm{Ti}$ spectral data generated by the $\mathrm{Nd}$ : glass laser and the vacuum spark source were interpreted. Wavelengths of the $\mathrm{Na}$ like satellite lines were measured in the 15-30 \& region to an accuracy of 10 milli-angstroms. These lines were classified with the aid of atomic structure calculations.

2. Highly ionized Mo spectra collected with the Nd: glass laser at NRL and with a vacuum spark device at NBS have been studied. The UV spectral region between 30 and $90 \AA$ has been interpreted and lines measured to an accuracy of $10 \mathrm{~m} \AA$ over this wavelength region. In the $60-90 \AA$ region the $3 \mathrm{p}-3 \mathrm{~d}$ transition in Mo XVII and Mo XVIII have been interpreted by comparison with atomic structure calculations. The complex $3 d^{9}-3 d^{8} 4 p$ and $3 d^{9}-3 d^{8} 4 f$ transitions in Mo XVI have been classified and an energy level diagram for the $3 d^{8} 4 p$ and $3 d^{84 f}$ configurations were constructed. I'his work was performed in collaboration with Joseph Reader at NBS and Robert Cowan at LASL. A report on this work has been drafted.

3. X-UV spectra of Ti has been acquired from exploded-wire experiments. Line identifications have been performed in the complex UV region and ionization stages Ti XII to Ti XX were found to be present.

\section{Plans}

1. Collect and interpret $x$-ray and UV spectra taken with laser, exploded-wire, gas puff or vacuum spark sources.

2. Design and construct an $\mathrm{x}$-ray spectrograph for use on TEXT. 


\section{Milestones}

1. Acquire low temperature Ti spectral data with a focused ruby laser.

2. Report on intermediate stages of ionization in Mo spectra.

3. Collect high-temperature Ti spectra from plasma implosions formed by exploded-wire arrays.

4. Complete $\mathrm{x}$-ray spectrograph design for TEXT and submit proposal to use on TEXT.

5. Report on X-UV spectra from gas puff plasmas.

6. Complete building of $\mathrm{x}$-ray spectrograph for TEXT and test at NRL.

Graduate Students (\% DOE support)

None

Graduates (Year)

Not applicable

Other Professional Staff

J.W. Criss (10\%)

\section{Major Recent Publications}

1. "X-Ray Spectra from a Gas Puff Z-Pinch Device", P.G. Burkhalter, J. Shiloh, A. Fisher, and " Robert D. Cowan, J. Appl. Physics 50 (7), 4532 (1979).

2. "L-Series Satellite Spectra in Ti XII and Fe XVI", P.G. Burkhalter; Leonard Cohen, Robcrt D. Cowan and U. Feldman, J. Opt. Soc. Am. 69 (8), 1133 (1979).

3. “X-Ray Line Spectra from Exploded-Wire Arrays", P.G. Burkhalter, J. Davis, J. Ranch, W. Clark, G: Dahlbacka, and R. Schneider, J. Appl. Physics 50 (2), 705 (1979). 


\section{Project}

Electron Capture and Loss Cross Sections: Formation of $\mathrm{D}^{-}$Beams

(J.R. Peterson)

FY80 \$89K op

Purpose

To find optimum target and operating conditions for $\mathrm{D}^{-}$beam production for high energy neutral beam heating and fueling of MFE plasmas.

\section{Approach}

Sequential double electron capture of $\mathrm{D}^{+}$in metal vapors is a promising method of producing $\mathrm{D}^{-}$ beams for high energy neutral $\mathrm{D}^{0}$ injection. Angular scattering and total cross sections are needed in order to model the $\mathrm{D}^{-}$beam formation. These quantities will be measured for individual $\mathrm{D}^{+}$, $\mathrm{D}^{\mathbf{0}}$, and $\mathrm{D}^{-}$electron capture and loss processes in various promising metal vapor targets. A modeling effort will be carried out simultaneously, using available results of both experiment and theory, to guide the $\mathrm{D}^{-}$source development to the best target and operating conditions.

\section{Progress}

This work was initiated on 2 January 1980.

\section{Plans}

Modification to an existing apparatus will be made to carry out angular differential cross section measurements using several alkali and alkaline earth vapor targets. Particular importance will be paid to projectile energies below $1 \mathrm{keV}$ in the alkalis, for which little information exists. Initial work will be performed on Cs targets. Some will repeat earlier work to test the apparatus and the detection methods (particle counting techniques for $\mathrm{D}^{+}, \mathrm{D}^{-}$, and $\mathrm{D}^{\circ}$ ). Modeling will be initiated using already available data; it will include scattering but will ignore excited states initially.

\section{Milestones}

1. Design and construct movable oven and differential angle detectors, install, and test April 1980.

2. Calibrate oven temperature/Cs vapor line densities using $\mathrm{He}^{+}$, compile model data and develop low current model - June 1980.

3. Measure $\sigma_{+_{0}}, \mathrm{~d} \sigma_{+_{o}} / \mathrm{d} \Omega$ in Ds, determine $\mathrm{D}^{\mathrm{O}}$ detection efficiency versus energy - August 1980. 
4. Apply model to $\mathrm{D}^{+}+$Cs system. Install duoplasmatron and test $\mathrm{D}^{-}$beams - September 1980 .

5. Measure $\sigma_{-0}$ and $d \sigma_{-0} / \mathrm{d} \Omega$ in Cs (start). Evaluate model and determine needs (compare to experiments) - December 1980.

\section{Professional Staff}

Dr. J.R. Peterson

Dr. M.J. Coggiola

Dr. R.V. Hodges

Dr. D.L. Huestis 
Experimental Plasma Research

UCLA

Category AM

Project

Improved Ion Sources For Neutral Beam Generation

A. Theodore Forrester

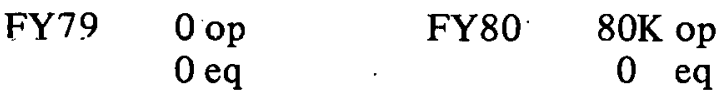

\section{Purpose}

To develop long pulse, high efficiency ion sources for neutral beam lines.

\section{Approach}

Magnetic multiple ion sources utilizing hollow cathode discharges for plasma production have generated $\mathrm{H}^{+}$ion currents of $1 / 3 \mathrm{~A} / \mathrm{cm}^{2}$ with $<2 \%$ uniformity and $<2 \%$ density fluctuations over large extraction areas and a power efficiency of only 350 watts per extractable ampere in continuous operation. This configuration has been scaled to sources with $10 \mathrm{~cm} \times 10 \mathrm{~cm}$ and $10 \mathrm{~cm} \times 40 \mathrm{~cm}$ extraction areas with increases in plasma generation length and magnetic yield intensity at the multiple cusp in order to achieve improved gas utilization efficiency and low molecular species output.

\section{Progress}

Hollow cathodes with indirectly heated lanthanum hexaboride electron emitters have produced over $1000 \mathrm{~A}$ of discharge current continuously with projected lifetimes of thousands of hours. Construction of rectangular ion sources utilizing two cathodes has been completed along with initial investigations of the discharge parameters as characterized by different cathode modes. Stable operation for 10 second pulse lengths has been achieved and diagnostics to determine gas efficiency, species output and plasma uniformity have been installed.

\section{Plans}

Complete discharge testing of the rectangular ion sources for stable, efficient operation to determine the optimum contiguration of ion sources of this type for neutral beam generation. Hollow cathodes with improved heater designs and alternate electron emitters are being developed and will be tested for lifetime and current capability with emphasis on impurity control during operation. The $10 \mathrm{~cm} \times 40 \mathrm{~cm}$ plasma generation will be delivered to Lawrence Berkeley Laboratory for $120 \mathrm{KV}$ beam extraction. Work will start on applying the $10 \mathrm{~cm} \times 10 \mathrm{~cm}$ source to neutral beam injection studies on the UCLA Tokamaks. 


\section{Milestones}

1. Obtain $1 / 3 \mathrm{~A} / \mathrm{cm}^{2} \mathrm{H}^{+}$current from $10 \mathrm{~cm} \times 10 \mathrm{~cm}$ ion source with $<2 \%$ plasma fluctuations in continuous operation - April 1979.

2. Achieved stable 10 second operation at low noise levels in $10 \mathrm{~cm} \times 40 \mathrm{~cm}$ ion source November 1979.

3. Deliver $10 \mathrm{~cm} \times 40 \mathrm{~cm}$ source to LBL for high voltage extraction - January 1980 .

4. Determine total performance characteristics including species measurement and gas efficiency of $10 \mathrm{~cm} \times 10 \mathrm{~cm}$ ion source - May 1980 .

5. Operate ion source with $20 \mathrm{KV}, 20 \mathrm{~A}, 1 / 3 \mathrm{~A} / \mathrm{cm}^{2} \mathrm{D}^{+}$ion beam - September 1980.

Graduate Students (\% DOE support, degree)

D. Goebel (100\%, PhD); S. Park (100\%, PhD); E. Bowles (100\%, PhD).

\section{Graduates (Year)}

F. Blau (1977), J.T. Crow (1978).

\section{Major Recent Publications}

1. Lanthanum Hexaboride Hollow Cathode Magnetic Multiple Ion Sources, D.M. Goebel, A.T. Forrester, 8th Symposium on Engr. Prob. of Fusion Research, San Francisco, California, November 1979 (to be published).

2. Neutral Beam Line Improvements Resulting From A Reduction in Gas Flow, A.T. Forrester, J.M. Dawson, IEEE Trans. on Plasma Sci., PS-6, 574, (Dec. 1978).

3. High Performance, Low Energy Ion Source, J.T. Crow, A.T. Forrester, D.M. Goebel, IEEE Trans. on Ylasma S'ci., PS-6, 535 (Dec. 1978).

4. IBIS: A Hollow Cathode Multiple Boundary Ion Source, A.T. Forrester, D.M. Goebel and J.T. Crow, Appl. Phys. Lett. P-33, 11 (1978).

5. Lanthanum Hexaboride Hollow Cathode for Dense Plasma Production, D.M. Goebel, J.T. Crow and A.T. Forrester, Rev. Sci. Instr. P-49, 469 (1978). 
Experimental Plasma Research

University of Maryland

\section{Project}

Atomic Physics in High-Temperature Plasmas

H.R. Griem

FY79 \$80K op $\quad$ FY80 $85 \mathrm{~K}$ op

$15 \mathrm{~K} \mathrm{eq}$

\section{Purpose}

Measure collisional rate coefficients of highly ionized iron ions

\section{Approach}

Quantitative spectroscopy of highly ionized iron ions in a $\theta$-pinch plasma.

\section{Progress}

Improved measured dielectronic recombination rates for $\mathrm{Fe} \mathrm{IX}-\mathrm{Fe} \mathrm{XI}$ and acquired experimental data for excitation coefficients for Fe XI. Verified ionization rate coefficients for Fe X-XII. Developed one-dimensional computer mode for time histories of iron lines.

\section{Plans}

1. Determine excitation rates for Fe XI relative to FeX.

2. Develop method for absolute determination of excitation coefficients.

3. Interact with TEXT - Tokamak group, for possible use of TEXT to extend these measurements to even higher ionization stages of iron.

\section{Milestones}

1. Determine excitation rates of Fe XI relative to FeX - March 1980.

2. Measure absolute excitation rate coefficients for FeX - December 1980.

3. Measure rate coefficients for higher ionization stages of iron - November 1981.

\section{Graduate Students}

J. Wang (100\%) 


\section{Graduates}

R.L. Brooks, Ph.D (1978)

\section{Other Professional Staff}

Dr. A. Marotta, Research Associate; Dr. H.J. Kunze, Senior Visiting Scientist.

\section{Major Recent Publications}

Measurement of Dielectronic Recombination Rates for the Iron Ions Fe IX - Fe XI, Phys. Rev. Lett. 41, 107 (1978).

Measurement of Effective Ionization and Recombination Rate Coefficients for Intermediate Ions in a Laser-Generated Theta-Pinch Heated Plasma, R.L. Brooks, Jr., Ph.D. Thesis, University of Maryland Technical Report No. 78-100 (1978).

Measurement of Effective Dielectronic Recombination Rates for Fe IX, X and Xi, Phys. Rev. A (in press), also University of Maryland Technical Report 80-005. 


\section{Project}

Cross Sections and Equilibrium Fractions of Deuterium Ions and Atoms in Metal Vapors Thomas J. Morgan

FY79 25K op . FY80 31K op

$$
5 \mathrm{~K} \text { eq }
$$

\section{Purpose}

Measure cross sections and equilibrium fractions of importance to neutral beam injection. $D^{+}, D^{0}$ and $\mathrm{D}_{2}{ }^{+}$incident projectiles are used to determine charge transfer, excitation, dissociation and electron loss cross sections and equilibrium fractions in magnesium, strontium, calcium and barium.

\section{Approach}

Beams of $\mathrm{D}^{+}, \mathrm{D}^{\mathrm{O}}$ and $\mathrm{D}_{2}^{+}$in the energy range from 1 to $100 \mathrm{keV}$ are passed through a metal vapor target cell and the resulting yield of ions and atoms is measured. Cross sections are obtained from the slope of yield vs. thickness curves and equilibrium fractions are obtained from asymptotic value of yields.

\section{Progress}

1. A comprehensive study of $\mathrm{D}^{-}$equilibrium fractions in alkaline-earth metal vapor targets ( $\mathrm{Mg}$, $\mathrm{Ca}, \mathrm{Sr}, \mathrm{Ba}$ ) has been completed over the energy range from 1.25 to $90 \mathrm{keV}$.

2. Electron capture cross sections have been calculated in alkaline-earth targets using the binary encounter approximation. Factor of two agreement with experiment is found over the entire energy range from 1 to $100 \mathrm{keV}$.

3. $\mathrm{D}^{-}$equilibrium fraction measurements have been made for $\mathrm{D}_{2}^{+}+\mathrm{Mg}$ collisions.

4. Secondary emission coefficients for $\mathrm{D}^{+}$and $\mathrm{D}^{-}$ions incident on dirty stainless steel have been measured over the energy range $1.5-60 \mathrm{keV}$.

5. Apparatus modifications have been completed to allow production of a fast beam of ground state deuterium atoms.

6. A cooperative research program is underway with Professor Alvarez and Professor Cisneros of the Institute of Physics, University of Mexico. The program involves the measurement of the differential scattering cross section for $\mathrm{H}^{-}$formation in double electron capture collisions. 


\section{Plans}

1. Undertake a comprehensive study of cross sections for $\mathrm{D}^{\circ}$ and $\mathrm{D}_{2}{ }^{+}$in collision with alkalineearth targets.

2. Extend measurements to excited state content of $D^{\circ}$ beams formed by electron detachment of $\mathrm{D}^{-}$.

3. Continue the collaboration with the University of Mexico on differential cross sections for $\mathrm{H}^{-}$ ion formation.

\section{Milestones}

1. Complete $\mathrm{D}^{+}, \mathrm{D}^{\circ}$ and $\mathrm{D}_{2}^{+}$cross section measurements in Sr and Ca. - June 1980.

2. Complete $\mathrm{D}^{\circ}$ and $\mathrm{D}_{2}{ }^{+}$cross section measurements in $\mathrm{Mg}$ and $\mathrm{Ba}$ - October 1980.

3. Begin measurements of excited state population of $D^{0}$ beam formed by electron detachment of $\mathrm{D}^{-}-$January 1980.

Graduate Students (\% DOE support, degree)

Marguerite Mayo (0, Ph.D.)

\section{Other Professional Staff}

Jack Stone, Research Associate

\section{Major Recent Publications}

1. Single and double-electron capture by $1-100 \mathrm{keV}$ protons in collision with $\mathrm{Mg}$ and $\mathrm{Ba}$ atoms, T.J. Morgan and F.J. Eriksen, Phys. Rev. A 19, 1448 (1979).

2. Formation of metastable hydrogen atoms by charge exchange of fast protons in $\mathrm{Mg}$ and $\mathrm{Ba}$ vapors, T.J. Morgan and F.J. Eriksen, Phys. Rev. A 19, 2185 (1979).

3. $\mathrm{D}^{-}$production by multiple charge-transfer collisions in alkaline-earth vapors, T.J. Morgan, J. Stone, M. Mayo and J. Kurose, Phys. Rev. A 20, 54 (1979).

4. Investigation of nonadiabatic effects in molecular-hydrogen Rydberg states by electric field ionization, T.J. Morgan, C.F. Barnett, J.A. Ray, and A. Russek, Phys. Rev. A 20, 1062 (1972). 


\section{Project}

Electron-ion Collision Studies Relevant to the CTR Program

J.Wm. McGowan, H.R. Froelich, T.M. Luke, J.B.A. Mitchell and P. Mul
FY78-79
$\$ 196,000$ op
FY80
$\$ 110,000$ op
65,000 eq
0 eq

\section{Purpose}

'l'o measure electron-ion dielectronic recombination, and some electron polyatomic-ion dissnciative recombination cross sections relevant to the CTR program.

\section{Approach}

Utilize a merged electron-ion beam apparatus MEIBE-I for studies of dissociative recombination and the first attempts at dielectronic recombination measurements for singly charged ions. Commission and use MEIBE-II for eielectronic recombination studies of multiply charged atomic ions.

\section{Progress}

1. With the MEIBE-I approach:

a. Measured or remeasured dissociative recombination cross sections between 0.01 and $\sim 2 \mathrm{eV}$ for the following species:

$$
\begin{aligned}
& \mathrm{H}_{2}^{+} \ldots \mathrm{D}_{2}^{+}, \mathrm{H}_{3}^{+} \ldots \mathrm{D}_{3}^{+} ; \mathrm{CH}^{+} \ldots \mathrm{CH}_{5}^{+} ; \mathrm{NH}^{+} \ldots \mathrm{NH}_{4}^{+}, \\
& \mathrm{C}_{2}^{+} \ldots \mathrm{C}_{2} \mathrm{H}_{4}^{+} ; \mathrm{N}_{2}^{+} ; \mathrm{N}_{2} \mathrm{H}^{+} ; \mathrm{N}_{2} \mathrm{D}^{+} ; \mathrm{OH}^{+} \ldots \mathrm{H}_{3} \mathrm{O}^{+} \mathrm{O}_{2}^{+} ; \mathrm{NO}^{+} .
\end{aligned}
$$

All of the papers covering this subject have been or will be soon submitted for publication.

b. Completed an extensive study of energy resolution and experimental limitations of the MEIBE apparatus - in preparation for pulblication.

c. Studied the effects of vibrational excitation of some species particularly $\mathrm{H}_{2}{ }^{+}$and $\mathrm{H}_{3}{ }^{+}$. Work is continuing and a preliminary report dealing with electron impact dissociation in conjunction with dissociative recombination is in preparation. 
d. Completed design and construction of two new ion sources for the dome of the van der Graaff. One is a colutron plasma source and the other is a high pressure source designed for producing ground state ions.

e. Continuing studies of negative ion formation and $\mathrm{H}_{2}^{+}$and $\mathrm{H}_{3}{ }^{+}$dissociative recombination.

2. Completed a detailed study of charge transfer into the continuum involving collisions of ions with foils and atoms. Material published.

3. MEIBE-II nearing completion. All vacuum cans now being cleaned at Stanford University. The liquid helium cryo pump system under manufacture at the National Research Council Laboratory in Ottawa. The collision chamber is now being assembled in the University workshop.

4. MEIBE-I is being modified in an attempt to measure dielectronic recombination of several monoatomic species, such as $\mathrm{Li}^{+}, \mathrm{Mg}^{+}, \mathrm{Ne}^{+}$and $\mathrm{C}^{+}$.

5. The NATO supported cooperative program with the Universite de Louvain-la-Neuve is continuing. The past year Professor W. Claeys worked in the laboratory while Professor Bouillard visited for several weeks. It is expected that Dr. P. Defrance will return to the laboratory for part of 1980 . An active exchange program is being considered with the electronion collision scientists at Nagoya University.

\section{Plans}

1. Complete and commission MEIBE-II.

2. Improve the vacuum for MEIBE-I.

3. Complete testing of special ion sources. Design and test high current ion sources for the dielectronic recombination studies. Complete dissociative recombination studies of $\mathrm{H}_{2}^{+}$ and $\mathrm{H}_{3}{ }^{+}$.

4. Examine the dependence of dissociative recombination and pair production $\left(\mathrm{H}^{+}+\mathrm{H}^{-}\right)$ upon the state of vibration of the ion.

5. Examine several dielectronic recombination prototype systems such as $\mathrm{HeH}^{+}, \mathrm{He}_{2}^{+}$.

6. Using MEIBE-I again dielectronic recombination cross section measurements for singly charged ions, e.g., $\mathrm{Li}^{+}, \mathrm{Mg}^{+}, \mathrm{Ne}^{+}$and $\mathrm{C}^{+}$.

7. Using MEIBE-II, begin studies of electron-multiply charged ion dielectronic recombination.

\section{Milestones}

1. Complete MEIBE-II - May 1980: 
2. Using MEIBE-II make first measurements of dielectronic recombination of electrons with multiply charged ions such as $\mathrm{C}^{2+}, \mathrm{C}^{3+}, \mathrm{O}^{2+} \ldots$

3. Upgrade MEIBE-I for dielectronic recombination measurements - March 1980.

4. With MEIBE-I:

a. Complete dissociative recombination studies dealing with vibrational excitation of $\mathrm{H}_{2}{ }^{+}(\mathrm{v}), \mathrm{H}_{3}{ }^{+}(\mathrm{v})-$ April 1980.

b. Complete measurements of $\mathrm{H}^{-}$formation from $\mathrm{e}-\mathrm{h}_{2}{ }^{+}$and $\mathrm{e}-\mathrm{H}_{3}{ }^{+}$collisions - April 1980.

c. Complete measurements of $\mathrm{HeH}^{+}$and $\mathrm{He}_{2}{ }^{+}$recombination measurements as molecular analogue to dielectronic recombination - June 1980.

d. Measure dielertronic recombination of $\mathrm{Mg}^{+}, \mathrm{Li}^{+}$by $\mathrm{F}$ all 1980.

Graduate Students (\% DOE)

P. Mul (100 Ph.D); A. Sen (33, Ph.D); C. Ng (66, Ph.D)

\section{Graduates}

K.C.R. Chiu (Ph.D. - Bell Laboratories, Murray Hill)

V.S. D'Angelo (M.Sc. - Althouse College of Education)

\section{Other Professional Staff}

Visiting Fellow - Center for Chemical Physics - Dr. T. O'Malley

Visiting Fellow - Center for Chemical Physics - Professor Willie Claeys, Louvain-la-Neuve

Mr. Dave Miko - Project Technician

Mr. K. Bailey - Project Engineer

Mr. J. Keyser, Electronics. Engineer, Physics Department

Mr. Irold Schmidt, Machinist, Physics Department.

\section{Major Recent Publications}

P.M. Mul and J.Wm. McGowan, "Dissociative Recombination of $\mathrm{N}_{2} \mathrm{H}^{+}$and $\mathrm{N}_{2} \mathrm{D}^{+}$, Astrophys. Journal 227 L157-1.59 (1.97.9).

G. Poulaert, F. Brouillard, W. Claeys, J.W. McGowan and G. Van Wassenhove, " $\mathrm{H}_{2}{ }^{+}$formation in low energy $\mathrm{H}^{+}-\mathrm{H}^{-}$collisions." (A Merged Beam Study of the Associative Ionization Reaction), J. Phys. B: Atom. Molec. Phys. Vol 11, No. 21 (1978). 
P.M. Mul and J. Wm. McGowan. "Dissociative Recombination of $\mathrm{C}_{2}^{+}, \mathrm{C}_{2} \mathrm{H}^{+}, \mathrm{C}_{2} \mathrm{H}_{2}{ }^{+}$and $\mathrm{C}_{2} \mathrm{H}_{3}{ }^{+}$. The Astrophys. J. accepted for publication.

J. Wm. McGowan, Invited Paper "Electron-Ion Collisions - An Update," XI ICPEAC Conf. Kyoto, Japan, August/September 1979.

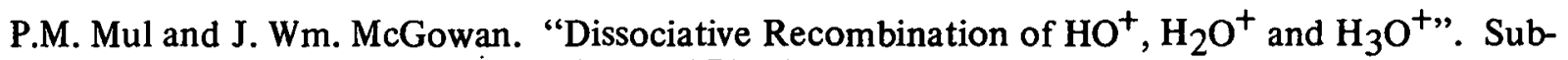
mitted for publication Journal of Chemical Physics.

P.M. Mul; W. Claeys; V.S. D'Angelo; H.R. Froelich, and J. Wm. McGowan. "Direct Determination of Resolution in Electron-Ion Merged Beam Experiments." Submitted for Publication. 


\section{FUSION PLASMA RESEARCH FACILITY (FPRF) PROGRAM}

The Fusion Plasma Research Facility (FPRF) is the first national user facility dedicated to research on fusion plasmas. The FPRF centers around the Texas Experimental Tokamak (TEXT), built and operated by the University of Texas at Austin. It is a general purpose device with excellent experimental access designed to provide facilities for fusion experiments which are not compatible with the commitments of the major tokamaks. TEXT is typically well suited for experiments in the areas of atomic processes, impurity transport, rf heating, plasma/ surface interactions and impurity control, plasma formation studies, plasma edge effects, disruptive instabilities and diagnostic development.

The characteristic tokamak parameters are major radius, $1 \mathrm{~m} . ;$ limiter radius, $28 \mathrm{~cm} . ;$ magnetic field, 3T; and nominal plasma current, $400 \mathrm{kA}$. Fourteen port boxes provide full views of the plasma from the top, bottom, and outside. The plasma parameters will depend upon operating conditions, but densities of a few times $10^{13}$ and electron temperature approaching $2 \mathrm{keV}$ at the center can be expected. Basic diagnostics for plasma density temperature, etc., will be provided as part of regular machine operation. A computer-based data system will provide numerous channels of $A / D$ data recording and archiving.

The selection and general scheduling of all experiments for TEXT will be done by the TEXT Program Advisory Committee-(TPAC). Membership in the TEXT Users Organization is open to all persons with a potential interest in performing experiments on TEXT. Further information and copies of the TEXT Users Handbook are available from Dr. Kenneth W. Gentle, TEXT Program Director, Department of Physics, University of Texas, Austin, TX 78712

(512-471-3926). 


\section{Progress - Fusion Plasma Research Facility}

Fabrication of the TEXT Fusion Plasma Research Facility is now $80 \%$ complete. Delivery of all the components except the vacuum vessel and center post has been completed by United Technologies Research Center, the prime subcontractor for the basic tokamak assembly. Site preparation for installation of the tokamak and motor generator has been completed. The TF coils have been fabricated, delivered and installed. Acceptance testing of the VF and HF coil has been completed, and the vacuum vessel is to be completed in May, 1980. The alternator for the basic power source, to be provided by Westinghouse Electric Company, has been delivered and installed.

The construction schedule calls for completion of Major Device Fabrication with the attainment of $50 \mathrm{kA}$ of plasma current by September 30,1980. The remainder of 1980 will be devoted to further machine improvements and exploration of the range of operating parameters. The first experiments by off-site users are planned to begin in January, 1981.

Planning of the experimental program on TEXT is progressing well. Informal meetings for potential users have been scheduled and advertised at the APS Division of Plasma Physics' annual meeting for several years. The formative meeting of the Users Organization was held on November 15, 1979, in Boston, at which an Organizing Committee of six members was nominated. It is responsible for selecting and organizing a simple governing structure for the Users Organization, and submitted a Draft Charter for consideration by the Organization at its second meeting in Los Angeles on March 18, 1980.

The members of the TEXT Program Advisory Committee were selected and appointed by Kenneth W. Gentle, University of Texas, and will serve for two-year staggered terms. They are James Callen (Univ. of Wisconsin) at large, Earl Ensberg (GA) Users' Organization, Harold Eubank (PPPL) at large, Warren Moos (Johns Hopkins) Users' Organization, and Philip M. Stone (DOE) ex-officio. A number of proposals for experiments to be done on TEXT have been submitted and are under consideration by the TPAC. The calendar for TEXT is:

$7 / 7 / 80$ Submit proposals for $10 / 80$ to $3 / 81$ scheduling and post $-3 / 81$ selection

$7 / 21-24 / 80$ TPAC meeting to schedule $1 / 81$ to $3 / 81$ period and select future experiments

1/5/81 Appoint two new TPAC members

Submit proposals for $10 / 81$ thru $3 / 82$ scheduling and future selection

\section{1/26-30/81 TPAC Meeting}

$7 / 6 / 81$ Submit proposals for $10 / 81$ thru $3 / 82$ scheduling and future selection

7/27-31/81 TPAC Meeting

1/4/82 Appoint two new TPAC members

Submit proposals for $4 / 82$ thru $9 / 82$ scheduling and future selection

1/25-29/82 TPAC meeting 


\section{Project}

\section{TEXT}

K. Gentle

TEC $\$ 10,300 \mathrm{~K}$

\section{Purpose}

The TEXT device provides a facility for the MFE program to conduct research and development projects on a plasma that is typical of major confinement experiments. The facility will be available to users from throughout the fusion community including universities, industry and government laboratories. The objectives for TEXT are complimentary to the tokamaks at. PPPI., ORNL, and GA and consist of important fusion development projects that cannot be undertaken on a timely basis by the main-line programs. In particular, the objectives of projects on TEXT include:

1. Provide atomic and molecular data of impurity ions in tokamaks required for analysis of plasma heating and cooling mechanisms, surface interactions and diagnostics.

2. Test, evaluate, and standardize existing diagnostics and develop new diagnostic techniques.

3. Serve as a facility to test new ideas in order to improve plasma heating, equilibrium, and stahility.

4. Provide quantitative tests of theoretical plasma models, particularly large computer codes.

5. Train scientists directly on confinement devices.

\section{Background}

One of the primary recommendations of the Overview Panel in "The 1974 Review of the Research Program", ERDA-39, was the establishment of medium-scale confinement devices as research facilities to accommodate user groups from all sectors of the MFE program. In December 1974 an Ad Hoc Committee on Fusion Plasma Research Facilities was formed to further evaluate the need for and to determine characteristics of this kind of device. A report of the Committee, ERDA-106, concluded that one or more Fusion Plasma Research Facilities (FPRF) should be established consisting primarily of high duty cycle, medium-scale, research-oriented confinement devices capable of producing plasmas with near-thermonuclear parameters. A tokamak device was accorded the highest priority for the first FPRF.

The University of Texas submitted a proposal to build an FPRF in July 1976. A contract was formally awarded for TEXT in October 1977, and major subcontracts were awarded to United Technologies for the tokamak subassembly and to Westinghouse for the motor-generator. The toroidal field coils were completed in September 1979. 
To implement operation as a user facility, meetings are held each year at the APS/DPP November meeting with potential users. The first edition of the TEXT Users Handbook was issued in June 1979 , giving technical information on the device and setting forth the procedure for submitting proposals to the TEXT Program Advisory Committee, the external committee which will allocate all experimental time on TEXT. In November 1979, an organizing committee for the independent Users Organization was selected.

\section{Plans}

TEXT is designed with a major radius of $100 \mathrm{~cm}$, limiter radius of $28 \mathrm{~cm}$, magnetic field of $3 T$, pulse length of $300 \mathrm{~ms}$, and a repetition rate of a shot each two minutes. Estimates of the plasma characteristics suggest a density of $3 \times 10^{13}$, average electron temperature of a kilovolt, and a central ion temperature of similar magnitude. These properties, together with good geometric access to the plasma and the provisions of complete diagnostics and computer data acquisition, will make an excellent research facility.

TEXT will begin operation in the summer of 1980 with users experiments scheduled to begin in January 1981. The first selection of experiments will be from proposals for machine time due February 1980. Subsequent scheduling will be based on submissions and evaluations every six months as stated in the Handbook. The University of Texas will submit proposals for several experiments, including ones on atomic physics and impurity effects. Proposals for machine time may be submitted at any time.

The User Handbook, the basic document describing the facility and its operation, will be revised and issued each June. A newsletter will also be mailed to all interested persons regularly.

\section{Milestones}

1. Receive motor-generator set - March 1980.

2. Complete assembly of TEXT - June 1980

3. Complete MDF: 50kA operation as normal tokamak - August 1980.

4. Begin operation as user facility - January 1981.

\section{Comments}

Requests for information about TEXT, copies of the Handbook, or any other inquiries should be sent to:

Kenneth Gentle, Director of TEXT

Department of Physics

University of Texas

Austin, TX 78712

Telephone: (512) 471-7581 FTS 397-5325 


\section{ADVANCED ȘUPERCONDUCTING MATERIALS (S/C) PROGRAM}

Some mainline and alternate fusion concepts will require very high magnetic fields. In order to make these systems energy efficient, superconducting magnets will be needed. Materials which are both ductile and capable of these high fields (i.e., $\geqslant 12 \mathrm{~T}$ ) are not present. To meet this need an Advanced Superconducting Materials Program was initiated.

This program consists of two parts. The first is a search for new and/or advanced materials and the detailed investigation of their mechanical and superconducting properties. The second involves improved processing and fabrication techniques to upgrade the performance of existing materials such as $\mathrm{Nb}_{3} \mathrm{Sn}$. 
Experimental Plasma Research

Massachusetts Institute of Technology

Category S/C

R.M. Rose, B.B. Schwartz and S. Foner

\section{Project}

Development of a Ductile 15 Tesla Superconductor

FY79 \$330K FY80 \$360K op

$25 \mathrm{~K} \mathrm{eq}$

\section{Purpose}

To develop a strong, relatively ductile superconductor with the ability to carry $10^{5} \mathrm{amps} / \mathrm{cm}^{2}$ at $15 \mathrm{~T}$ magnetic field and to withstand at least $2 \%$ strain without significant degradation of these capabilities.

\section{Approach}

Several interdependent avenues of approach are used:

1. The development of in situ composites of compound superconductors in normal matrices by rapid quenching of melts and wire drawing, and other methods which result in similar microstructures.

2. The development of superior composite microgeometrics by analysis of degradation mechanisms in currently manufactured multifilamentary bronze-matrix $\mathrm{Nb}_{3} \mathrm{Sn}$ composites; development of model composites, as experimental tests and as prototypes of superior materials.

3. The development and testing of fatigue models to predict performance of superconducting . composites under cyclic stresses typical of fusion devices.

4. To characterize and analyze the mechanical and superconducting properties of compound superconductors in order to develop an analytical base for approach No. 2 and to identify compounds with superior mechanical properties. This includes the lattice dynamical basis for mechanical and superconducting properties.

\section{Progress in FY79}

1. $\mathrm{Nb}_{3} \mathrm{Sn}$-based multifilamentary composites produced in FY78 were found to have the highest critical current densities of any Nb3Sn-based composites, at high magnetic fields; at $15.4 \mathrm{~T}$ the overall critical current density $J_{c}$ was well over $2 \times 10^{4} \mathrm{amps} / \mathrm{cm}^{2}$ for $25 \% \mathrm{Nb} 3 \mathrm{Sn}$ and over $104 \mathrm{~A} / \mathrm{cm}^{2}$ for $12 \% \mathrm{Nb}_{3} \mathrm{Sn}$, corresponding to current densities of over $10 \% \mathrm{~A} / \mathrm{cm}^{2}$ in the superconductor at $15.4 \mathrm{~T}$. At $12 \mathrm{~T}$, overall $\mathrm{J}_{\mathrm{c}}$ was nearly 105 in some specimens.

2. Mechanical properties measurements on some of the multifilamentary superconductors (see above) showed no less than $4 \%$ degradation of $\mathrm{J}_{\mathrm{c}}$ at high fields for applied strains up to $2 \%$ and stresses ca. 105 psi. 
3. A method (and basic explanation) was discovered for the elimination of Kirkendall porosity in the external diffusion process. A conceptual breakthrough, it differs from the methods proposed in the FY80 task proposal. It eliminates the main obstacle to scaleup of the ultrafine fibre multifilamentary technology and promises substantial cost reductions in the manufacture of conventional multifilamentary geometries.

4. It was found that the improved mechanical properties were not associated with the finest fibre sizes and, in fact, that further improvements in mechanical properties can be anticipated with geometries which eliminate collective behavior.

5. The mechanical properties of bronze at $4.2^{\circ} \mathrm{K}$ as a function of Sn content were determined, as an essential parameter for the fatigue model development and micromechanics.

6. The fatigue model was refined to include the effects of work hardening during each stress (or strain) cycle, as preparation for critical experimental testing.

7. The mechanical properties of completely characterized $\mathrm{Nb}_{3} \mathrm{Ge}$ dc-sputtered films have been determined. Their strain fracture limits is greater than that of the fabrication substrates. Their superconductivity transition temperature changes reversibly (by $\sim .4 \%$ ) where the substrates failed.

8. The preferred orientation study of diffusion layer $\mathrm{Nb}_{3} \mathrm{Sn}_{n}$ showed that the breaking stress of polycrystalline $\mathrm{Nb}_{3} \mathrm{Sn}$ is due to material with $\mathrm{Al}$ 15-(111) orientation; non-(111) ${ }^{3}$ diffusion layers have a breaking stress in excess of $125 \mathrm{Kp} / \mathrm{mm}^{2}$.

9. Growth of $\mathrm{Nb}_{3} \mathrm{Sn}$ on single crystal $\mathrm{Nb}$ substrates showed that at the bcc-(111) substrate (and within a surrounding orientation region $\sim 1^{\circ}$ or $35 \mu$ ), the interface between the A15 layer and the $\mathrm{Nb}$ exhibits anomalous features that could arise from voids, second phases, stress fields, or orientationally dependent tin diffusion profiles (for which there is evidence). This interface disposition is a likely cause for mechanical failure and superconducting degradation of $\mathrm{Nb}_{3} \mathrm{Sn}$ composites.

10. We have shown that commercial processing of $\mathrm{Nb}$ stock foil probably enhances the formation of degraded $\mathrm{Nb}_{3} \mathrm{Sn}$ material by increasing the foils $\mathrm{Nb}-(111)$ component.

11. Four point bending measurements at room and liquid $\mathrm{N}_{2}$ temperatures have confirmed that the mechanical properties of $\mathrm{C} 15 \mathrm{ZrV}_{2}$ are superior to those of A15's and that in their pure bulk state both behave far more like ceramics than as metals.

12. "In Situ" Cu-V-Ga materials were successfully fabricated using an external Ga plating. The resulting materials showed critical currents above the best "In Situ" $\mathrm{Cu}-\mathrm{Nb}$-Sn materials for fields ahove 14 tesla.

13. The mechanical and electrical properties of "In Situ" Cu-V-Ga were evaluated. This material showed exceptional mechanical properties with no degradation in $\mathrm{J}_{\mathrm{c}}$ for stresses up to 1000 $\mathrm{MPa}$ and for large strains.

14. Semicontinuous casting of "In Situ" materials with a controlled high temperature-gradient technique has been successful. Yields of directionally solidified materials of about $300 \mathrm{~g} \mathrm{(a}$ factor of 10 over the first chill-cast quantities) were obtained with varied controlled growth rates. 
15. Directionally solidified $\mathrm{Cu}-\mathrm{Nb}$-Sn "In Situ" materials with various growth rates showed that the mechanical and electrical properties were improved as the dendrite size and fibre cross section was decreased. Performance equal to the best "In Situ" chill cast materials was achieved for the rapid growth rates.

16. Small scale fabrication of cold powder metallurgy processed $\mathrm{Cu}-\mathrm{Nb}-\mathrm{Sn}$ was achieved and electrical and mechanical properties evaluated. Circular wires were produced with values of $J_{c}$ and strain tolerance equal to the best "In Situ" processed $\mathrm{Cu}-\mathrm{Nb}-\mathrm{Sn}$.

17. Preliminary fabrication of a cold powder metallurgy processed one-step $\mathrm{Cu}-\mathrm{Nb}$-Sn material, where all the powders are included in the original compact, has been successful .

18. Mechanical testing facilities have been assembled and tested. These are now being incorporated in the NML facilities for use by visitors.

\section{Plans}

1. The attainment of still higher critical current densities and strain tolerances by the elimination of collective effects. This can be done by attaining more uniform spacings. We are planning some new billets of intermediate size in order to do this. Additionally, such billets represent the first demonstration that scaleup is feasible, and longer lengths of wire will be produced.

2. Void elimination technologies for large/long wires in the external diffusion process. Based on the heterogeneous nucleation concept developed in FY80, we plan to develop larger-scale methods for porosity elimination which may not require pre-annealing. The initial studies will focus on the effects of composition and interface cleanliness on void nucleation at $\mathrm{Cu}-\mathrm{Cu}$ interfaces during Sn diffusion.

3. Control of internal residual stresses in multifilamentary composites. It is apparent that control of mechanical and superconducting properties requires control of the residual stresses, and, in any case, we wish to do the latter as part of our studies on fatigue. We have designed (and are constructing) a thermal-mechanical apparatus which (according to our calculations) should do this. We then propose to study, in a controlled way, the effects of residual stresses on all engineering properties.

4. Testing of the refined fatigue model; this will follow step No. 3, as the model shows that residual stresses are an important parameter.

5. The use, on an exploratory basis, of quaternary elements to raise $\mathrm{J}$ (and $\mathrm{Hc}_{2}$ ) still further, as well as to improve mechanical properties and reduce or eliminate void formation. (The latter is possible if the quaternary addition reduces the vacancy flux.) Such additions are straightforward in most cases when the external diffusion method is used.

6. Low-volume fraction composites. These are attractive as competitors for Nb-Ti-based materials because of the sharply increasing prices anticipated for $\mathrm{Nb}$; the excellent mechanical properties of low $v_{f}$ composites; and the feasibility of the external diffusion technique. There is no

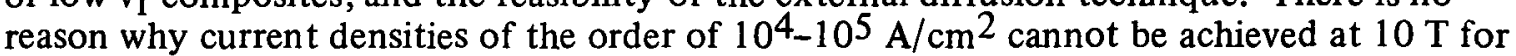
volume fractions as low as $1-5 \% \mathrm{Nb}$. This would remove a formidable economic barrier to the construction of large superconducting magnets. 
7. Continued studies of collective mechanical behavior and the basic reason(s) for the improvement in mechanical properties of these multifilamentary composites.

8. Long length external diffusion of "In Situ" wires using commercial process. The "In Situ" development of multifilamentary superconducting materials has now progressed to the point where it has a large current density at 14 tesla and has demonstrated mechanical properties which are superior to conventional commercial multifilamentary superconductors. The "In Situ" process thus shows promise for commercial feasibility. We have arranged for a cooperative program with IGC (Intermagnetics General) to explore the problems associated with use of their external plating process. Because of restricted funding, this will be a minimal effort to explore feasibility. IGC will support work done at IGC and we will support work done at the Francis Bitter National Magnet Laboratory. There will be joint development of the processing variables after plating and we will furnish "In Situ" materials to IGC for final drawing and plating.

9. Establish parameters for long length externally plated wires. Because the IGC process has not been developed for "In Situ" materials we plan to establish an optimum diffusion and heat treatment procedure for the long length "In Situ" wires.

10. Electrical and mechanical evaluation of long length "In Situ" wires. After diffusion and reaction of long length "In. Situ" wires, we will measure $J_{C}$ and the mechanical properties at high field. Wires using our Laboratory processing with conventional external plating will be fabricated in order to compare performance of short sections of laboratory material versus IGC externally plated materials.

11. Attainment of increased $\mathrm{J}_{\mathrm{c}}$ for "In Situ" materials. Conventional multifilamentary $\mathrm{Cu}-\mathrm{Nb}_{3} \mathrm{Sn}$ materials have been made elsewhere with $\mathrm{Ta}$ additions which increased $\mathrm{J}_{\mathrm{c}}$. We plan to fabricate Cu-NbTa-Sn "In Situ" wires in order to explore whether such improvement can be realized for "In Situ" processed materials.

12. Optimization of $J_{c}$ for "In Situ" materials. There is a tradeoff in $J_{c}$, strain insensitivity, and coupling between filaments in "In Situ" materials. Below the percolation limit $\mathrm{J}_{\mathrm{c}}$ drops rapidly. We plan to examine the electrical and mechanical properties of $\mathrm{Cu}-\mathrm{Nb}-\mathrm{Sn}$ as a function of composition in order to determine the best operating regions for practical high field superconducting materials.

13. Internal diffusion of "In Situ" materials. An alternative to external plating is to use various methods for furnishing Sn internally to the "In Situ" billet. Such processing would reduce the number of operations required for fabrication and thus reduce costs of the final product. We plan to explore methods for internal diffusion.

14. Cold powder metallurgy processing with isostatic extrusion. In order to produce large quantitics of cold powder metallurgy processed materials, extrision technolngies could he used. Conventional extrusion technology requires large amounts of material, is costly, and has a long turn-around time. In order to minimize costs and turn-around time, we plan to use the isostatic extrusion facilities at Northeastern University to model conventional extrusion processes. This arrangement permits rapid processing of extrusion at various temperatures for our conventional (small) cold metallurgy process billets. This procedure will allow rapid development and testing of extrusion processing. 
15. Improvement of one-step cold powder metallurgy processed materials with atomized prealloyed powders. The cold powder metallurgy process permits all the component powders to be included in the initial compact so that, in principal, a fine-grained internal diffusion of $\mathrm{Sn}$ is possible in the $\mathrm{Cu}-\mathrm{Nb}-\mathrm{Sn}$ materials, in a single step (the one-step process). Preliminary materials have been made by us using the one-step process. However, in order to increase the $\mathrm{Sn}$ content we will fabricate various atomized prealloyed $\mathrm{Cu}-\mathrm{Sn}$ powders to improve the process.

16. Improved $\mathrm{J}_{\mathrm{c}}$ of cold powder metallurgy $\mathrm{Cu}-\mathrm{Nb}-\mathrm{Sn}$ using NbTa. As discussed in No. 11 above, additions of $\mathrm{Ta}$ to $\mathrm{Nb}_{3} \mathrm{Sn}$ should yield improved $\mathrm{J}_{\mathrm{c}}$. We plan to fabricate $\mathrm{Cu}-\mathrm{NbTa}$-Sn by the cold powder metallurgy process using prealloyed NbTa powders in order to increase the critical current.

17. Evaluation of hot powder metallurgy processing. Hot powder metallurgy processing is one alternative to the cold powder metallurgy process and has been explored elsewhere. Powders are sintered at high temperature after which the compact is processed in a manner similar to that of the "In Situ" materials. Although there are limitations to the hot process, we will fabricate hot processed materials and compare the processing parameters with the cold processed materials using isostatic extrusion techniques discussed in No. 14 above. This would permit us to evaluate advantages and limitations of both processes for large quantity production.

\section{Milestones}

1. A new high in critical current density and mechanical properties at high magnetic fields Summer 1980.

2. Long length technologies for the elimination of voids in multifilamentary composites June 1980.

3. Control of residual stresses in superconducting composites - July 1980.

4. The role of residual stresses in fatigue of multifilamentary superconductors - October 1980.

5. A new generation of low-cost, high-field superconductors - October 1980.

6. Achieve external plating of long lengths of "In Situ" Cu-Nb-Sn materials in cooperation with Intermagnetic General - March 1980.

7. Establish diffusion and reaction heat treatments for "In Situ" materials of (6) above April 1980.

8. Evaluate $J_{C}$ mechanical properties of long length materials of (6) and (7) above and compare with materials fabricated with conventional external plating process used at National Magnet Laboratory - June 1980.

9. Develop and evaluate "In Situ" Cu-NbTa-Sn materials in order to explore higher $\mathrm{J}_{\mathrm{C}}$ possibilities - March 1980. 
10. Further optimize $J_{C}$ versus strain tolerance of "In Situ" Cu-Nb-Sn - August 1980.

11. Begin exploration of internal Sn diffusion methods for "In Situ" materials - February 1980.

12. Begin exploration of extrusion using isostatic extrusion of cold powder metallurgy (P/M) processed materials - December 1979.

13. Begin one-step $(\mathrm{P} / \mathrm{M})$ process using atomized prealloyed powders in order to eliminate external tin plating and diffusion - December 1979.

14. Fabricate cold (P/M) processed Cu-NbTa-Sn materials - May 1980.

15. Fabricate hot $(\mathrm{P} / \mathrm{M})$ processed $\mathrm{Cu}-\mathrm{Nb}-\mathrm{Sn}$ materials and begin comparison and evaluation with respect to our conventional cold (P/M) processed materials - March 1980.

\section{Graduate Students}

1. Project Students (\% of DOE support, degree, years to complete):

S.F. Cogan (100, Ph.D, graduated 1979); J.A. Gregory (100, Ph.D, graduated 1979);

J.D. Klein (100, Ph.D, 3); J.F. DeBroux (0, S.M., graduated 1979); L. Salamanca-Riba (0, S.M. 2); A. Hezaveh (0, S.M., 3); T. Lee (60, Ph.D, 2).

2. Graduated during the past three years: S.F. Cogan, V. Diadiuk, J.A. Gregory, J.F. DeBroux. 